\title{
A COMPARISON OF LIDAR GENERATED CHANNEL FEATURES WITH GROUND-SURVEYED CHANNEL FEATURES IN THE LITTLE CREEK WATERSHED
}

\author{
A Thesis \\ presented to \\ the Faculty of California Polytechnic State University, \\ San Luis Obispo
}

\author{
In Partial Fulfillment \\ of the Requirements for the Degree \\ Master of Science in Forestry Sciences \\ by \\ Ryan McKenzie Hilburn
}

May 2010 
(C) 2010

Ryan McKenzie Hilburn ALL RIGHTS RESERVED 
COMMITTEE MEMBERSHIP

TITLE: A COMPARISON OF LIDAR GENERATED CHANNEL FEATURES WITH GROUND-SURVEYED CHANNEL FEATURES IN THE LITTLE CREEK WATERSHED

AUTHOR: Ryan McKenzie Hilburn

DATE SUBMITTED: May 10, 2010

Brian C. Dietterick

Advisor and Committee Chair

Walter R. Mark

Committee Member

Douglas D. Piirto

Committee Member 


\begin{abstract}
A Comparison of LiDAR Generated Channel Features to Ground-Surveyed Channel Features in the Little Creek Watershed

Ryan McKenzie Hilburn
\end{abstract}

Detecting change in stream channel features over time is important in understanding channel morphology and the effects of both natural and anthropogenic influences.

Channel features historically, and now currently, are being measured using a variety of ground survey techniques. These surveys require substantial time commitments and funding to complete. Light Detection and Ranging (LiDAR) is an airborne laser mapping technology that holds promise to provide an alternative to ground-based survey methods.

For this study, ground surveys were used to verify the accuracy of data collected using airborne LiDAR. Fifty nine cross-sectional profiles were surveyed in the Little Creek watershed at Cal Poly's Swanton Pacific Ranch and compared to LiDAR-generated profiles of the same location. LiDAR data were collected in two flights during April and May of 2002.

The vertical accuracy of LiDAR elevations was determined to be $0.610 \mathrm{~m}$ RSME based on a point-to-point comparison of the elevation of ground survey points in each crosssectional profile to the corresponding LiDAR elevation. The average ground spacing of the LiDAR survey within the study area was one point every 5.2 square meters. In comparison to ground surveys it was found that with this level of vertical precision and horizontal resolution it would be difficult to detect change in bankfull channel 
characteristics of a relatively small channel, such as Little Creek. These difficulties are largely attributed to poor point coverage in forested, steep, and mountainous terrain, along with technological limitations of LiDAR that have since improved. 


\section{Acknowledgements Page}

I thank my advisor, Brian Dietterick, for his patience and guidance throughout the process. I would also like to thank all those that have been a part of this project and part of the Little Creek Study. Without their hard work this study would not have been possible.

I would also like to thank my wife. Without her understanding, support, and encouragement I would not have been able to complete this project. 


\section{Table of Contents}

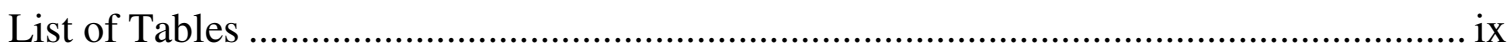

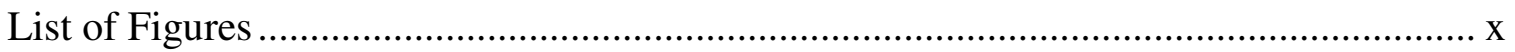

Chapter 1 Background ................................................................................................. 1

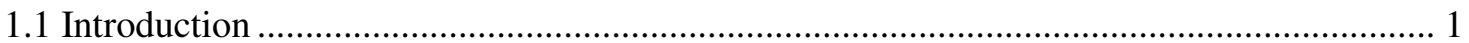

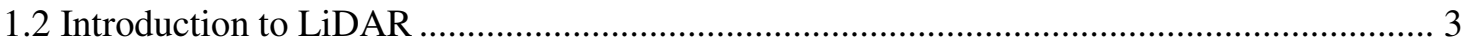

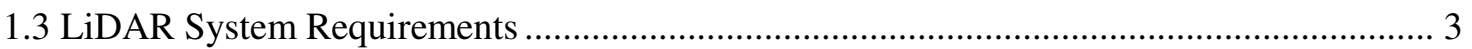

1.4 The need for a more efficient way to monitor geomorphic change in stream channels........ 4

1.5 LiDAR vs. Conventional Survey Methods...................................................................... 7

1.8 LiDAR as part of Little Creek Study ............................................................................. 8

Chapter 2 Literature Review …………………………………………………………... 10

2.1 LiDAR

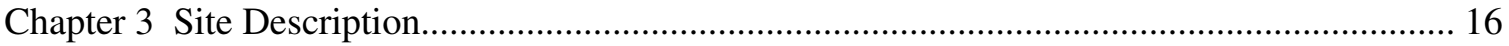

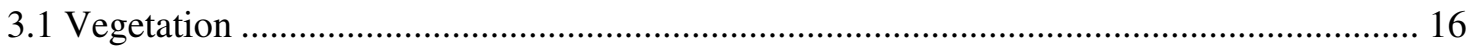

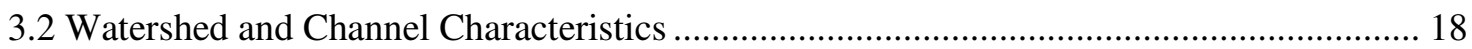

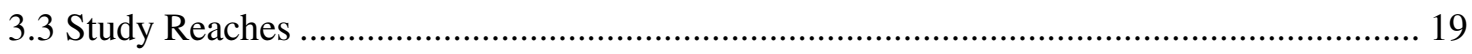

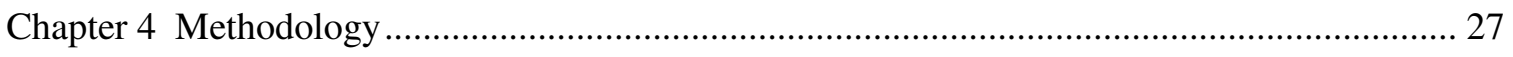

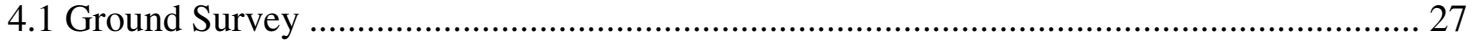

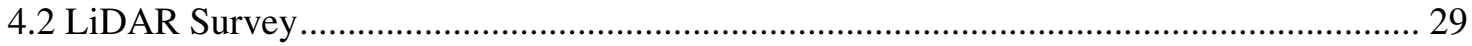

Chapter 5 Results and Analyses ....................................................................................... 34

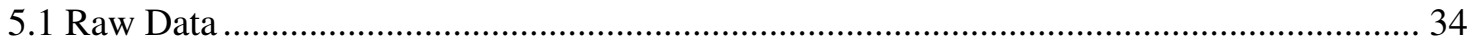

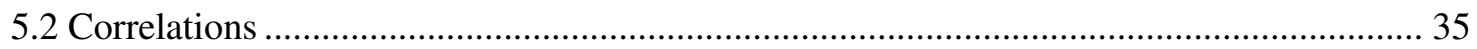

5.3 One Sample T-tests for horizontal positions ………………………………………..... 44

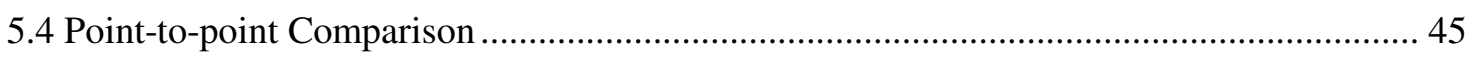

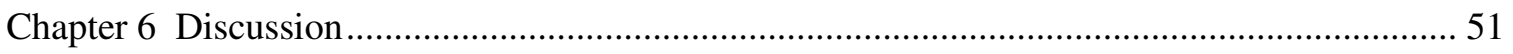

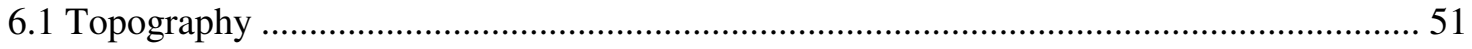

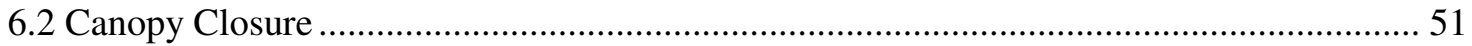

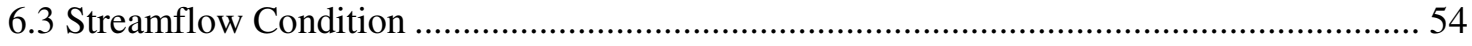

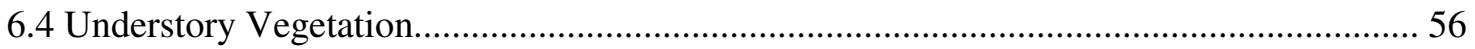

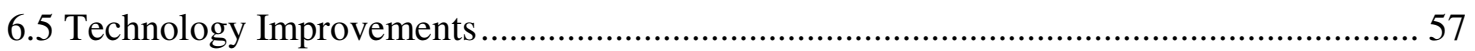

6.6 Comparison to Other Studies................................................................................... 57

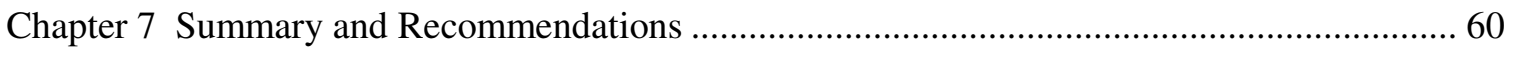

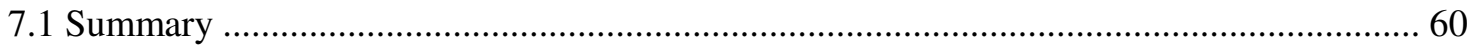




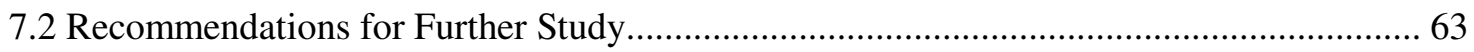

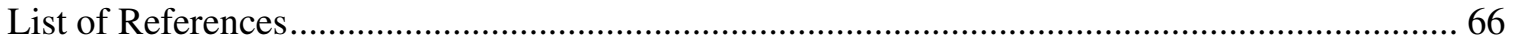

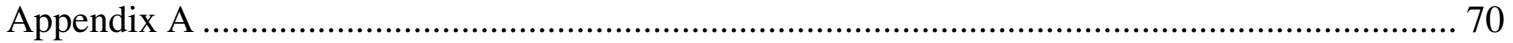

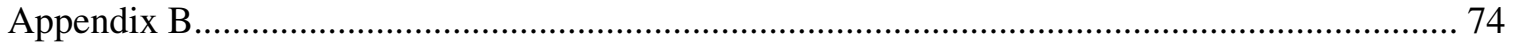

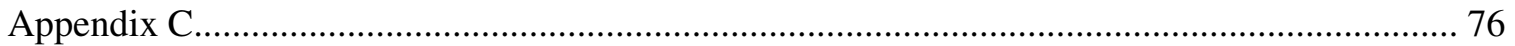




\section{List of Tables}

Table 3.1. Common species associated with redwood vegetation series (Hickman 1993, Sawyer and Keeler-Wolf 1995).

Table 4.1. Validation elevations collected prior to LiDAR data collection for Little

Creek.

Table 5.1 Average difference for cross-sectional characteristics between ground observations and LiDAR observations, and the number of observations in each

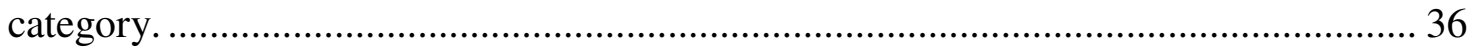

Table 5.2. Pearson's Correlation Results. ............................................................. 43

Table 5.3. Correlation results for the thalweg elevations by study reach. .................. 43

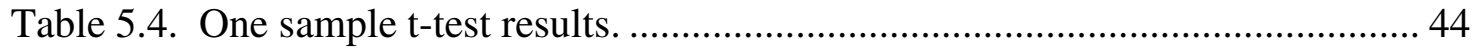

Table 6.1. Canopy cover was determined by completing a survey at each study reach using a vertical densitometer........................................................................ 52

Table 6.2. Vertical densitometer and LiDAR based canopy cover estimates by study reach.

Table 6.3. Average water depths at all study reaches at the time of the Ground Survey. 


\section{List of Figures}

Figure 3.1. Locations of study reaches

Figure 3.2. Hillshade with cross-sectional profile lines and permanent benchmarks at Main Stem A. Orange points are control points located in the study reaches, yellow points are cross-sectional profile end points and black points represent the LiDAR ground returns.

Figure 3.3. Channel, bank and vegetation conditions at study reach Main Stem A, looking upstream.

Figure 3.4. Channel, bank and vegetation conditions at study reach Main Stem B on Little Creek, looking upstream.

Figure 3.5. Channel, bank and vegetation conditions at study reach Main Stem C on Little Creek, looking upstream.

Figure 3.6. Channel, bank and vegetation conditions at study reach North Fork D on Little Creek, looking upstream.

Figure 3.7. Channel, bank and vegetation conditions at study reach North Fork E on Little Creek, looking upstream.

Figure 3.8. Channel, bank and vegetation conditions at study reach South Fork F on Little Creek, looking upstream.................................................................... 26

Figure 4.1. The flight lines used for the LiDAR survey are shown in blue.

Figure 5.1. Linear regression comparing the observed thalweg elevation from the ground survey to the thalweg elevation determined from the LiDAR-generated TIN for all study reaches.

Figure 5.2. Linear regression comparing the bankfull width, depth, and area as calculated using the ground survey data and the TIN data.

Figure 5.3. Two representative cross-sectional profiles (A8 and B6) visually show a good relationship between the ground-surveyed profile and derived profiles from the raw LiDAR point data, the TIN, and the GRID.

Figure 5.4. Differences in elevations between ground-survey elevations and LiDAR-

derived TIN elevations.

Figure 5.5. Number of differences in elevation between LiDAR points and ground points by reach in $15 \mathrm{~cm}$ increments.

Figure 5.6. The percentage of all observations within a reach according to elevation difference classes

Figure 6.1. LiDAR returns for Mainstem A. Green points represent returns from the canopy. Brown points represent returns from the ground surface. 


\section{Chapter 1 Background}

\subsection{Introduction}

It has become clear that a better understanding of natural systems requires research at intermediate spatial scales, ranging from watersheds to hillslopes and stream channel reaches (McKean and Roering, 2005). Disturbance to fluvial systems, both natural and anthropogenic, occur at this intermediate spatial scale throughout low-order subwatersheds contributing to cumulative effects. Likewise, the primary focus of landuse planning and environmental regulation occur at this intermediate scale. Effective documentation and analysis of existing conditions require not only the ability to accurately map the topographic features, but to do so over broad spatial scales, up to several square miles.

Detecting change in stream channel features over time is important in understanding channel morphology and the influence of both natural and anthropogenic influences. Channel features are now measured using a variety of ground-survey techniques. These surveys can take long periods of time and often require large amounts of funding to complete. Additionally, the data collected during ground surveys may only describe a small area within the watershed. These small areas, commonly referred to as study reaches, may be helpful in determining the conditions of specific areas, but may not aid in describing conditions found in the larger watershed. In large watersheds, or in areas of highly-variable channel conditions, surveying small study reaches provides only a limited understanding of processes or influences occurring throughout the watershed. 
Currently, ground surveys are capable of obtaining reasonably accurate and precise data for comparisons to detect change over time. For this study, ground surveys were used to verify the accuracy of data collected through the use of airborne Light Detection and Ranging (LiDAR).

LiDAR is an airborne laser mapping technology that provides an alternative to groundbased survey methods. The application of LiDAR technology for this purpose must still be evaluated to determine accuracy, the ability to detect changes in topography, and the ability to describe watershed processes.

The objective of this study is to evaluate the accuracy of LiDAR-derived channel crosssectional profiles for the purpose of detecting change. It is hypothesized that LiDARderived channel characteristics are statistically similar to ground-surveyed channel characteristics.

Airborne LiDAR flights of the study area were conducted in the spring of 2002. Groundreturn data from these flights were compared to ground-surveyed channel cross-sectional profiles to determine the accuracy and suitability of LiDAR for measuring stream channel conditions within steep terrain and densely-forested conditions found in the Santa Cruz Mountains. 


\subsection{Introduction to LiDAR}

LiDAR is an airborne laser mapping technology that is being used to collect high density three-dimensional point cloud data that is becoming commonly used to create detailed and accurate Digital Elevation Models (DEM) of the ground surface. The use of LiDAR allows for the collection of large amounts of data on a large spatial scale in a short period of time at comparable cost to a ground survey of study reaches in the same area. .

There is growing literature that documents the ability of LiDAR to provide high resolution terrain mapping in forested and rugged terrain (Hodgson et al., 2003 and Hyyppa et al., 2005). However, more research of a site specific nature is necessary to guide the application of this technology for uses in geomorphology and cumulative impacts analyses.

\subsection{LiDAR System Requirements}

Airborne LiDAR systems are expensive, technologically-advanced-systems that require much pre-flight planning, flight precision, and post-processing by highly-trained personnel. The typical components of a LiDAR system include:

- A laser scanner mounted in an airplane or helicopter capable of sending and receiving returns from approximately $20,000-100,000$ pulses per second. The LiDAR system used for this study provided 20,000 pulses per second.

- An airborne GPS unit that is updated with a new set of $\mathrm{x}, \mathrm{y}$, and $\mathrm{z}$ coordinates every half second. 
- An inertial measurement unit (IMU) which collects the roll, pitch, and yaw data of the aircraft flying the survey area that is updated approximately every two tenths of a second.

Ground control points throughout the area being flown are essential with this type of aerial survey for the calibration of the system and for validation of the data collected. These can be National Spatial Reference System Control or other survey markers that were installed by professional surveyors having positional and elevation accuracy deemed appropriate for calibration purposes.

Due to the large amounts of data being collected by these systems, there is a need for robust computer support. Before each flight all systems must be calibrated to ensure data quality. Calibration is typically done by collecting data of a structure or area with known physical characteristics. LiDAR flights can be flown day or night, depending only on clear skies. The presence of shadows does not influence LiDAR data, coordinates for each point can be obtained from one origin and the data has the same accuracy as data obtained using photogrammetric methods (Kraus and Pfieffer, 1998).

\subsection{The need for a more efficient way to monitor geomorphic change in stream channels.}

The detection of changes in channel features over time is important in understanding morphology and overall watershed health. These changes can be very subtle and difficult to detect depending on the influence of climatic conditions, geology, and landscape ruggedness. As previously mentioned, the most accurate way to detect these changes has been through highly-controlled, repeated filed surveys, which are expensive, time- 
consuming, and can be difficult to maintain from year to year. Repeated cross-sectional profiles have been surveyed throughout Redwood Creek on the north coast of California to measure geomorphic changes. Due to flood events and extensive erosion, Redwood Creek has experienced extremely high sediment loads and subsequent adjustments. Cross-sectional profiles were used to track the downstream movement of a large "sediment wave" in the lower portions of a gravel bedded river (Madej and Ozaki, 1996). In addition, repeated channel surveys conducted on a channelized reach of the North Nashwaaksis stream over a 10-year period was able to quantify not only changes in the size and shape of the channel but also changes in riparian vegetation (Bray, 2006). These surveys take countless hours and in most applications are only able to describe small study reaches in comparison to an entire watershed. The use of these small study reaches may lead to misinterpretation of the actual processes occurring on a landscape level. In order to better understand changes on a landscape or ecosystem level a more efficient way of collecting topographic data is needed.

Topographic data collected at the landscape scale could substantially reduce the errors and uncertainty associated with interpreting ground survey data from limited study reaches. For instance, a ground-surveyed cross-sectional profile provides information regarding only the line segment that was surveyed. Over a period of time this information can help explain whether aggradation or degradation is taking place and if the stream is widening, narrowing, or changing pattern. Some inferences can be made regarding the areas directly up and downstream of the cross-sectional profile, but this site specific data does not help determine a cause of these changes in stream topography. 
There is little evidence to know if a bank failure upstream of the cross-sectional profile is the cause of the aggradation or whether large wood, that was providing grade control, was dislodged and transported downstream of the location causing the area to headcut. More investigation would be required to determine the overall channel change cause in a reach. The creation of a three-dimensional model of a stream channel has proven to be a useful alternative to traditional measures of stream channel morphology (Keim and Skaugset, 1999). This suggests that topographic surveys, possibly derived from LiDAR, could provide an alternative means for evaluating channel change.

As part of the Little Creek Study, a long-term monitoring study at Cal Poly's Swanton Pacific Ranch, channel features were surveyed at six study reaches in the Little Creek watershed. LiDAR data were collected for the 528 hectare Little Creek watershed. The Little Creek study established six clusters consisting of 9 to 10 cross-sectional profiles that are approximately $4.6 \mathrm{~m}$ apart over approximately $50 \mathrm{~m}$ of stream channel. This was done to attempt to capture more data in one small area that could be easily repeated in annual surveys. However, inferences made at these study reaches must be carefully evaluated before extrapolation to other reaches throughout the watershed is considered. There are many factors that determine channel morphology, and the cause-effect relationship observed at the study reach may not hold true for reaches throughout the entire watercourse. If topographic data for the entire stream channel and watershed was available it may be possible to determine the direct cause and effect of these geomorphic changes. This could be accomplished using repeated topographic surveys, however, the effort would be significantly greater, and the repeatability for detecting change would be 
significantly more problematic. LiDAR may provide the alternative means for deriving topographic mapping of channels.

\subsection{LiDAR vs. Conventional Survey Methods}

LiDAR, unlike conventional survey methods, is capable of collecting large amounts topographic data in a short period of time. By using LiDAR, topographic data for an entire watershed can be collected in a matter of hours or days depending on the size of the watershed. LiDAR can collect the same cross-sectional profile data for miles of stream channel in the time required to complete a flight of the area. To understand the utility and limitations of LiDAR it must be determined whether or not LiDAR data is statistically similar to ground survey data.

The re-survey of control points completed in Little Creek for this study was found to be consistent to $0.03 \mathrm{~m}$ vertically and $0.15 \mathrm{~m}$ horizontally. This accuracy enables you to detect very slight changes in the topography of the stream channel. LiDAR is advertised by different vendors to be accurate anywhere from $\pm 0.02 \mathrm{~m}$ to $0.30 \mathrm{~m}$ root mean square error (RMSE) vertically and 0.15 to $0.30 \mathrm{~m}$ horizontally. Most vendors do not advertise what conditions are required to obtain these accuracies. However, studies show that LiDAR can only meet these advertised claims when the conditions are optimal with flat consistent terrain, free from obstructions, such as vegetation.

If LiDAR is able to generate data with the same accuracy expectation as conventional ground surveys, it may change the way in which topographic data of stream channels is collected and analyzed. Even if LiDAR is not accurate to the level of detail that can be 
achieved by conventional ground survey techniques, it may be able to greatly enhance our knowledge of watershed processes due to the relatively large area that can be surveyed.

\subsection{LiDAR as part of Little Creek Study}

LiDAR is being used as a tool to gather large amounts of topographic data in the Little Creek watershed. The Little Creek Study features paired and nested watershed study designs that intend to evaluate the effectiveness of timber harvesting practices to protect water quality. The study will consider the effects caused by single tree selection silviculture applied in the Santa Cruz Mountains in conformance with the current California Forest Practice Rules (FPRs). This set of rules is regarded as being among the most extensive regulations in the country, the majority of which were created with the intent to protect water quality (CAL FIRE, 2009).

The application of these rules in the planning process can require the need for large amounts of accurate topographic data of not only the entire watershed, but also the fish bearing stream channels within the project area. A pool/riffle survey has been required as part of a Timber Harvest Plan under the FPRs. The efficiency, in which some of the FPR requirements could be performed, may be greatly increased if LiDAR data could prove to provide the level of accuracy needed for these channel and watershed evaluations.

LiDAR data is also being used as part of the Little Creek Study to help obtain the locations, lengths and, conditions of roads within the watershed (White, 2010). Other 
topographic data collected by LiDAR provides the location of small drainages that are not shown on a typical 7.5 minute USGS Quadrangle. 


\section{Chapter 2 Literature Review}

\subsection{LiDAR}

LiDAR technology has proven to be a superior method to collect terrain data when compared to photogrammetric methods (Kraus and Pfieffer, 1998). The increasing use of LiDAR technology in a growing variety of industries and an increasing awareness and interest in the application of the technology by the general public has paralleled the advent of global positioning systems (GPS) availability and accuracy in recent years. GPS is relied upon heavily to ensure LiDAR provides accurate measurements of the earth's surface. The three-dimensional position of each LiDAR return is determined by an airborne GPS unit and IMU. GPS applications for surveying purposes have become increasingly common, and many have put to use or speculate about the ability for LiDAR to aid in surveys of landscape features, depending on the desired accuracy.

LiDAR technology has been used to measure forest structure and terrain. Forest terrain can be difficult to capture using LiDAR and other airborne methods due to the dense vegetation. To evaluate the effect of forest canopy on LiDAR accuracy, LiDAR-derived elevations were compared from four different silvicultural treatments, clearcut, heavily thinned, lightly thinned and uncut (Reutenbuch, et al., 2003). The clearcut canopy class had the highest vertical accuracy of $16 \mathrm{~cm} \pm 23 \mathrm{~cm}$, while the uncut canopy class had the lowest accuracy of $31 \mathrm{~cm} \pm 29 \mathrm{~cm}$. This study concluded LiDAR accuracies were sufficient to model micro-topography of a conifer forest. However, this study also showed that the canopy closure does play an important part in how accurate topographic 
data collected using LiDAR technology can be. The sparse spacing of ground returns can degrade the quality and accuracy of the LiDAR-derived terrain surface.

Other findings have shown that over rugged terrain or heavily-forested areas the vertical accuracy declines due to the inability of the laser to reach the ground surface. In 2002, a study used LiDAR to measure river corridor topography (Bowen and Waltermire, 2002). The terrain surveyed was steep and variable with sagebrush cover. The overall vertical accuracy reported was $43 \mathrm{~cm}$ (RMSEz). This was a lower accuracy than what is commonly cited, however, the error changed depending on the terrain type.

LiDAR accuracies are typically reported through vertical root mean square error between LiDAR point elevations and the control ground survey elevations. Reported LiDAR accuracy must be viewed with respect to the variables associated with ground conditions and the parameters of the flight design. Reported accuracies range from $\pm 10 \mathrm{~cm}$ in areas of sparse vegetation (McKean and Roering, 2005) to $\pm 20 \mathrm{~cm}$ in low relief boreal forest setting (Hyyppä, et al., 2005), to $36.1 \mathrm{~cm}$ RMSEz in low relief scrub-shrub (Hodgson, et al., 2005). These results illustrate the promising capability of LiDAR in various conditions. However, none of these conditions are particularly challenging landscapes in terms of canopy cover or varied types of more extreme topography.

There is general agreement among current publications regarding the sources of LiDAR error in mountainous and forested terrain. These factors include field conditions, such as terrain slope (Kraus and Pfeifer, 1998), aspect and topographic ruggedness (McKean and 
Roering, 2005), forest canopy, understory vegetation and target conditions (Reutebuch, et al., 2003; Hodgson, et al., 2005). Other factors pertain to the mission flight parameters including flying height, aircraft speed, pulse rate, scan angle and positional error imparted from the GPS and IMU (Hyyppä, et al., 2005). Finally, error can be introduced through the software algorithms designed to filter and interpolate LiDAR points necessary to produce the final digital surface model.

The amount of error contributed by each factor, and actions to minimize these effects are still being investigated. For example, typical flying heights range from $200 \mathrm{~m}$ to $6,000 \mathrm{~m}$ and have a strong influence on other flight parameters. A low flying height of $200 \mathrm{~m}$ has been used to collect data in a coniferous forest environment (Reutebuch, et al., 2003). Conversely, flying heights of $1,900 \mathrm{~m}$ to $3,048 \mathrm{~m}$ have been used to evaluate vertical accuracy in the Grand Canyon, Arizona (Mietz, et al., 2002). In another study, the effects of flying height were tested by performing repeated surveys at the altitudes of 400,800 and 1,500 $\mathrm{m}$. In this test, the across-track point spacing increased from $0.80 \mathrm{~m}$ at $400 \mathrm{~m}$, $1.6 \mathrm{~m}$ at $800 \mathrm{~m}$ to $3.0 \mathrm{~m}$ at $1,500 \mathrm{~m}$, respectively. The magnitude of LiDAR pulse sizes on the ground were also shown to increase from 0.4, 0.8 to $1.5 \mathrm{~m}$ (Hyyppä, et al., 2005). As the flying height increases, the size of the laser pulse reaching the ground is enlarged and the density of points is reduced. Pulses with larger diameters will interact with more objects before reaching the ground surface. Multiple and scattered reflections from these LiDAR returns may limit the ability to identify true ground returns, reducing the accuracy of the generated terrain data. 
LiDAR is capable of receiving and recording multiple returns for each pulse. These returns result from the reflection of the pulse off of different objects in the area. Each pulse may be reflected from the top of the forest canopy, the middle of the canopy, understory vegetation and finally the ground surface. The round trip travel time of each return, measured in nanoseconds, is then used to calculate the elevation. The data can then be filtered to provide more accurate elevations and positions for different levels of the vegetative canopy, or when using only the last returns, the ground surface. For the purpose of topographic mapping, points representing vegetation, buildings and other objects must be eliminated leaving only a bare earth surface. The inability to filter out vegetation and other structures is a concern to investigators. Some automated filtering algorithms have a tendency to smooth steep ground features that may actually be vertical streambanks or road cuts. LiDAR analysts involved with applying these filters acknowledge that the greatest improvement in the quality of LiDAR topography will likely be achieved by reducing the misclassification of vegetation and structure returns as ground and by increasing the density of actual LiDAR ground returns (Haugerud and Harding, 2001).

Technical improvements in regards to the acquisition and storage of LiDAR data help improve performance when surveying areas of dense vegetation and steep slopes. With a laser pulse rate of 7,000 points per second and a relatively slow flying speed it is possible to record 5 pulses per square meter (Csanyi, et al., 2005). With a flying height of $400 \mathrm{~m}$ and a scan rate of 83 kilohertz (kHz) (Hyyppä, et al., 2005) reports nominal point densities of 8 to 10 pulses per square meter. It is likely that LiDAR technology will 
continue to improve in terms of pulse rate, and the density of returns recorded in a variety of terrain conditions, while improved identification, filtration and interpolation of the data will produce more accurate representations of ground surface.

Many studies have been conducted that consider the capabilities of LiDAR technology to accurately map stream channel characteristics. By nature, the studies differ in terrain and vegetation types. In 2004, a study was conducted in the Walnut Gulch Experimental Watershed to compare DEMs derived from two remote sensing technologies (Miller, 2004). This study used LiDAR and IFSAR (Interferometric Synthetic Aperture Radar) to create two separate terrain models of $1 \mathrm{~m}$ and $2.5 \mathrm{~m}$. The study compared ground-based surveys with LiDAR- and IFSAR-derived surveys of channel cross-sectional width, depth, and area, similar to this study. It was found that there were high correlations within both of the models. The best correlation came when comparing cross section depth. The watershed where this study was conducted was located in a desert transition zone. The main vegetation type was a mixture of grassland and shrub-steppe. It was reported that the riparian overstory has a low canopy density

Another study conducted on the River Coquet in Northumberland, U.K. (Charlton, 2003) also considered the application of LiDAR in a river environment. This study used single return LiDAR data to create a $2 \mathrm{~m}$ grid. Eighteen cross sections were part of the study. Only six of the original eighteen were selected for detailed comparison. The study found that the presence of vegetation and deep water introduced anomalies in the LiDAR data. Spikes in the LiDAR data were noted where vegetation had colonized the streambanks. 
A study, conducted in the Grand Canyon, evaluated the use of LiDAR and photogrammetric methods for monitoring volume changes in riparian resources (Davis, 2002). As part of the study vegetated and bare sediment deposits were mapped for comparison. The goal of the study was to produce a ground topographic model accurate to $20 \mathrm{~cm}$ capable of measuring the sediment volume to within $3 \%$. Both high resolution and moderate resolution LiDAR was used to create grids of $1.5 \mathrm{~m}$, and $3.75 \mathrm{~m}$. The study used 2000 ground elevations from the DEM for its assessment of accuracy. A one meter radial search was conducted around each ground point to find a corresponding LiDAR point. Mean errors for the moderate-resolution LiDAR was reported at 33 to 84 $\mathrm{cm}$, and 19 to $49 \mathrm{~cm}$ for the high-resolution LiDAR. Only one out of four study areas containing vegetation produced vertical accuracies of less than $20 \mathrm{~cm}$. The vegetation was reported to be 4 to $6 \mathrm{~m}$ high.

In 2003, LiDAR-based data were considered for use in support of a high-resolution geomorphologic and hydraulic model (French, 2003). The study reported a LiDAR accuracy of \pm 0.10 to $\pm 0.15 \mathrm{~m}$ in a $12 \mathrm{~km}$ by $4 \mathrm{~km}$ coverage area. The RMSE determined from 50 well-distributed elevation checkpoints was $3.7 \mathrm{~m}$. A systematic offset of $0.1 \mathrm{~m}$ was removed, improving the RMSE to $0.16 \mathrm{~m}$. There were no trees located within this study area. 


\section{Chapter 3 Site Description}

Located roughly twelve miles north of Santa Cruz, California and four miles north of Davenport, Little Creek (Figure 3.1) is one of seven subwatersheds that combine to form the Scotts Creek watershed. The lower half of the 526-hectare Little Creek watershed is within Swanton Pacific Ranch, a coastal property that is owned by Cal Poly Corporation and managed by the Cal Poly College of Agriculture, Food and Environmental Sciences. Little Creek is typical among smaller coastal mountain watersheds found along the central and northern California coast. It includes first, second and third-order tributaries,

as defined by Strahler (1964), and Class I, II, and III streams, as defined by the California Forest Practice Rules (CAL FIRE, 2009).

\subsection{Vegetation}

The watershed is dominated by second-growth redwood (Sequoia sempervirens (D. Don) Endl.) that characterize the redwood vegetation series (Sawyer and Keeler-Wolf, 1995). Common species found in association with the redwood vegetation series are listed in Table 3.1. 
Table 3.1. Common species associated with redwood vegetation series (Hickman 1993, Sawyer and Keeler-Wolf 1995).

\begin{tabular}{|c|c|c|}
\hline Latin name & Author & Common name \\
\hline Abies grandis & (D. Don) Lindl. & Grand fir \\
\hline Acer macrophyllum & Pursh & Bigleaf maple \\
\hline Arbutus menziesii & Pursh & Madrone \\
\hline Berberis nervosa & Pursh & Little Oregon-grape \\
\hline Blechnum spicant & (L.) Sm. & Deer fern \\
\hline Carex globosa & Boott & Round-fruited sedge \\
\hline Gaultheria shallon & Pursh & Salal \\
\hline Iris douglasiana & Herb. & Douglas iris \\
\hline Lithocarpus densiflora & (Hook. \& Arn.) Rehder & Tanoak \\
\hline Marah fabaceus & (Naudin) Greene & Man root \\
\hline Oxalis oregana & Nutt. & Redwood oxalis \\
\hline Polypodium californicum & Kaulf. & California polypody \\
\hline Polystichum munitum & (Kaulf.) C. Presl & Sword fern \\
\hline Pseudotsuga menziesii & (Mirbel) Franco & var. menziesii Douglas fir \\
\hline Pteridium aquilinum & (L.) Kuhn & Bracken \\
\hline Sequoia sempervirens & (D. Don) Endl. & Redwood \\
\hline Trillium ovatum & (Pursh) & Trillium \\
\hline Tsuga heterophylla & (Raf.) Sarg. & Western hemlock \\
\hline Umbellularia californica & (Hook \& Arn) Nutt. & California bay \\
\hline Vaccinium ovatum & Pursh & Black huckleberry \\
\hline Woodwardia fimbriata & Sm. & Chain fern \\
\hline
\end{tabular}


Most species listed in Table 3.1 can be found in the Little Creek watershed. Though not included in Table 3.1, knobcone pine (Pinus attenuata Lemm.) and hairy manzanita (Arcostaphylos tomentosa (Pursh) Lindl. ssp. crinita (Mcminn) Gankin) also exist but are limited to portions of the ridgelines. The riparian corridor in Little Creek, from the confluence with Scotts Creek to the North and South Fork confluence, is dominated by red alder (Alnus rubra Bong.). Other plant species located in the riparian corridor are blackberry (Rubus ursinus), elderberry (Sambucus nigra L. ssp. canadesis (L.) R.Bolli), and stinging nettle (Urtica dioica L.) The riparian corridor above the confluence of the North and South Forks contains a mixture of the dominant conifers and hardwoods of the watershed including some quantities of red alder.

\subsection{Watershed and Channel Characteristics}

Topographic elevations range from approximately $12 \mathrm{~m}$ to $490 \mathrm{~m}$, with an average ground surface slope of $42 \%$. Mean annual precipitation ranges from approximately 1.02 $\mathrm{m}$ at the watershed outlet to $1.40 \mathrm{~m}$ on the ridgelines. The stream network within the watershed includes the Main Stem and the North and South Forks (Figure 3.1). The Little Creek watershed is 526 hectares in size. The channel in the Main Stem of Little Creek has an average bankfull width of $5.13 \mathrm{~m}$, an average bankfull depth of $0.63 \mathrm{~m}$, and average bankfull area of 2.13 square meters. The channels that make up the North Fork and South Fork are similar in size and shape, however slightly smaller. Both the North Fork and South Fork have steeper channel gradients (approximately 5\% within the study reaches) than the Mainstem (approximately 3\% within the study reaches). 


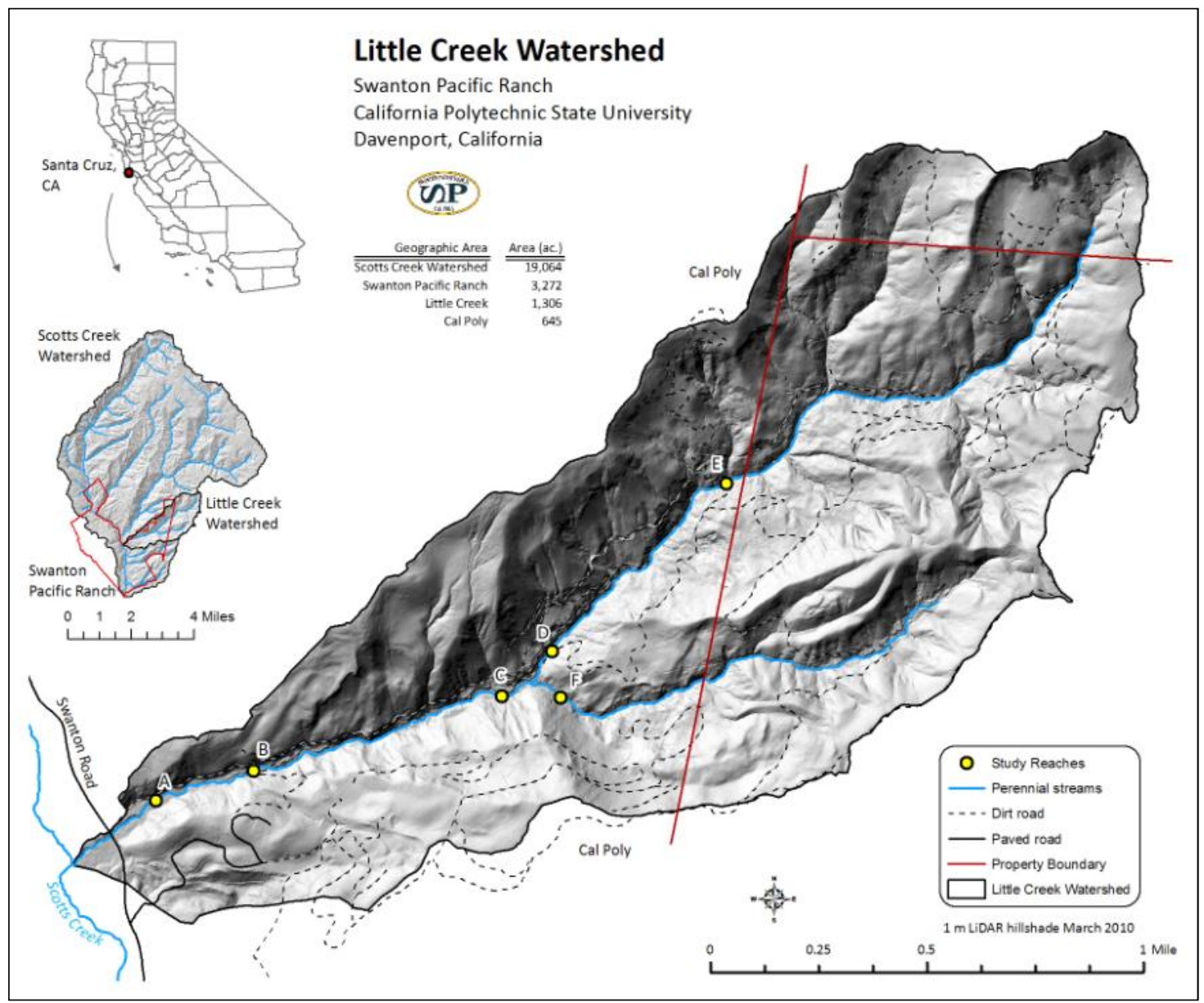

Figure 3.1. Locations of study reaches.

\subsection{Study Reaches}

Included in Figure 3.1 are the locations of study reaches used in this study. There are three study reaches located on the main stem of Little Creek and two study reaches located on the North Fork and one study reach located on the South Fork.

All of the study reaches contain 9 to10 cross-sectional profiles that are spaced approximately $4.6 \mathrm{~m}$ apart. At three of the study reaches the cross-sectional profiles were clustered in groups of five upstream and downstream of features that were suspected to 
influence change. The study reaches that include the cross-sectional profile clusters of five include Main Stem A (Figure 3.2), Main Stem C, and the North Fork D. The crosssectional profiles, clustered in groups of five, are still spaced approximately 4.6 meters apart for the upstream and downstream groupings. The study reach located in the upper most reaches of the North Fork (under Cal Poly's ownership) is located under a bridge on the main haul road accessing the watershed. This bridge falls directly over one of the cross-sectional profiles in the study reach, making it impossible to extract high quality LiDAR data for this cross-sectional profile. That profile was removed from consideration for the purposes of this study. Hillshades showing cross-sectional profile locations for the remaining study reaches can be found in Appendix A.

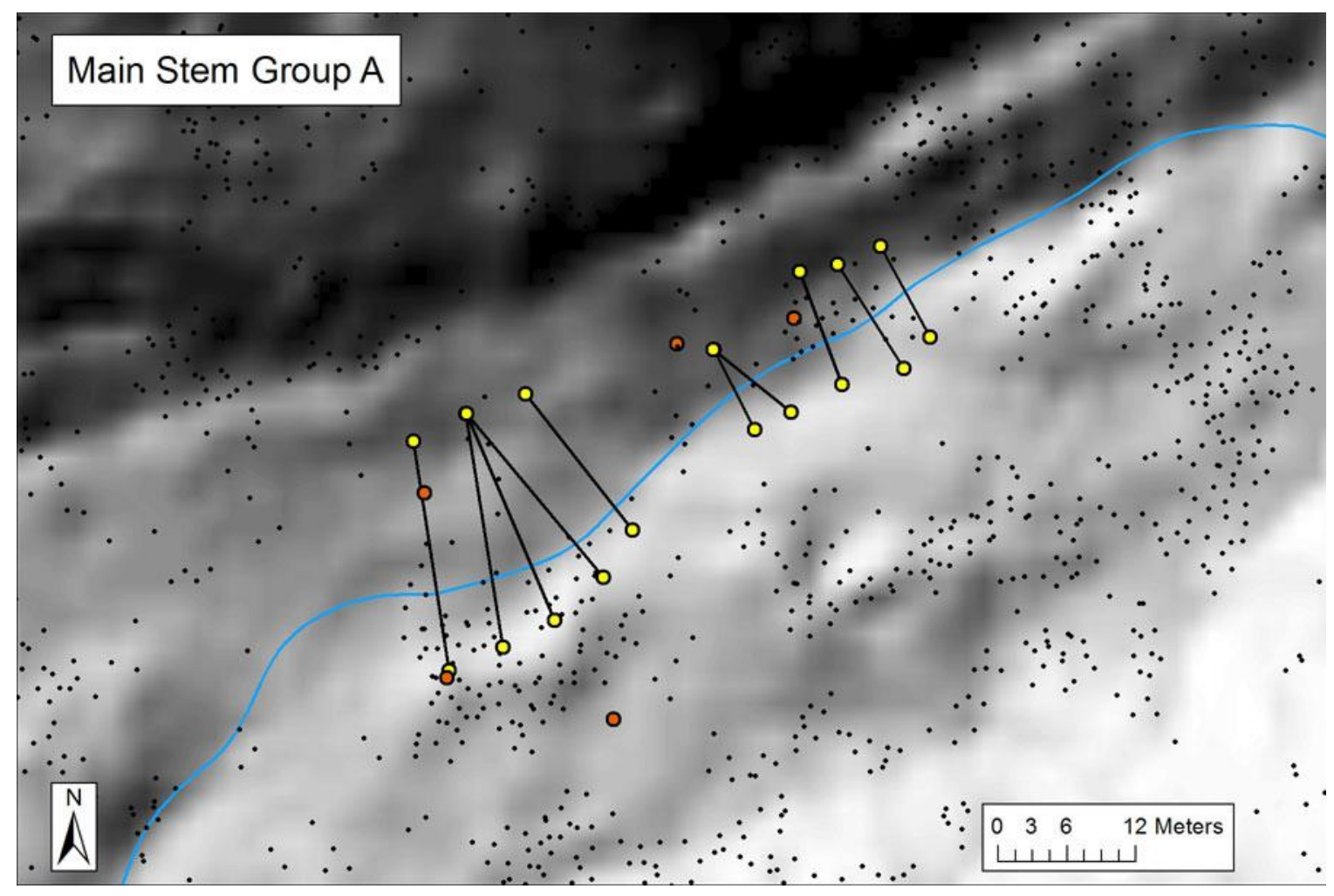

Figure 3.2. Hillshade with cross-sectional profile lines and permanent benchmarks at Main Stem A. Orange points are control points located in the study reaches, yellow points are cross-sectional profile end points and black points represent the LiDAR ground returns. 
The study reaches differ in channel size and shape, valley topography, and canopy cover. The study reach located in the lower watershed is Main Stem A (Figure 3.3). This reach is located in an area with the widest valley floor of all of the study reaches and consists of a floodplain that has been very active in the past. The overstory canopy in this reach is dominated by red alder with lesser amounts of California bay laurel and redwood. The wide floodplain in this reach has also allowed for the establishment of several understory species such as elderberry, blackberry, and stinging nettle immediately adjacent to the active channel. The channel in this reach is a low gradient channel. This study reached has two groups of five cross-sectional profiles.

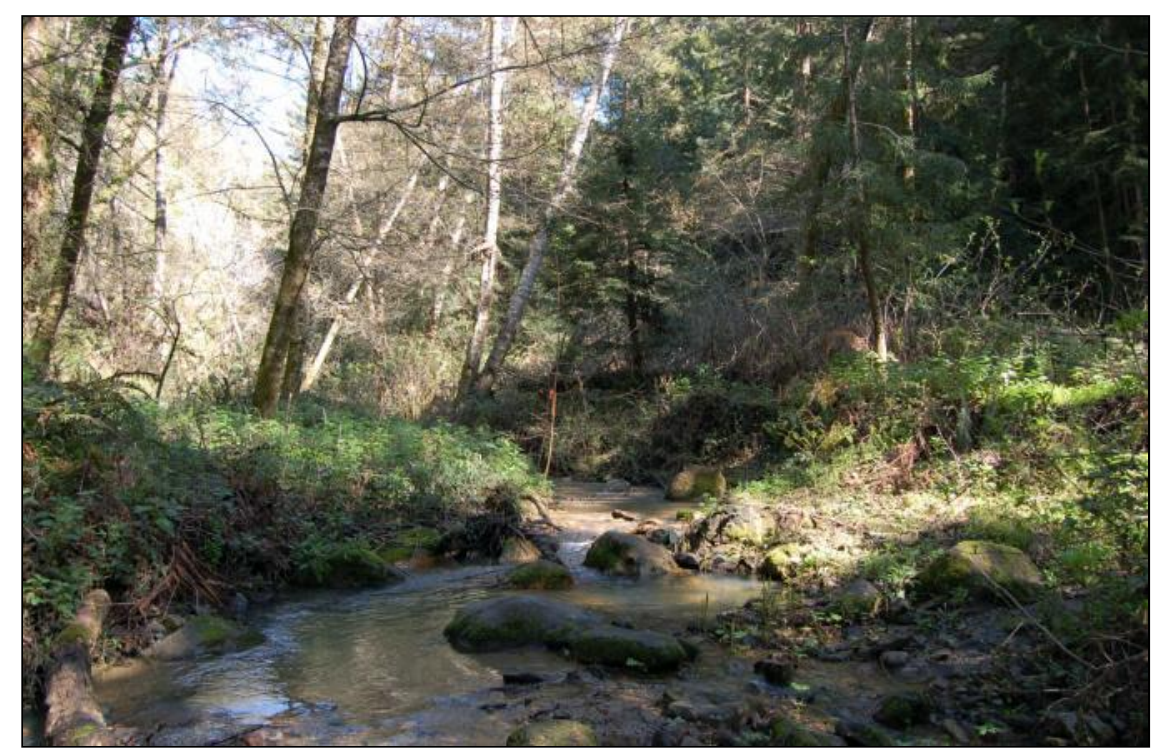

Figure 3.3. Channel, bank and vegetation conditions at study reach Main Stem A, looking upstream.

The second study reach in the Main Stem, Main Stem B (Figure 3.4), is the middle reach approximately halfway up the Main Stem of Little Creek. This study reach has more inner gorge type characteristics than Main Stem A. It has a very narrow valley floor with steep slopes on the south side. The overstory canopy here is dominated by bigleaf maple 
with lesser amounts of alder, redwood, and California bay laurel. Due to the steeper valley topography there is less understory vegetation immediately adjacent to the active channel. The species most commonly found in the understory in this reach are sword fern and redwood sorrel.

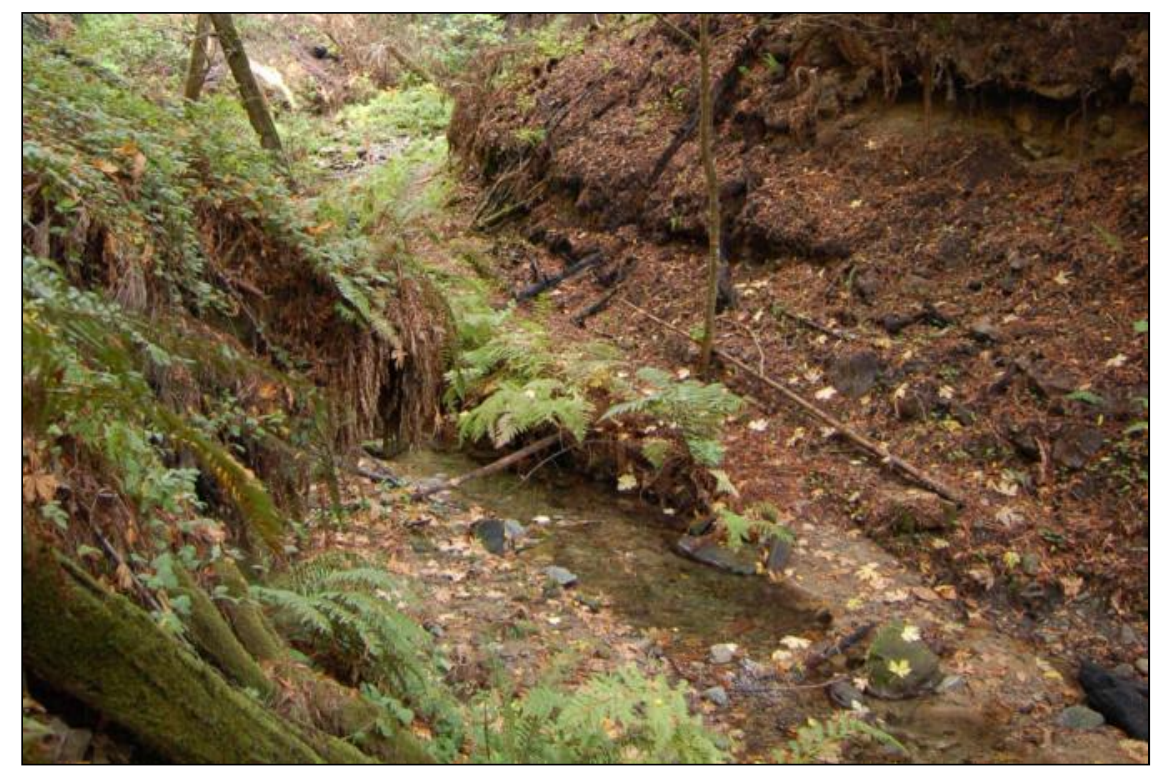

Figure 3.4. Channel, bank and vegetation conditions at study reach Main Stem B on Little Creek, looking upstream.

The uppermost study reach in the Main Stem Little Creek, Main Stem C (Figure 3.5), is located immediately downstream of the confluence of the North and South Forks of Little Creek. The cross-sectional profiles in this reach are separated into two groups of five. The profiles are separated by a small debris jam in the main channel. The valley slopes on the western side are not as steep as those found in Main Stem B. To the north of this site is a swimming pool that was part of a Boy Scout Camp that was on the property during the 20's and 30's. The valley slopes on the south side of the valley are extremely steep with slopes well over 45 percent. The overstory canopy in this study reach is dominated by red alder and bigleaf maple with lesser amounts of redwood, Douglas fir, 
tanoak, and California bay laurel. The understory vegetation consists mainly of sword fern with lesser amounts of redwood sorrel and stinging nettle.

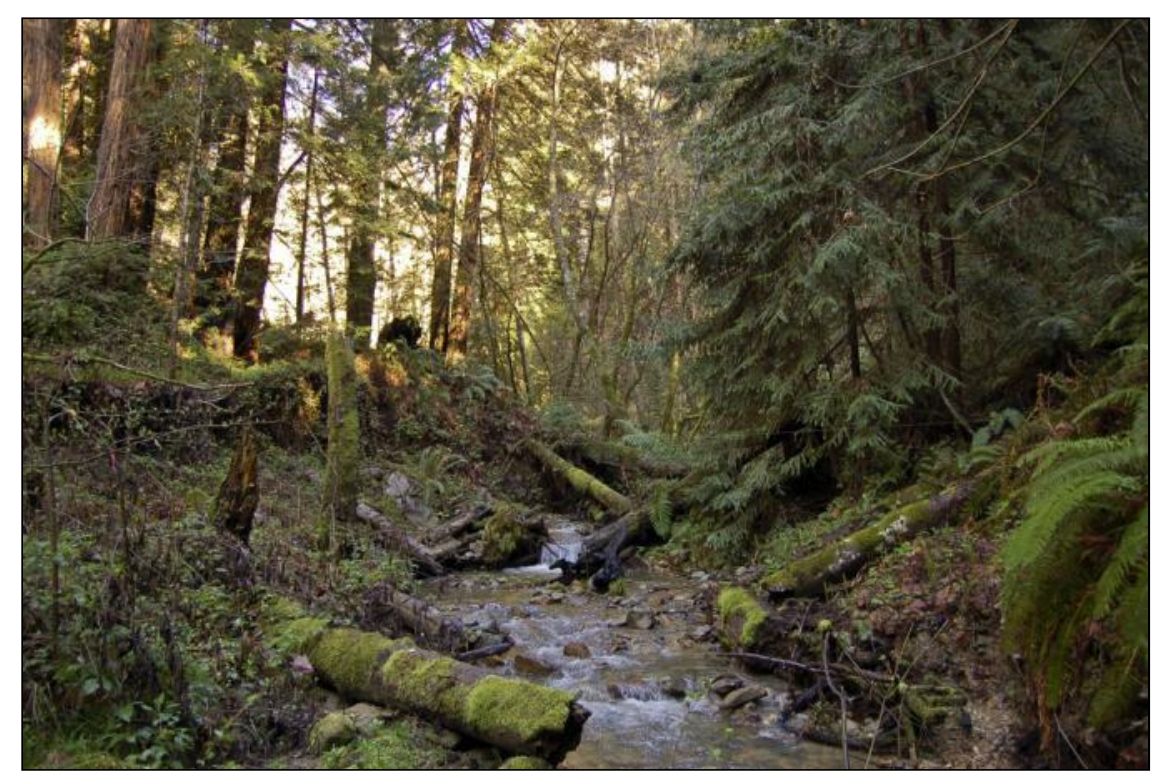

Figure 3.5. Channel, bank and vegetation conditions at study reach Main Stem C on Little Creek, looking upstream.

The lower study reach in the North Fork Little Creek, North Fork D (Figure 3.6), is located upstream of the Lower North Fork monitoring station. This set of 9 crosssectional profiles is also split into two groups one of four and one of five. This study reach has an overstory dominated by redwood with lesser amounts of red alder, Douglas fir, tanoak and bigleaf maple. There is less understory vegetation in this study reach as well. The species making up the understory consists of redwood sorrel, sword fern, and blackberry. The valley slopes in this study reach are typical of the area with slopes ranging from 30 to 50 percent. 


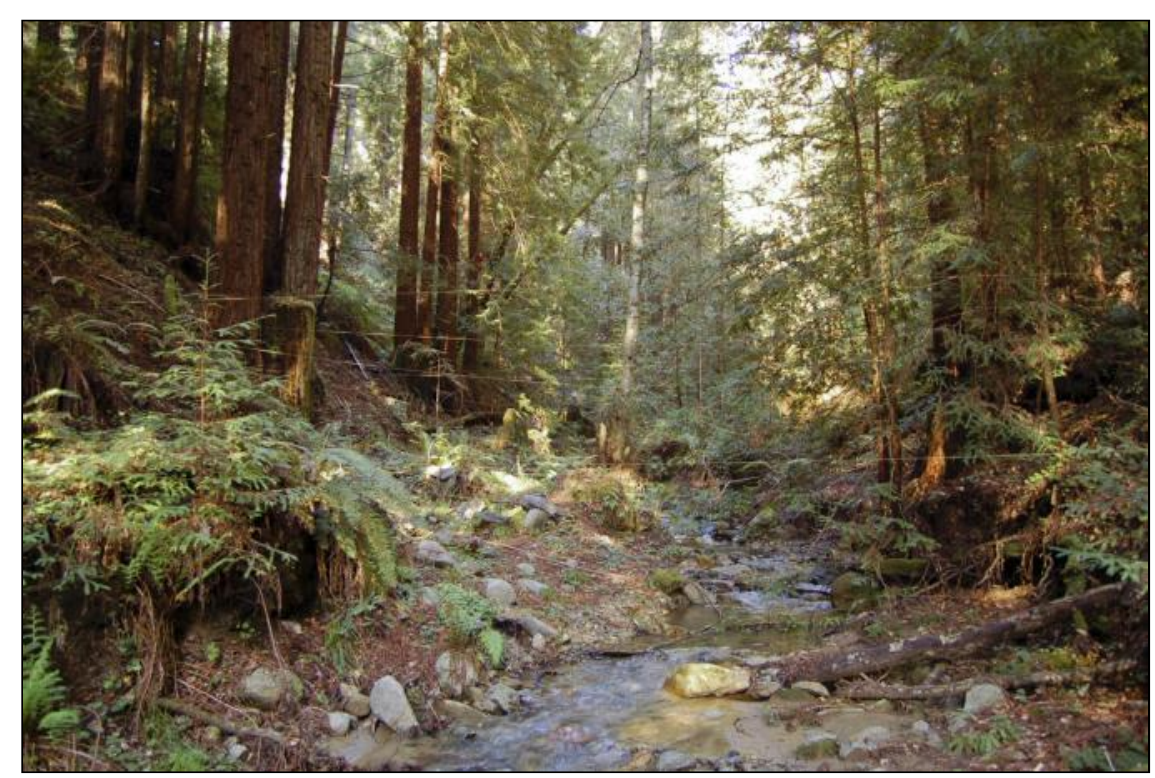

Figure 3.6. Channel, bank and vegetation conditions at study reach North Fork D on Little Creek, looking upstream.

The upper study reach in the North Fork Little Creek, North Fork E (Figure 3.7), is located in the upper most portion of the North Fork watershed under the ownership of Cal Poly. This study reach is located directly downstream of the Upper North Fork monitoring station. This study reach has steep valley sides on both sides of the reach with little to no floodplain present. The dominant overstory vegetation is redwood with lesser amounts of tanoak. 


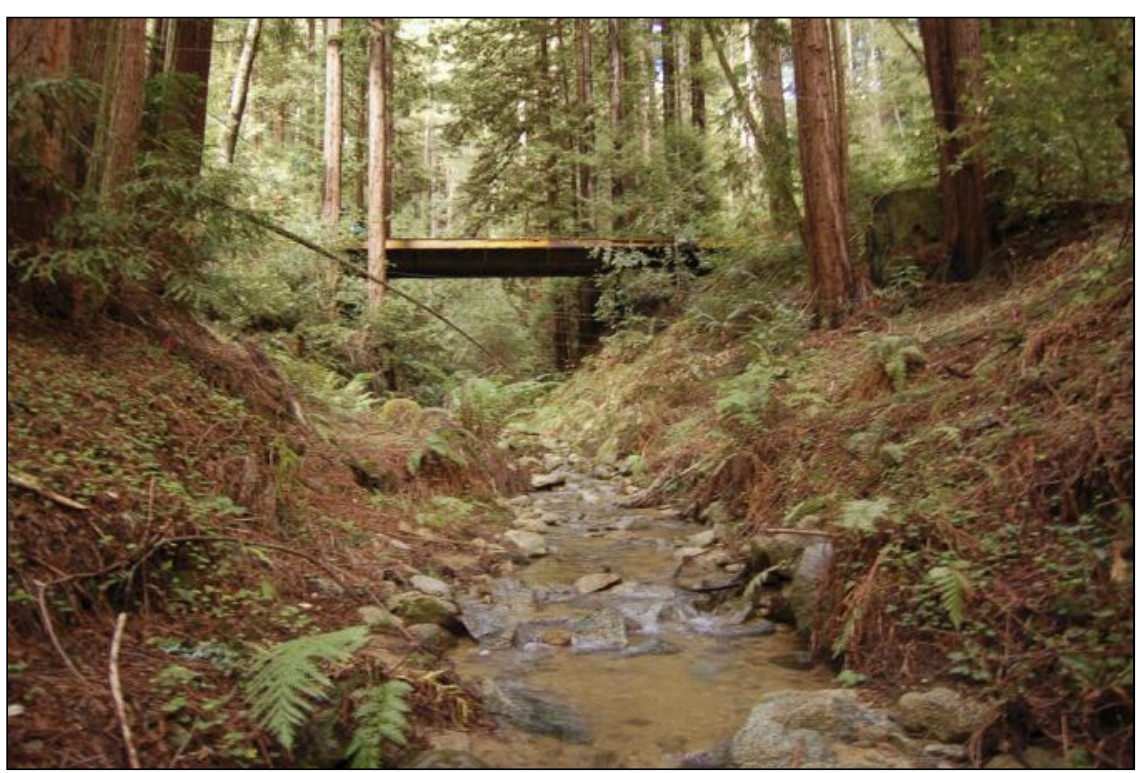

Figure 3.7. Channel, bank and vegetation conditions at study reach North Fork E on Little Creek, looking upstream.

The only study reach in the South Fork Little Creek, South Fork F (Figure 3.8), is located in the lower reaches of the South Fork watershed just upstream of the South Fork monitoring station. This study reach has an extremely dense overstory canopy predominantly comprised of redwood. The overstory canopy also contains red alder, tanoak, and Douglas fir. The valley in this area is very steep on both sides of the watercourse with a small floodplain in the bottom. This floodplain surface material consists primarily of unconsolidated decomposed granite. This study reach has the most narrow active channel among all of the study reaches in the watershed. 


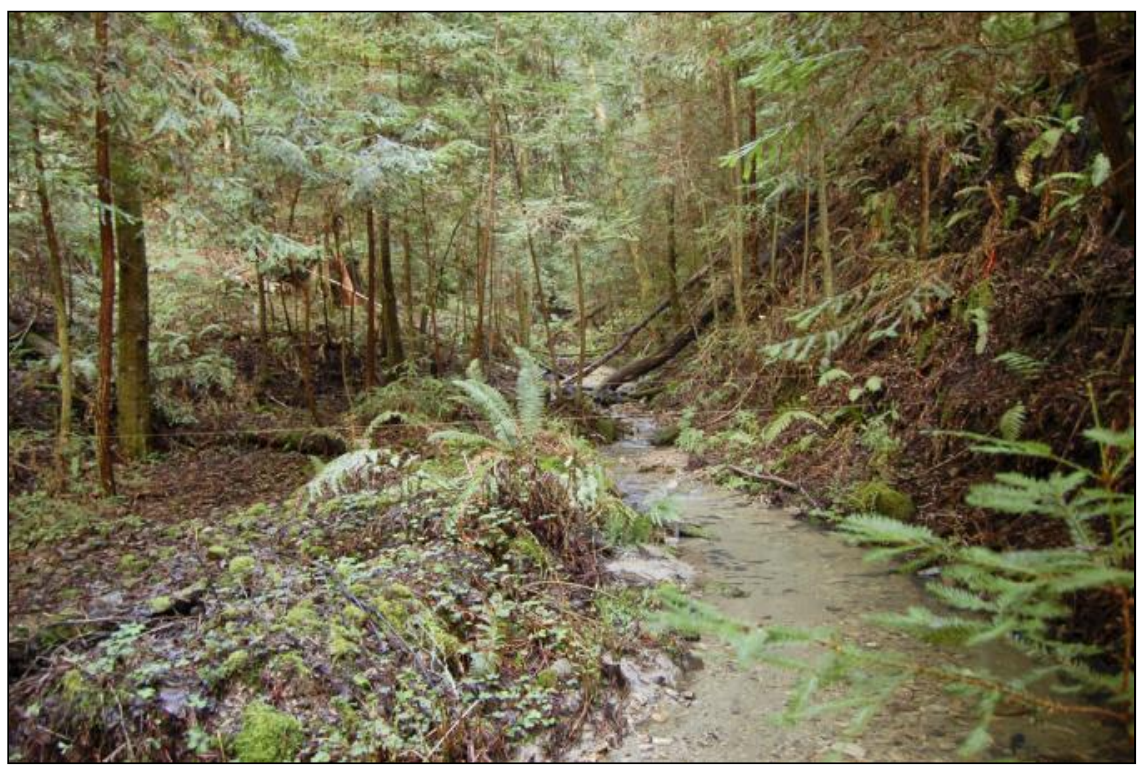

Figure 3.8. Channel, bank and vegetation conditions at study reach South Fork F on Little Creek, looking upstream. 


\section{Chapter 4 Methodology}

\subsection{Ground Survey}

The six groups of cross-sectional profiles in Little Creek were installed for the purposes of monitoring the geomorphic changes that occur in a specific reach over time. Each grouping consists of 9 or 10 cross-sectional profiles spaced approximately $4.6 \mathrm{~m}$ apart. This relatively close spacing was intended to produce more detail in a $50 \mathrm{~m}$ study reach, than typically used, evenly-spaced, cross-sectional profiles, over much longer reaches of channel. The closer spacing aids in detecting and quantifying channel change throughout the study reach (Madej, 2000). Although the spacing between cross-sectional profiles was not a critical factor in this study, the smaller spacing is more appropriate for comparison to LiDAR-derived profiles. In addition, comparing to LiDAR using this smaller spacing reflects on the utility of LiDAR to produce accurate high-resolution topographic maps of channels.

The 59 channel cross-sectional profiles used in this study were measured using conventional survey techniques, specifically, the standard leveling techniques described in Stream Channel Reference Sites (Harrelson, et al., 1994). Each cross-sectional profile is identified in the field by rebar stakes located on either end of the profile outside of the bankfull channel. The field survey was completed by stretching a cloth tape across the channel between the two end point stakes. A Philadelphia rod and automatic level were then used to determine an elevation for any significant break in slope located along the cross-sectional profile. The end points were then located horizontally and vertically using a Total Station. The field-surveyed data were linked to a control survey completed 
by the professional surveying firm, Dunbar and Craig. The control survey is accurate to 0.03 meters vertically and less than 0.15 meters horizontally. The datum was changed to NAVD88 to match the LiDAR data.

A three-dimensional location was determined for every significant change in slope occurring in each cross-sectional profile. For the purposes of this study a significant change in slope is defined as any significant deviation from the previous average slope. Typically, the magnitude of the vertical change necessary to warrant an additional data point was 0.1 meters. These changes in slope are often found where the floodplain meets the bottom of the canyon wall or at the junction of a point bar and the active channel. As part of the field survey, characteristics that are used to describe geomorphic changes, such as the bankfull elevation, the thalweg elevation, and the edge of water were identified. This information was used to calculate bankfull area (bfa), bankfull depth (bfd), and bankfull width (bfw), for each cross-sectional profile.

In addition, as part of the ground survey, a survey of the canopy condition using a vertical densitometer (Stumpf, 1993) at each study reach was completed. One hundred readings were taken at each study reach. Densitometer readings were taken at each endpoint stake, at the edge of the bankfull channel, and at the thalweg of the channel. Readings were taken at each cross-sectional profile and between each cross-sectional profile. This procedure provided a representation of the canopy over directly above the areas of the study reach being considered. 


\subsection{LiDAR Survey}

An aerial LiDAR survey was completed of the Little Creek watershed by small fixed-

wing aircraft on April 30, 2002 and May 28, 2002. Due to adverse weather conditions in the area the survey was conducted in two separate flights. The data were collected at a flying height of $1,829 \mathrm{~m}$ using a pulse rate of 20,000 pulses per second. There were a total of 10 flight lines over the Little Creek watershed (Figure 4.1).

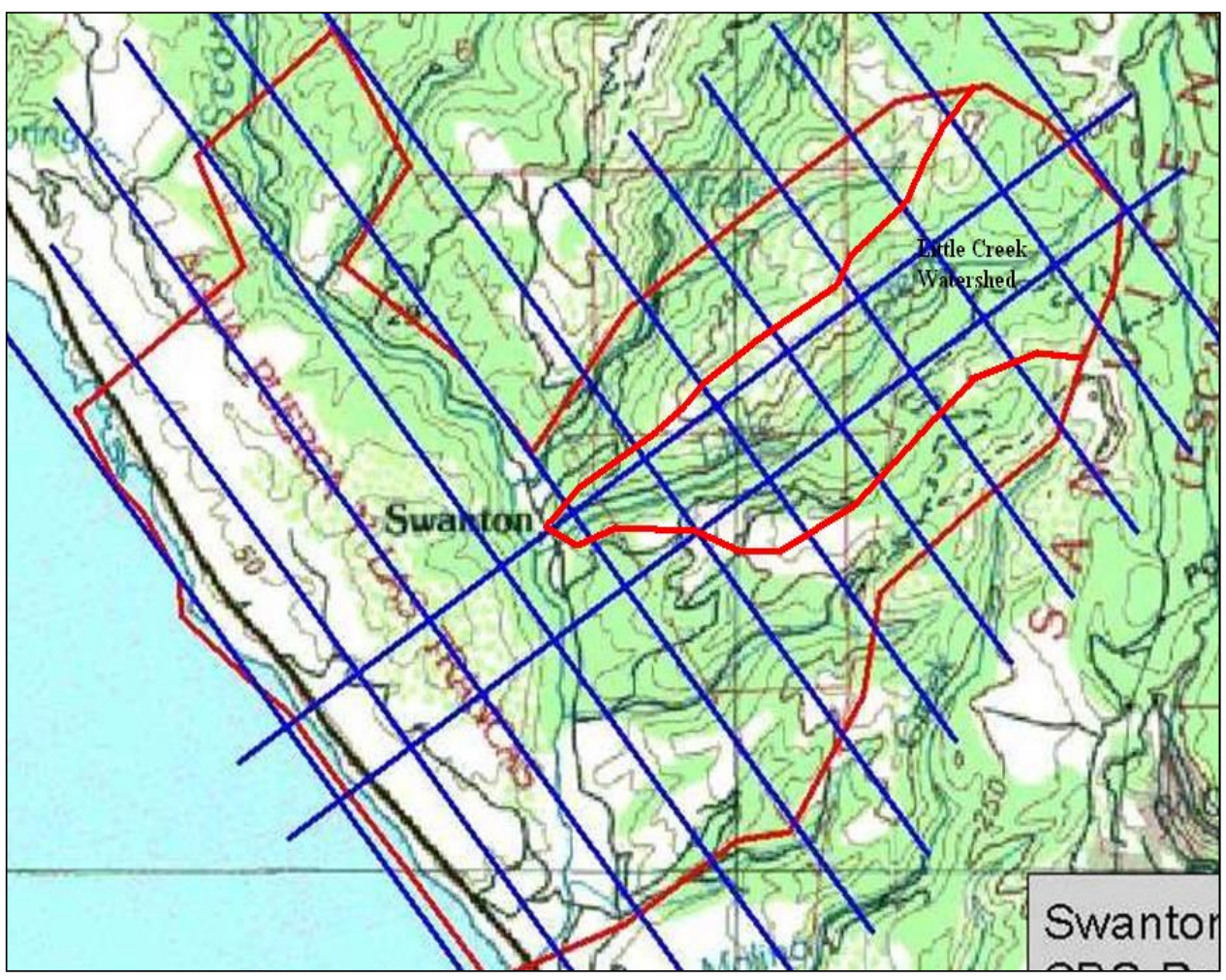

Figure 4.1. The flight lines used for the LiDAR survey are shown in blue.

Eight flight lines were completed northwest to southeast and two northeast to southwest for multidirectional coverage. The bi-directional flight lines were recommended by the contractor in order to obtain the best data possible with as many points returning from the ground surface given the steep terrain and inner gorge characteristics of the Little Creek watershed. 
The Project Base Station was set up at the Watsonville Airport. The GPS Receiver was set over the point "Goldie" (KWVI). The base station GPS was co-initialized and lock was maintained during each mission. A three-dimensional validation array was set and surveyed; the target was flown with LIDAR and digital imagery for each lift. The contractor provided an airport validation survey for both of the flights that occurred. The RMSE for the April $30^{\text {th }}$ flight was reported to be $8.59 \mathrm{~cm}$ with a standard deviation of $8.17 \mathrm{~cm}$. The mean vertical difference for the flight was reported to be $4.08 \mathrm{~cm}$. The validation survey for the May $28^{\text {th }}$ flight reported a RMSE of $8.78 \mathrm{~cm}$ with a standard deviation of $9.48 \mathrm{~cm}$. The mean vertical difference reported for this flight was $-0.27 \mathrm{~cm}$.

Return data collected from the LiDAR flight was processed by the contractor to filter the returns associated with the tops of vegetation using a proprietary algorithm. This data were then compared to control data provided to the contractor by California Polytechnic State University, SLO. The control points that were considered to be in the open (not under vegetation) were within the vertical specifications of 15 to $20 \mathrm{~cm}$. The points that were under vegetative canopy frequently did not meet the specifications after the filtering process was completed. Table 4.1 shows the points used to validate the LiDAR data located in the Scotts Creek watershed. The bold data points are points that had a difference of greater than $45 \mathrm{~cm}$. These points were found to fall in areas where the physical surroundings impeded the ability of a laser pulse to reach the ground surface. For example point number 96 is found on a bridge in the survey area that is under dense red alder canopy. 
Table 4.1. Validation elevations collected prior to LiDAR data collection for Little Creek.

\begin{tabular}{|c|c|c|c|c|}
\hline & & & \multicolumn{2}{|c|}{ Difference } \\
\hline $\begin{array}{c}\text { Point } \\
\text { Number } \\
\end{array}$ & $\begin{array}{c}\text { Ground } \\
\text { Elevation } \\
\end{array}$ & $\begin{array}{c}\text { LiDAR } \\
\text { Elevation } \\
\end{array}$ & Feet & cm \\
\hline 96 & 74.40 & 136.34 & -61.935 & -1865.48 \\
\hline 97 & 73.95 & 74.52 & -0.572 & -17.2286 \\
\hline 98 & 61.80 & 62.41 & -0.614 & -18.4937 \\
\hline 2001 & 47.93 & 47.72 & 0.209 & 6.29508 \\
\hline 2002 & 89.22 & 91.04 & -1.821 & -54.8485 \\
\hline 2003 & 52.08 & 52.15 & -0.065 & -1.9578 \\
\hline 2004 & 63.57 & 65.11 & -1.541 & -46.4149 \\
\hline 2006 & 777.23 & 776.85 & 0.377 & 11.35524 \\
\hline 2007 & 26.04 & 25.91 & 0.13 & 3.9156 \\
\hline 2008 & 40.63 & 41.71 & -1.077 & -32.4392 \\
\hline 2009 & 457.53 & 457.38 & 0.15 & 4.518 \\
\hline 2010 & 456.77 & 458.73 & -1.961 & -59.0653 \\
\hline 2011 & 468.23 & 468.04 & 0.193 & 5.81316 \\
\hline 2012 & 467.44 & 467.62 & -0.181 & -5.45172 \\
\hline 2013 & 103.78 & 106.39 & -2.612 & -78.6734 \\
\hline 2014 & 103.29 & 106.32 & -3.028 & -91.2034 \\
\hline 2015 & 632.47 & 632.21 & 0.257 & 7.74084 \\
\hline 2016 & 27.90 & 28.57 & -0.666 & -20.0599 \\
\hline 2017 & 45.54 & 44.96 & 0.585 & 17.6202 \\
\hline & & Mean & -0.64 & -19.40 \\
\hline
\end{tabular}

From the surface return data, a Triangular Irregular Network (TIN) and a $3 \mathrm{~m}$ grid (GRID) were created. The raw return data (LiDAR), TIN, and $3 \mathrm{~m}$ grid were used to create cross-sectional profiles based on the locations determined by the ground survey. From these cross-sectional profiles, bankfull area, bankfull depth, and bankfull width, were calculated for comparison with the ground survey data.

Due to the large size of the complete LiDAR dataset for the entire watershed, a smaller subset of the data encompassing each of the study reaches was extracted. This area was approximately 13 hectares and contained 181,594 total LiDAR returns. The low number of returns in the raw data made it necessary to use a $3.0 \mathrm{~m}$ wide cross-sectional profile 
( $1.5 \mathrm{~m}$ on the upstream and downstream sides of each profile) in place of a linear crosssectional profile. This swath was needed in order to obtain a large enough number of data points to create a cross-sectional profile that could be analyzed. This practice requires an assumption that the channel is relatively flat along the $3.0 \mathrm{~m}$ swath, so that little error would be introduced by including the LiDAR ground points $1.5 \mathrm{~m}$ upstream and downstream of the linear profile. This is similar to what was used in another comparison study on the Green River in North Eastern Utah (Bowen and Waltermire, 2002). In this study, cross-sectional profiles were only used for comparison if 8 or more LiDAR data points were located within $3.0 \mathrm{~m}$ of the profile.

Once all of the data were collected for both the ground and LiDAR surveys the data points for each cross-sectional profile were entered into an Excel@ spreadsheet that was created to calculate bankfull width, depth, and area based on the bankfull elevation that was determined in the field as part of the ground survey. This field elevation was used as the bankfull elevation because it was determined by personnel in the field that had the benefit of examining the physical characteristics used to determine the size of the bankfull channel. These characteristics, such as the top of the channel where flow would begin to enter the floodplain, changes in vegetation type from immature vegetation to more mature vegetation, debris deposits and the tops of point bars, can be more easily determined in the field rather than remotely. Additionally, due to the non-uniform shape of many of the LiDAR-generated cross-sectional profiles it was not possible to determine a bankfull elevation from the LiDAR data alone. 
The use of the bankfull elevation as determined during the ground survey by trained field staff was used as the basis for comparison of the ground and LiDAR datasets. The bankfull elevation as determined in the field was recorded in the survey notes and then used for the analysis. It was determined that the bankfull elevation would be a good reference point for the comparison of the datasets however any established elevation could be used for the comparison. For comparisons overtime it would be preferable to use an established elevation such as the bottom of one of the stakes at each endpoint. This is less likely to change overtime where as bankfull characteristics may change from survey to survey. 


\section{Chapter 5 Results and Analyses}

\subsection{Raw Data}

For the purposes of this study, the LiDAR data for the area immediately surrounding the stream channel was needed. This area was approximately 13 hectares and contained 181,594 total LiDAR returns. Of these returns, only 26,131 were considered ground returns by the contractor. This is $14.3 \%$ of the total number of returns, approximately 1,957 returns per hectare or 1 ground return every 5.2 square meters.

Due to the low number of actual ground returns, a low number of LiDAR observations were noted in many of the cross-sectional profiles created by the raw LiDAR, TIN, and GRID datasets. The average number of data points per cross-sectional profile for the ground survey was 21.67 observations, for the raw LiDAR dataset it was 7.32 observations, the TIN contained an average of 13.64 observations, and the GRID dataset contained an average of 12.12 observations. For the ground survey data there is an average of one data point every $0.49 \mathrm{~m}$ for all of the cross-sectional profiles. The raw LiDAR dataset provides a data point every $2.50 \mathrm{~m}$, points interpolated from the LiDAR data that make up the TIN and the GRID had an observation every $0.88 \mathrm{~m}$ (TIN) and an observation every $0.95 \mathrm{~m}$ (GRID) respectively. This result is to be expected due to the interpolation that is required to create both of these datasets. Many times the points developed from interpolations between the raw LiDAR observations prove to be helpful, but can also be a large source of error. 
Recall that the Green River study only used a cross-sectional profile if 8 or more LiDAR observations were available for the comparison (Bowen and Waltermire, 2002). Two of the three LiDAR-derived datasets provided 8 or more observations in a majority of the cross-sectional profiles. The raw LiDAR dataset contained the fewest cross-sectional profiles (26 profiles) having 8 or more observations. Through interpolation the TIN provided 47 profiles with 8 or more observations and the GRID provided 51 profiles with 8 or more observations. All of the ground-surveyed cross-sectional profiles contained 8 or more observations.

Of the 50 cross-sectional profiles that had less than 8 observations, 15 of the profiles contained 2 or less observations. All of the profiles that contained 2 or less observations were from the raw LiDAR dataset. Nine of the 50 profiles with less than 8 observations had between 2 and 4 total observations. Sixteen of the profiles contained between 4 and 6 observations and the remaining 10 cross-sectional profiles contained 7 observations.

\subsection{Correlations}

At all of the study reaches with the exception of the Main Stem reach B, LiDAR elevations tended to overestimate the depth of the cross-sectional profiles. The average difference in bankfull depth, width, area, and thalweg elevation of all cross-sectional profiles from the ground observations and the LiDAR datasets are shown below (Table 5.1). Overall LiDAR-derived cross-sectional profiles overestimated bankfull width by an average of $15 \%$. This may be due to the limitations of capturing abrupt changes in elevation at the channel banks with so few ground returns. 
Table 5.1 Average difference for cross-sectional characteristics between ground observations and LiDAR observations, and the number of observations in each category.

\begin{tabular}{|l|cc|cc|cc|}
\hline & \multicolumn{2}{|c|}{ Ground - TIN } & \multicolumn{2}{c|}{ Ground - GRID } & \multicolumn{2}{c|}{ Ground - LiDAR } \\
& $\mathbf{m}$ & \# of Obs. & $\mathbf{m}$ & \# of Obs. & m & \# of Obs. \\
\hline Bankful Depth & $\mathbf{- 0 . 2 1}$ & $\mathbf{5 8}$ & $\mathbf{- 0 . 0 7}$ & $\mathbf{5 8}$ & $\mathbf{- 0 . 2 5}$ & $\mathbf{5 4}$ \\
Bankful Width & $\mathbf{- 0 . 6 5}$ & $\mathbf{4 6}$ & $\mathbf{- 0 . 8 4}$ & $\mathbf{4 5}$ & $\mathbf{- 0 . 4 3}$ & $\mathbf{1 4}$ \\
Bankful Area & $\mathbf{- 2 . 7 2}$ & $\mathbf{4 2}$ & $-\mathbf{1 . 9 1}$ & $\mathbf{4 0}$ & $\mathbf{- 2 . 3 1}$ & $\mathbf{1 4}$ \\
Thalweg Elevation & $\mathbf{0 . 2 2}$ & $\mathbf{5 8}$ & $\mathbf{0 . 0 7}$ & $\mathbf{5 8}$ & $\mathbf{0 . 2 3}$ & $\mathbf{5 4}$ \\
\hline
\end{tabular}

The differences shown in Table 5.1 show that the LiDAR-derived datasets, on average, overestimated the bankfull characteristics in question. It also shows that LiDAR underestimated the thalweg elevation. For example the LiDAR thalweg elevation at cross-sectional profile Main Stem B1 was 38.83 m (TIN), 38.94 m (GRID), 38.83 m (LiDAR) while the true ground elevation of the thalweg as determined by the ground survey was $39.25 \mathrm{~m}$. This underestimation is one factor that causes the overestimation of the remaining bankfull characteristics.

Additionally, the number of observations that occurred in each category was shown in Table 5.1. The only categories that contained a full dataset of 58 cross-sectional profiles were the TIN and GRID observations for the thalweg elevation and the corresponding bankfull depth that is calculated using the thalweg elevation and the bankfull elevation as determined during the ground survey. The rest of the categories being investigated did not have complete datasets. This occurred due to a lack of LiDAR data points located between the endpoints of the cross-sectional profile. Typically this lack of data would not allow for the calculation of a bankfull width. Without a width a bankfull area could not be calculated. On some occasions, while the channel width was able to be calculated, 
the area calculated from that width would be less than 1 square foot. These were excluded from consideration.

As shown above, the dataset that contained the least amount of comparable observations was the LiDAR dataset. Recall that this dataset contained the least amount of points per cross-sectional profile. Four of the profiles had no observations at all.

Linear regression (Figure 5.1) and Pearson's correlation results show a strong relationship between the thalweg elevations observed in the field and those derived from LiDAR. Linear regression shows that there is a strong relationship occurring between the observed thalweg observations. The best relationship was found to be between the ground survey and the LiDAR-generated TIN at the Main Stem C study reach $\left(\mathrm{R}^{2}=0.9925\right)$. The study reach with the worst relationship between the ground data and the LiDAR-generated thalweg data were found to be at Main Stem $B\left(R^{2}=0.0642\right)$. This group of observations contains one outlier of the thalweg elevation at profile B6. Of note $_{2}$ the raw observation has an even greater difference than the TIN observation while the GRID observation is only $1.5 \mathrm{~cm}$ different. 


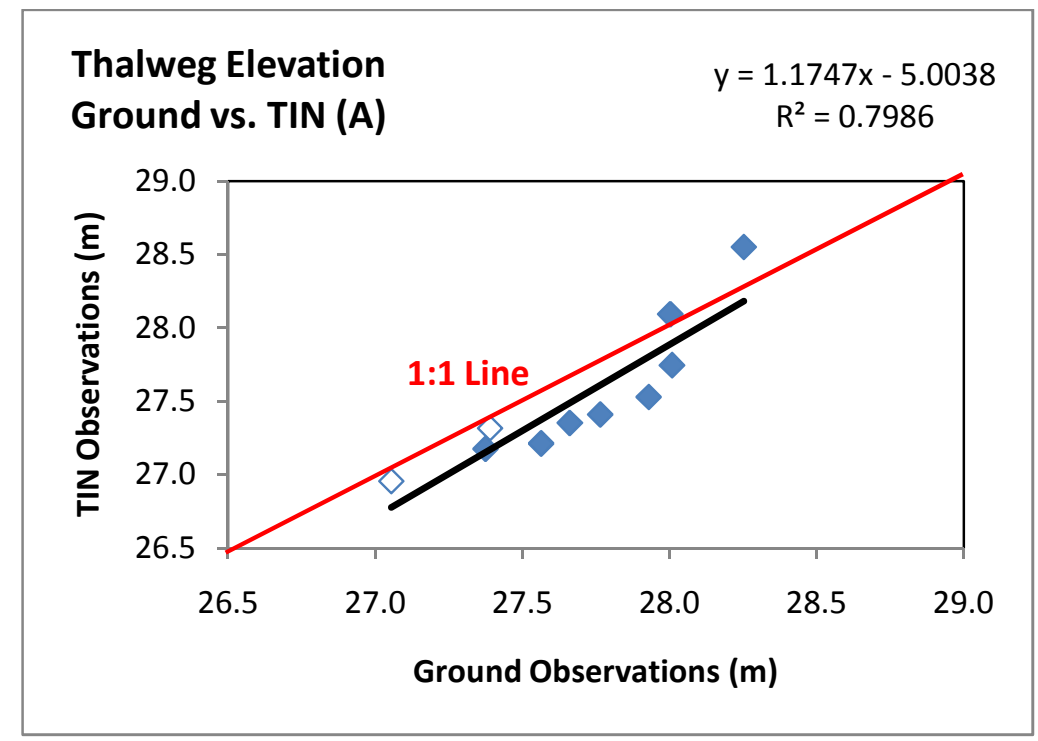
Thalweg Elevation $\quad y=0.1262 x+33.835$
Ground vs. TIN (B) $\quad R^{2}=0.0642$
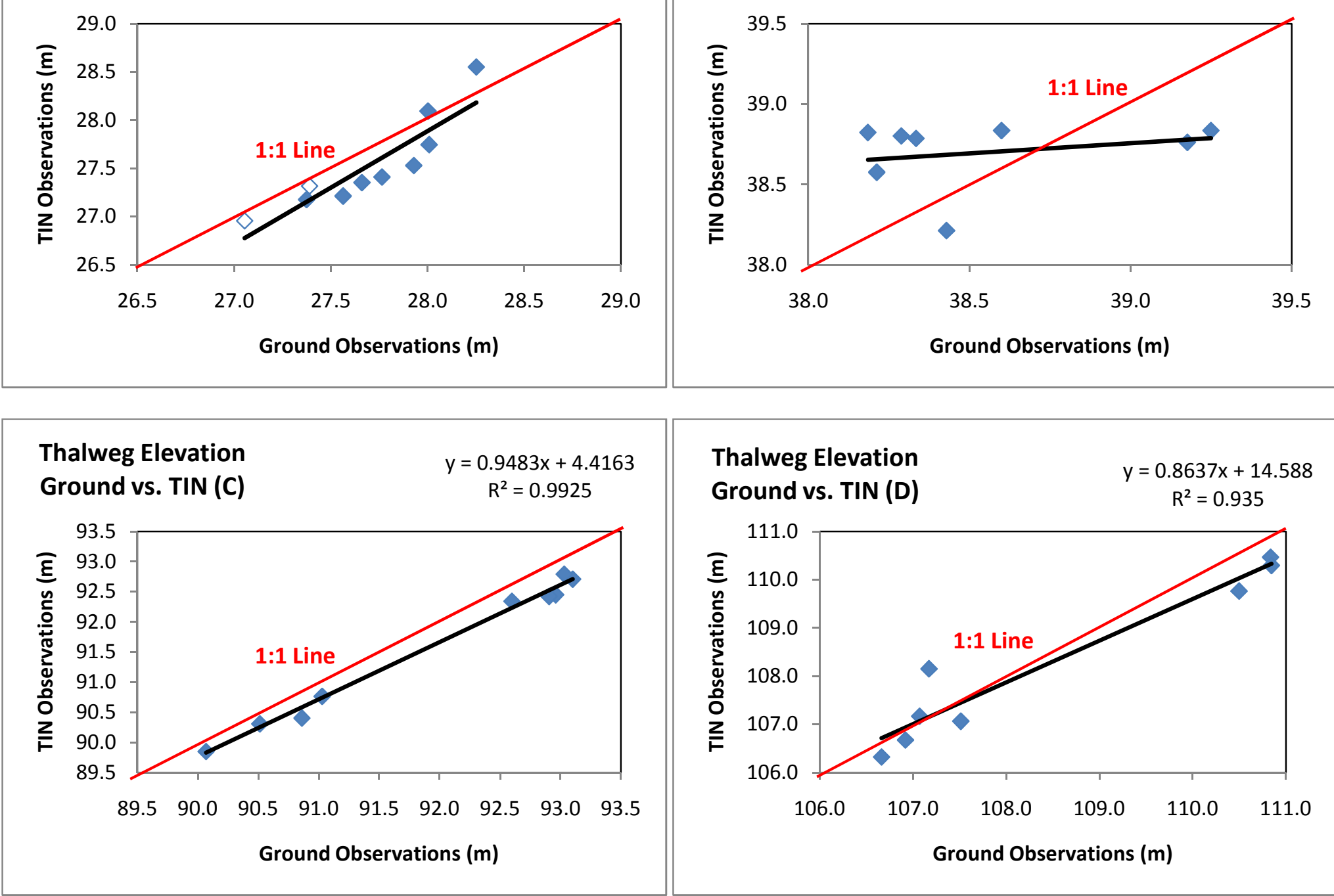

Thalweg Elevation

Ground vs. TIN (D)

$y=0.8637 x+14.588$ $R^{2}=0.935$

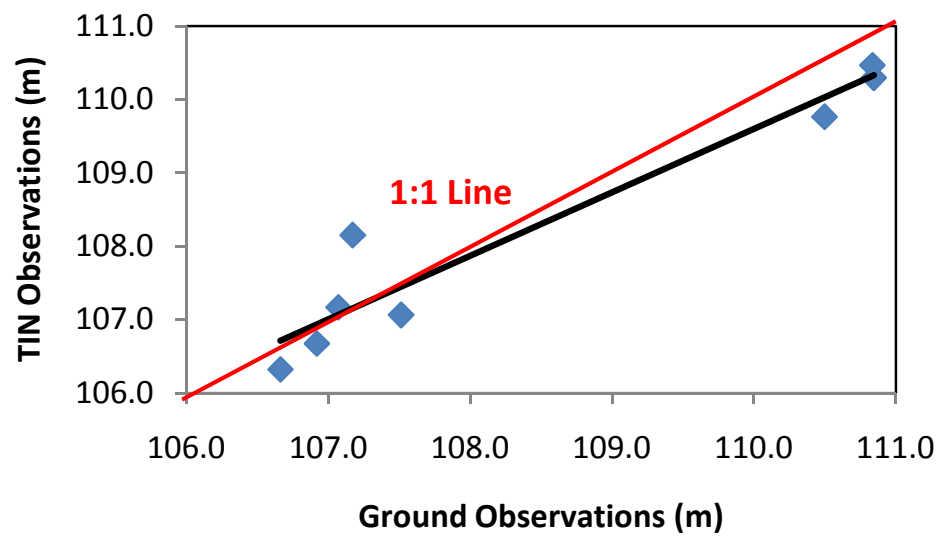




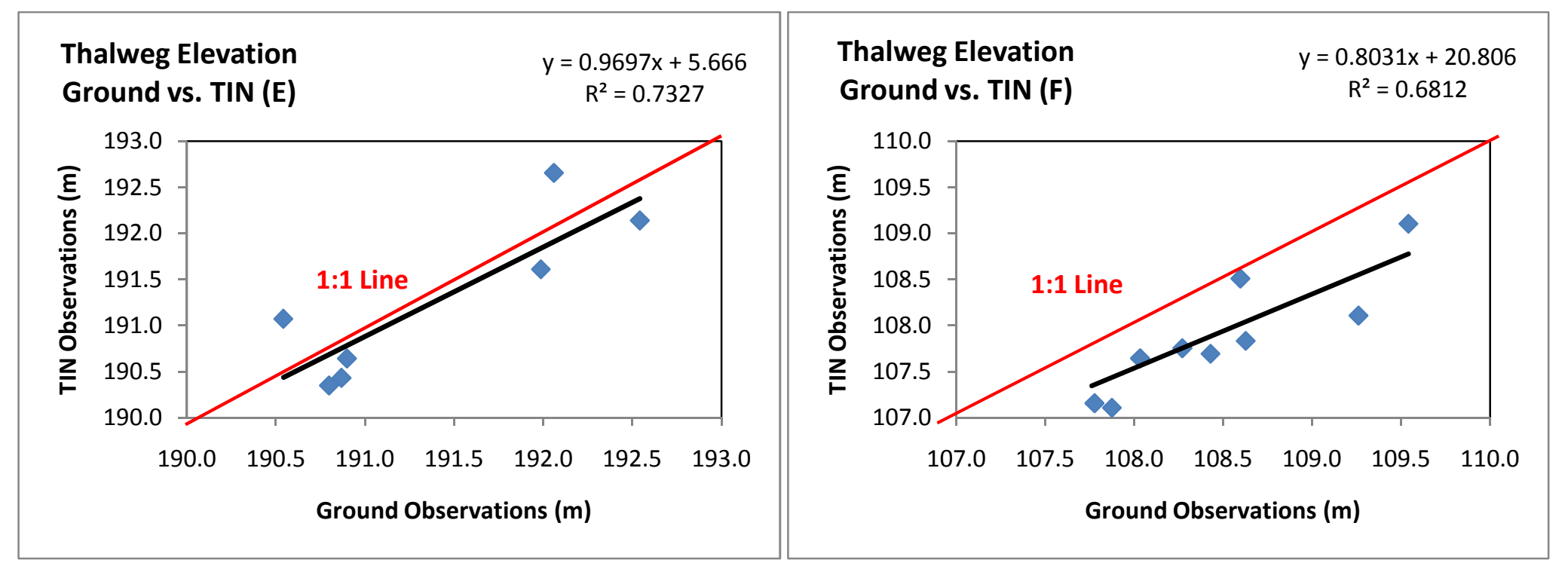

Figure 5.1. Linear regression comparing the observed thalweg elevation from the ground survey to the thalweg elevation determined from the LiDAR-generated TIN for all study reaches. 
A one-to-one line was added to each of the plots in order to discern if there appears to be a bias of the LiDAR-generated data. Most of the data points tend to fall below the oneto-one line implying that the LiDAR elevations are typically lower than the groundsurveyed elevations. This is consistent with what is shown in Table 5.1.

Each study reach was analyzed separately to remove the bias that results from the large increases in elevation from study reach to study reach. The examination of each reach separately also shows that while all but one of the reaches had strong relationships, there was some amount of variation between reaches.

Linear regression was also used to compare the other channel characteristics of interest (Figure 5.2). Figure 5.2 shows linear regression comparing bankfull width, depth, and area calculated from the ground and LiDAR surveys. Figures comparing the same ground-surveyed parameters to the LiDAR and GRID datasets can be found in Appendix B. The best relationship was found to be bankfull width and the worst relationship occurred with bankfull area. Once again a one-to-one line was added to the each of the plots in order to depict a potential bias in the data. As with the thalweg data, there does appear to be a bias. Figure 5.2 shows the comparison of bankfull width as calculated from the ground-survey and as generated from the LiDAR datasets. In this case the LiDAR-generated data-sets typically overestimated the bankfull depth, width, and area. The results of the bankfull width comparison showed the least amount of bias with bankfull depth and area showing the largest amount of bias. This would be expected 
since the LiDAR dataset typically underestimates the thalweg elevation making the depth and area that was calculated from the LiDAR datasets larger than the observations calculated from the ground data. 


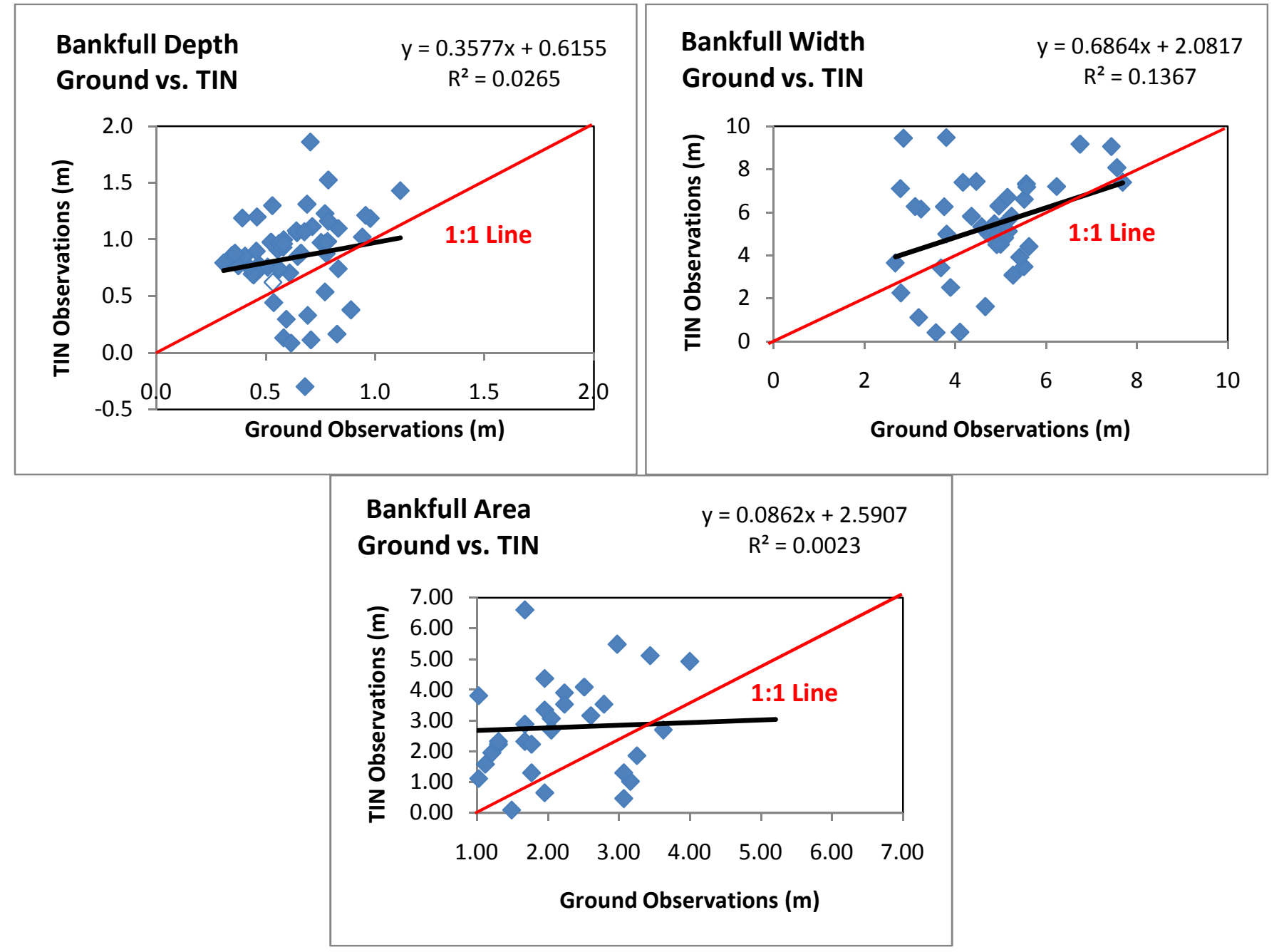

Figure 5.2. Linear regression comparing the bankfull width, depth, and area as calculated using the ground survey data and the TIN data. 
Pearson's Correlations were used to compare the bankfull depth, width, area, and thalweg elevations for the raw and derived LiDAR datasets. The results of the correlations show that there are insignificant relationships between the ground data and the LiDARgenerated data (Table 5.2) except for the relationship associated with the thalweg elevations. That has a correlation value of 1.000 in all of the datasets.

Table 5.2. Pearson's Correlation Results.

\begin{tabular}{|l|c|c|c|c|c|c|}
\hline & \multicolumn{2}{|c|}{ LIDAR } & \multicolumn{2}{c|}{ GRID } & \multicolumn{2}{c|}{ TIN } \\
\cline { 2 - 7 } & Correlation & P-value & Correlation & P-value & Correlation & P-value \\
\hline \hline Bankfull Area & 0.19 & 0.53 & 0.13 & 0.40 & -0.10 & 0.95 \\
\hline Bankfull Depth & -0.13 & 0.35 & 0.19 & 0.16 & 0.16 & 0.22 \\
\hline Bankfull Width & 0.14 & 0.63 & 0.27 & 0.08 & 0.17 & 0.25 \\
\hline Thalweg & 1.00 & 0.00 & 1.00 & 0.00 & 1.00 & 0.00 \\
\hline
\end{tabular}

The correlation of the thalweg elevation in this instance may be misleading. As shown above there is a significant relationship between the thalweg elevations, however in this instance the entire dataset was used from all of the study reaches. This introduced bias in the data due to the large increases in elevation from study reach to study reach. Correlations were then calculated on a reach by reach basis to identify if a bias was present (Table 5.3).

Table 5.3. Correlation results for the thalweg elevations by study reach.

\begin{tabular}{|l|c|c|c|}
\hline Study Reach & TIN & GRID & LiDAR \\
\hline Main Stem A & 0.89 & 0.86 & 0.89 \\
\hline Main Stem B & 0.25 & 0.55 & -0.19 \\
\hline Main Stem C & 1.00 & 0.99 & 1.00 \\
\hline North Fork D & 0.97 & 0.97 & 0.97 \\
\hline North Fork E & 0.86 & 0.87 & 0.53 \\
\hline South Fork F & 0.83 & 0.86 & 0.83 \\
\hline
\end{tabular}


The reach-by-reach analysis still shows a significant relationship is present in the thalweg elevation data. However, the relationship for each reach is not the perfect relationship that is portrayed when the whole dataset is analyzed together. This strong vertical relationship in just one category requires that more investigation be completed. These correspond similarly to the thalweg regression lines. Main Stem C elevations are best correlated to the ground survey elevations. Main Stem $\mathrm{C}$ has a relatively broad valley bottom which may have aided the LiDAR observations.

\subsection{One Sample T-tests for horizontal positions}

Due to the thalweg elevations providing the best vertical relationship with mean differences in elevation from the ground-surveyed surface of $0.44 \mathrm{~m}$ (GRID), $0.21 \mathrm{~m}$ (TIN), and $0.08 \mathrm{~m}$ (LIDAR), further investigation into the horizontal position of the thalweg points was completed. It was found that the horizontal positions of the thalweg points had mean differences from the surveyed location of $1.04 \mathrm{~m}$ (GRID), $1.22 \mathrm{~m}$ (TIN), and $1.37 \mathrm{~m}$ (LIDAR). One sample t-tests were completed for all three datasets against the ground data. In all cases, the hypothesis tested was that the mean difference in horizontal position would be equal to zero. In all cases that hypothesis was rejected (Table 5.4).

Table 5.4. One sample t-test results.

\begin{tabular}{|c|c|c|c|c|c|c|c|}
\hline & $\mathrm{N}$ & Mean & StDev & SE Mean & $95 \%$ CI & T & P \\
\hline \hline LIDAR & 55 & $1.37 \mathrm{~m}$ & $1.59 \mathrm{~m}$ & $0.21 \mathrm{~m}$ & $0.94 \mathrm{~m}, 1.80 \mathrm{~m}$ & 4.98 & 0.000 \\
\hline GRID & 58 & $1.04 \mathrm{~m}$ & $0.82 \mathrm{~m}$ & $0.11 \mathrm{~m}$ & $0.83 \mathrm{~m}, 1.26 \mathrm{~m}$ & 9.88 & 0.000 \\
\hline TIN & 58 & $1.22 \mathrm{~m}$ & $1.22 \mathrm{~m}$ & $0.16 \mathrm{~m}$ & $0.90 \mathrm{~m}, 1.54 \mathrm{~m}$ & 7.66 & 0.000 \\
\hline
\end{tabular}


While the results of the one sample t-test does not confirm a relationship between the LiDAR-derived data and the ground-surveyed data, as mentioned previously, that in order to capture more data points in the immediate vicinity of the profile line, a $3 \mathrm{~m}$ wide swath of data was extracted to construct each cross-sectional profile. Using this method has the potential to introduce a possible error of up to $1.5 \mathrm{~m}$ horizontally. All of the mean differences in horizontal position are less than $1.5 \mathrm{~m}$. This clouds any determination that could be made from the difference in horizontal positions. While the use of a $3 \mathrm{~m}$ wide profile introduced some error, error in horizontal position would also be expected if a linear profile was used. For the purposes of this study the thalweg elevation was considered to be the lowest elevation determined by the LiDAR data regardless of horizontal position. This procedure would also introduce some amount of horizontal error.

\subsection{Point-to-point Comparison}

While initial visual comparisons of some of the cross-sectional profiles seem to show a relationship in the overall shape and size (Figure 5.3), as discussed previously, a statistical comparison using a swath about the cross-sectional profile shows no significant relationship in regards to bankfull width, depth, and area. Plots of all cross-sectional profiles can be found in Appendix C. 

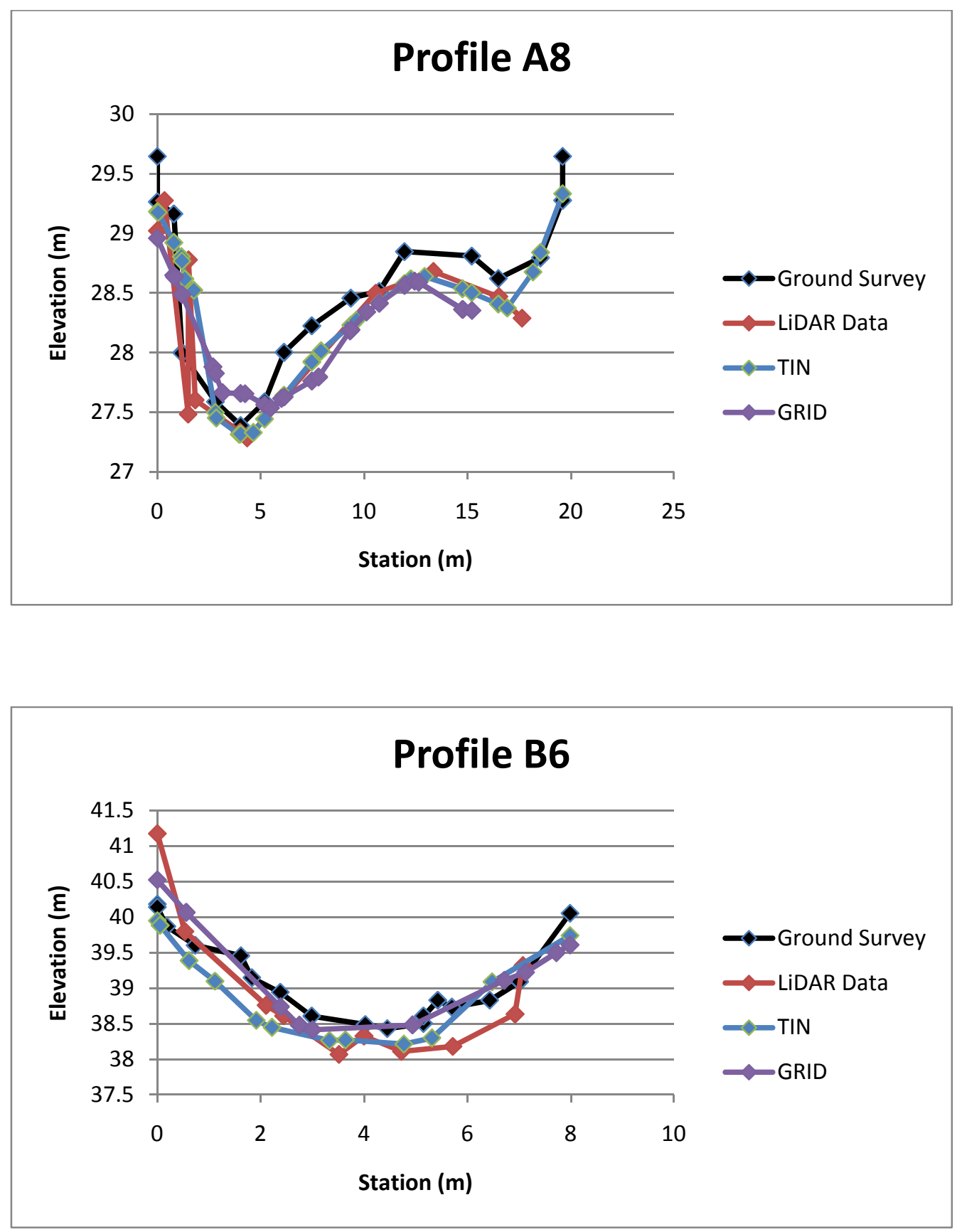

Figure 5.3. Two representative cross-sectional profiles (A8 and B6) visually show a good relationship between the ground-surveyed profile and derived profiles from the raw LiDAR point data, the TIN, and the GRID. 
Analyses have been performed using a simple point-to-point comparison to show the number of points that fell within the commonly advertised vertical accuracy of $15 \mathrm{~cm}$ (Pereira and Janssen, 1999). This analysis is valuable to more clearly evaluate the accuracy of the elevations extracted to describe the cross-sectional profiles.

The point-to-point comparison was completed using the ground-survey data and the TIN data. The TIN data were chosen to allow for the comparison of a specific ground-survey point to the corresponding point interpolated from the raw LiDAR data. As part of the analysis the difference in elevation was calculated for the point pairs. The results show that out of 1,122 pairs of ground survey points and the corresponding TIN points less than $20 \%$ of the points had an elevation difference of $15 \mathrm{~cm}$ or less. The largest percentage of data points had differences of greater than $61 \mathrm{~cm}(29.3 \%)$ (Figure 5.4). In the overall data comparison, $70 \%$ of the LiDAR elevations were lower than the true ground surface elevation. 


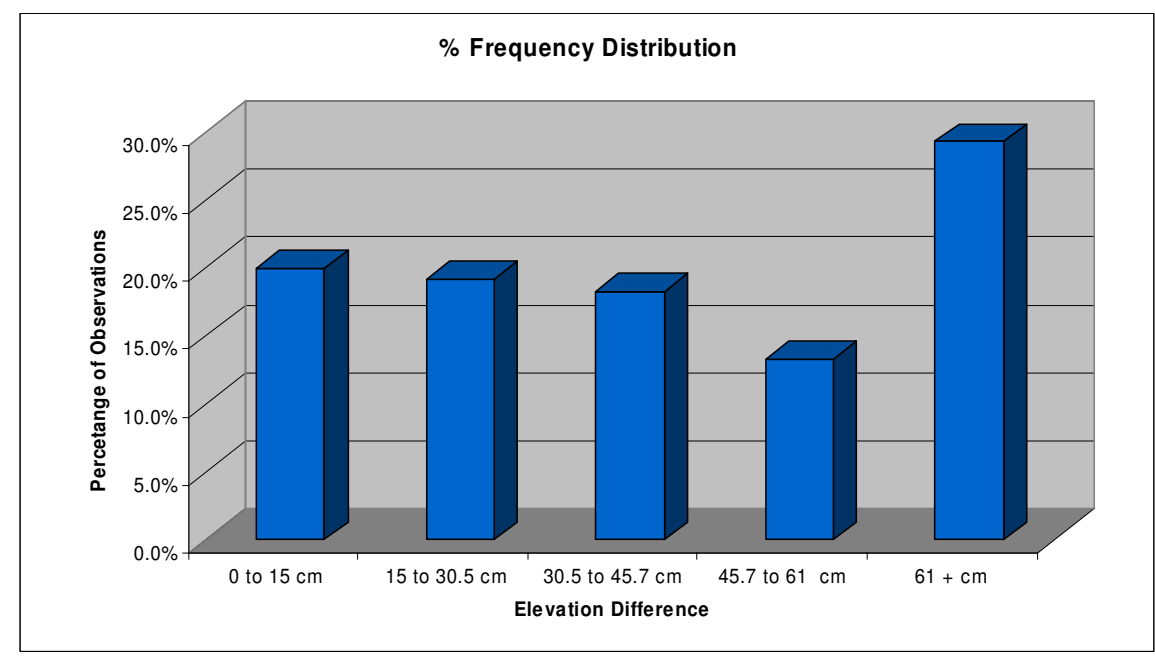

Figure 5.4. Differences in elevations between ground-survey elevations and LiDARderived TIN elevations.

When the data is separated on a reach-by-reach basis, three study reaches (Mainstem A, Mainstem C, and North Fork E) contain more data points with differences in the 0 to 30.5 $\mathrm{cm}$ range (Figure 5.5). Approximately $50 \%$ of all the differences in elevation are less than $30.5 \mathrm{~cm}$ for these three reaches (Figure 5.6). 


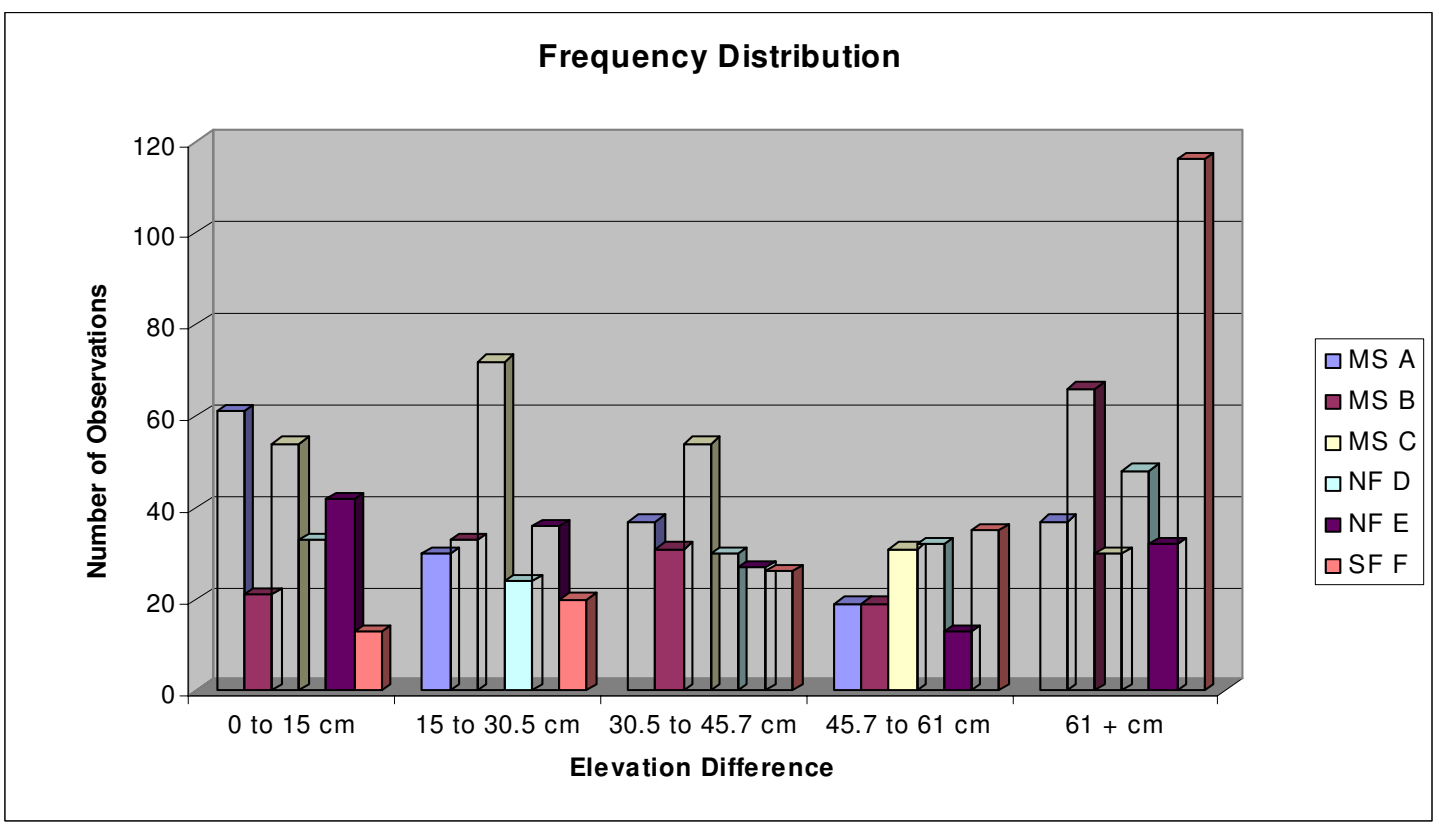

Figure 5.5. Number of differences in elevation between LiDAR points and ground points by reach in $15 \mathrm{~cm}$ increments.

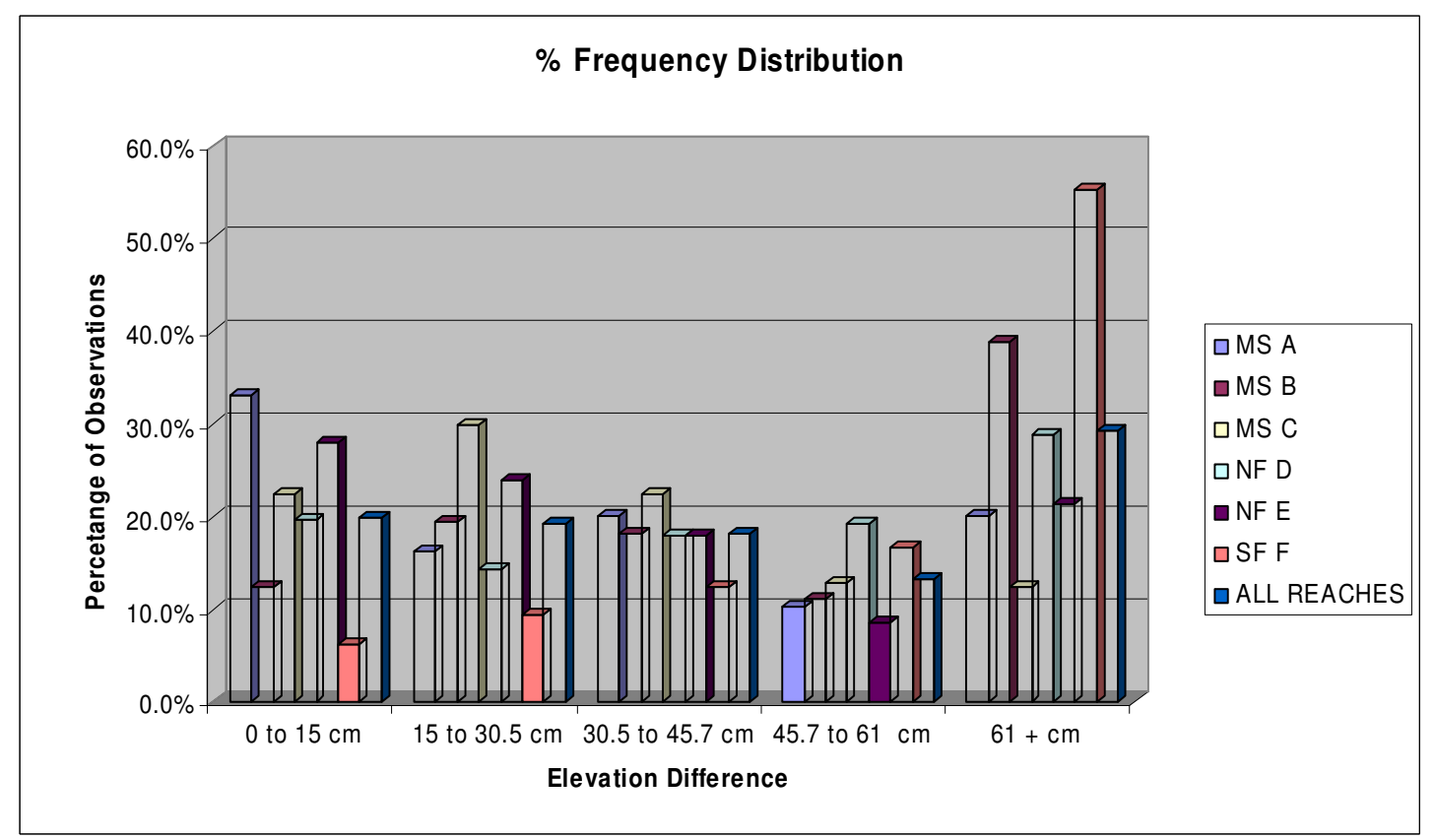

Figure 5.6. The percentage of all observations within a reach according to elevation difference classes.

The groups of cross-sectional profiles having $50 \%$ of the elevations within $30.5 \mathrm{~cm}$ are located in areas of the watershed where the valley bottom is wider and the side slopes are 
lower. The study reach that contained the largest number of data points with differences of less than $15 \mathrm{~cm}(33.2 \%$ of the total observations for that reach) is the reach with the widest valley bottom, Mainstem A. In contrast, the remaining three reaches (Mainstem B, North Fork D, and South Fork F) only $15 \%$ to $34 \%$ of the differences are less than 30.5 $\mathrm{cm}$ (Figure 5.3). South Fork F, which had the highest amount of observations with differences greater than $61 \mathrm{~cm}$ (Figure 5.4), has the most narrow valley floor and some of the steepest side slopes. This reach is contained in an inner gorge with dense canopy cover over the stream channel. 


\section{Chapter 6 Discussion}

The poor statistical significance between ground-surveyed channel characteristics and the channel characteristics extracted from the different LiDAR datasets may be attributed to different physical and environmental factors, such as topography, overstory canopy cover, understory canopy cover, and the leaf condition at the time of the LiDAR survey. Similarly, the overall low percentage of LiDAR elevations falling within $15 \mathrm{~cm}$ of the ground-surveyed elevations can also be explained by these factors.

\subsection{Topography}

The topography of the Little Creek watershed is indicative of the landscape throughout the Santa Cruz Mountains, and other youthful mountain environments along the Coastal Range. The watershed is very steep with slopes between 45 and 100\% in many areas and the stream channel is often found to be in the bottom of an inner gorge. The steep and narrow inner gorge canyons found here make it extremely difficult, and often impossible to get accurate GPS data from the bottom of the canyon. The topography and denselyforested landscape in these areas play a major role in both the ability to maximize the number of ground returns and the accuracy of those ground points.

\subsection{Canopy Closure}

A major factor contributing to the lack of return data from the ground was the density of canopy cover that was affected by the timing of the LiDAR survey. The overstory canopy is made up of red alder, redwood, California bay, and bigleaf maple. The leaf condition at the time of the LIDAR flights was less than optimal. Ideally, the flights 
would have taken place in complete leaf-off conditions, which would affect areas where red alder and bigleaf maple are dominant. The target month was early-to-mid April when baseflow conditions are low and prior to leaf-on conditions. The flights took place on of April 30, 2002 and May 28, 2002. Leaf-off conditions were prevalent during the April flight. At the time of the May flight trees had broken bud and leaves were beginning to form. While the leaf-on condition was not at a maximum during the May flight, these were not ideal conditions to maximize ground returns. Many of the LiDAR returns came from areas high in the overstory canopy with only a small percentage of the returns actually reaching the ground surface. There was approximately $90 \%$ canopy cover throughout all of the study reaches. (Table 6.1) as determined by a vertical densitometer (Stumpf, 1993).

Table 6.1. Canopy cover was determined by completing a survey at each study reach using a vertical densitometer.

\begin{tabular}{|l|c|}
\hline Study Reach & Percent Canopy Cover \\
\hline \hline Mainstem A & $\mathbf{9 2 \%}$ \\
Mainstem B & $\mathbf{9 8 \%}$ \\
Mainstem C & $\mathbf{8 8 \%}$ \\
North Fork D & $\mathbf{9 2 \%}$ \\
North Fork E & $\mathbf{8 7 \%}$ \\
South Fork F & $\mathbf{1 0 0 \%}$ \\
\hline
\end{tabular}

The canopy cover estimates as determined by the vertical densitometer are similar to the canopy cover that is calculated from the LiDAR survey (Table 6.2). The LiDAR-based 
canopy percentage is consistently less than the estimates made with the vertical densitometer, however, more area was sampled to complete the LiDAR-based calculation.

Table 6.2. Vertical densitometer and LiDAR based canopy cover estimates by study reach.

\begin{tabular}{|c|c|c|}
\hline Study Reach & $\begin{array}{c}\text { Vertical } \\
\text { Densitometer }\end{array}$ & LiDAR-based \\
\hline \hline A & $92 \%$ & $88 \%$ \\
B & $98 \%$ & $92 \%$ \\
C & $88 \%$ & $83 \%$ \\
D & $92 \%$ & $86 \%$ \\
E & $87 \%$ & $89 \%$ \\
F & $100 \%$ & $92 \%$ \\
\hline
\end{tabular}

As shown in Table 6.2, Study Reach F, was determined to have $100 \%$ canopy coverage by the vertical densitometer, but LiDAR still was able to penetrate the canopy and reach the ground, as shown by the $92 \%$ LiDAR-derived canopy coverage. Figure 6.1 below shows the large amount of return data coming from the overstory canopy. 


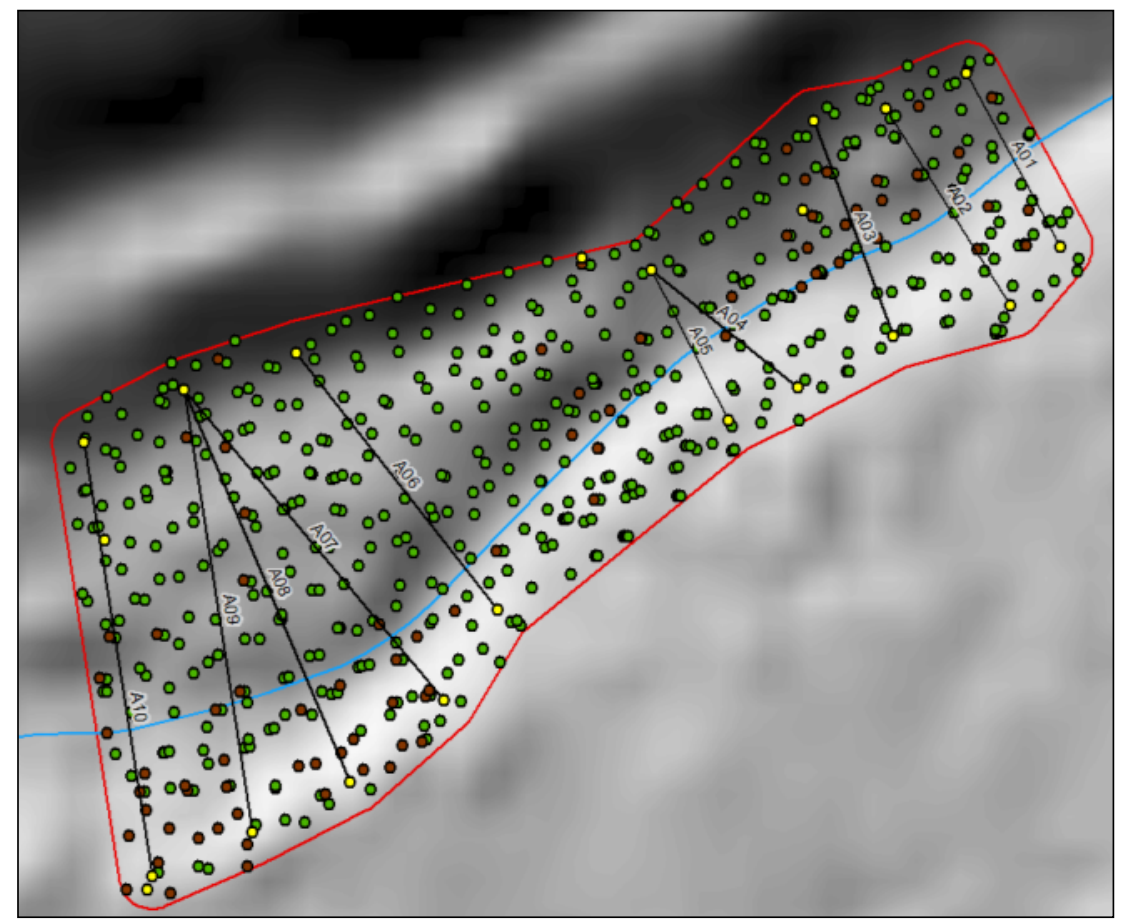

Figure 6.1. LiDAR returns for Mainstem A. Green points represent returns from the canopy. Brown points represent returns from the ground surface.

In addition to the canopy cover at the time of the flights, the flight paths may have played some role in the poor data collected for some areas. There were only two lines that were on a North East to South West trajectory with the remaining lines on a perpendicular trajectory.

\subsection{Streamflow Condition}

An additional desired site condition for optimal LiDAR data collection was minimum streamflow. The type of LiDAR sensor used was a topographic sensor that is not capable of penetrating water. This would normally occur sometime in August, September, or October depending on the rainfall occurring the previous season. Unfortunately, that time period also corresponds with full leaf-on conditions. However, the water level did not appear to have a significant effect on the return data in this instance. Average water 
depths in the study reaches at the time of the ground survey were $0.14 \mathrm{~m}$ to $0.20 \mathrm{~m}$ (Table 6.3). Visual comparisons of the cross-sectional profiles derived from the LiDAR TIN do not show evidence of the water surface and the thalweg elevations revealed a significant vertical relationship. These factors lead to the question of whether or not the water level was shallow enough at the time of the flights that any error caused by the water surface was less than error associated with the LiDAR flight itself. There is also some question whether the LiDAR pulses were able to penetrate these shallow depths when the channel bed was clearly visible.

Table 6.3. Average water depths at all study reaches at the time of the Ground Survey.

\begin{tabular}{|l|c|}
\hline Study Reach & Average Water Depth (m) \\
\hline Mainstem A & 0.20 meters \\
Mainstem B & 0.17 meters \\
Mainstem C & 0.16 meters \\
North Fork D & 0.16 meters \\
North Fork E & 0.17 meters \\
South Fork F & 0.14 meters \\
\hline
\end{tabular}

The airport verification of both flights reported an RMSE of approximately $8.53 \mathrm{~cm}$ or one half of the water depth that was present at the time of the survey. This also suggests that the water level may have been high enough to cause some amount of error in the LiDAR data. However, as stated above it did not appear to have a significant effect. This could be due to the large amount of error associated with the LiDAR data in the Little Creek watershed. The point-to-point comparison showed that the majority of the LiDAR points from the TIN had a difference in elevation of 0.15 meters or greater. This 
would suggest that in the Little Creek watershed the average water depth in most reaches was approximately the same or slightly greater than the error of the LiDAR survey.

In regards to the two factors mentioned above, leaf-off conditions and minimal water levels would be the ideal condition for the collection of LiDAR data. The data from this survey suggests that a complete leaf-off condition during the collection of LiDAR data would have had the most influence. The error that may have been caused by the water level in this situation is substantially less than the error that is introduced by full canopy closure. It would appear that a LiDAR survey that was completed in late winter or early spring during a complete leaf-off condition would be much more beneficial than waiting until fall when the water level is the lowest but a full leaf-on canopy conditions are present.

\subsection{Understory Vegetation}

Along with the concerns over the condition of the overstory canopy cover; there was a considerable amount of understory vegetation present. The understory is composed of elderberry, blackberry, thimble berry, sword fern, wood fern, redwood sorrel, and nettle. Once again it would have been optimal to fly the area during leaf-off conditions in the understory as well as the overstory, if at all possible. While these understory species may not have affected the area directly over the channel, the areas that were outside of the active channel zone or the outer edges of the cross-sectional profiles were likely affected. 


\subsection{Technology Improvements}

Another variable to be considered when examining the relationship between the two datasets is the technology available at the time of the flight. The system being used at the time was capable of 20,000 pulses per second, common for LIDAR instrumentation in 2002. Advances have been made in LIDAR technology allowing for a higher pulse rate and as a result more ground returns would be expected. Pulse rates of 50,000 to 100,000 pulses per second are now advertised. This is over 2.5 to 5 times what was available at the time of this study. This may or may not provide a large increase in true ground points collected during LiDAR surveys. A higher pulse rate may only increase the number of returns collected from the overstory vegetation. A question to answer is can a higher pulse rate penetrate the canopy more easily to increase the number of ground returns even under the dense vegetation and steep terrain found in the Little Creek watershed?

\subsection{Comparison to Other Studies}

The results of this study are comparable to the results of several other studies completed on steep rugged terrain with heavy vegetative cover. In 2002, the Bowen and Walternire (2002) study that used LiDAR to measure river corridor topography dealt with challenging vegetative conditions, but in a different physiographic setting. The terrain surveyed was steep and variable with sagebrush cover. The overall vertical accuracy reported was $43 \mathrm{~cm}$ (43 RMSEz). This is similar to the RMSE of $60.96 \mathrm{~cm}$ achieved by this study.

The Mietz et al., (2002) study completed in the Grand Canyon, reported vertical accuracies of $23 \mathrm{~cm}$ on bare ground and $63 \mathrm{~cm}$ on vegetated ground (Mietz, et al., 2002). 
The researchers did not believe the LiDAR accuracy achievable with 2002 LiDAR technology, was adequate to replace the current method of ground surveying.

Reutebuch et al., (2003) found that it can be difficult to capture data in forested environments. In this study, the LiDAR data were separated into four groups, clear cut, heavily thinned, lightly thinned and uncut. The clearcut canopy class had the highest vertical accuracy of $16 \mathrm{~cm} \pm 23 \mathrm{~cm}$, while the uncut canopy class had the lowest accuracy of $31 \mathrm{~cm} \pm 29 \mathrm{~cm}$.

The results of this study $(\mathrm{RMSE}=60.96 \mathrm{~cm})$ and others seem to show that LIDAR, using 2002 capabilities, is not as accurate as documented in certain less-challenging applications. However, advances in the technology since the time of these studies may allow for vast improvement. The increase in pulse rate combined with better timing of LIDAR flights during absolute leaf-off conditions may be needed to allow for improved accuracy and precision in the data. It has been shown that LIDAR used under particular conditions is capable of determining elevations correctly (Pereira and Janssen, 1999; Csanyi et al., 2005). These studies reported vertical accuracies of 8 to $38 \mathrm{~cm}$ and 3 to 5 $\mathrm{cm}$ respectively. Both were conducted in areas that were relatively flat and had little to no vegetation cover. Pereira and Janssen (1999) reported that the vertical accuracy of LiDAR declined when used on sloped terrain as opposed to flat terrain. Csanyi, et al. (2005), used LiDAR specific ground targets placed along a highway corridor in Ohio in an attempt to help improve vertical accuracies. 
The study conducted by Miller (2004) in the Walnut Gulch Experimental Watershed where LiDAR and IFSAR (Interferometric Synthetic Aperture Radar)were used to create two separate terrain models of 1 meter and 2.5 meters. Similar to this study, crosssectional characteristics were considered. Comparisons were made between cross section width, depth, and area for LiDAR and ground-surveyed cross-sectional profiles. It was found that there were high correlations of these characteristics in both of the models. The best correlation came when comparing depth. This study was conducted in a watershed located in a desert transition zone. The main vegetation type was a mixture of grass lands and shrub-steppe. It was reported that the riparian overstory has a low canopy density. Many of the channels in the watershed are said to be characterized by rapid and violent runoff events. This study may have also benefited from more current technology, as well as the effect of riparian vegetation type and density. 


\section{Chapter 7 Summary and Recommendations}

\subsection{Summary}

The LiDAR technology available in 2002 used in the Little Creek watershed produced data with a RSME of $60.96 \mathrm{~cm}$ as calculated from the point-to-point comparison. One ground observation every 5.2 square meters was recorded within the study area. It was found that with this level of precision it would be difficult to detect change in bankfull channel characteristics in watersheds with relatively small channels, such as Little Creek. Even using more current technology, there are very few studies attempting to quantify small, mountainous headwater channels. It may be that attempting to measure small channels lying in steep terrain and under thick canopy is considered too challenging and LiDAR-derived channel characteristics will not reach a level suitable for detecting change under these conditions. This is a question that remains to be evaluated as the technology advances.

For this study, the RSME was $60.96 \mathrm{~cm}$ within the study area and the average bankfull depth as determined by the ground survey was $63.40 \mathrm{~cm}$. Additionally, within the study area there was only one ground observation every 5.2 square meters while the average bankfull width as determined by the ground survey was $3.86 \mathrm{~m}$. The ground survey for this study averaged one data point every $0.49 \mathrm{~m}$ along the linear cross-sectional profiles while the raw LiDAR data averaged one observation every $2.50 \mathrm{~m}$ linearly in the study areas. This is almost five ground observations for every one LiDAR observation. It could be assumed that the ground survey provides, at the very least, the minimum number of points needed to accurately depict an individual cross-sectional profile and therefore, 
be regarded to be the minimum number of ground returns needed to detect change. The vertical error and low ground return density produced in this study has shown that LiDAR-generated cross-sectional profiles would not be able to detect change as effectively as the ground survey.

There were some occurrences where LiDAR performed well. In this study LiDAR is shown to be successful in providing a thalweg elevation that relates well to the groundsurveyed thalweg elevation. The thalweg is considered to be a well-defined point (the deepest point) in the channel. It is often found to be in the middle of the channel which typically has the least amount of overhead vegetation. In addition, it should be noted that this parameter (thalweg elevation), unlike the others, is not dependent on the elevations obtained for bankfull from the ground survey. Also, bankfull can be difficult to determine in the field due to often small and abrupt changes in the stream channel. These same characteristics may also make it difficult for LiDAR to depict the full detail of all of the bankfull features. Since the LiDAR-derived thalweg elevations showed a strong vertical relationship it may be possible to use LiDAR to detect changes in a longitudinal profile of stream channels similar to Little Creek.

Cross-sectional profiles A8, C9, D7 showed good relationships in terms of bankfull depth while B6 and C9 had marginal relationships for bankfull width. A2 and E1 had good relationships in terms of area. While there were cross-sectional profiles that had similarities in bankfull features between the ground and LiDAR surveys the occurrences 
were rare. These few occurrences do show that there is potential for LiDAR to produce data capable of accurately mapping bankfull characteristics under the right conditions.

LiDAR may be able to provide enough information regarding the general shape and size of a channel to make more broad-based determinations, such as a Rosgen Level I stream type. It may also allow for this type of general determination to be made on a much larger scale in the watershed than just a small study reach. In addition, LiDAR data may aid in the detection of large watershed events, such as larger shallow and deep-seated landslides, rotational slumps, and debris flows that are often major factors influencing channel change.

Under similar conditions (steep terrain, thick canopy cover), LiDAR may be more suited to measure larger-scale channels that have larger-scale changes that would allow for the error associated with the technology. To be able to accurately detect a small level of change in a channel, such as Little Creek, it would require a vertical accuracy that is at least two times finer than the bankfull depth. With the average bankfull depth being 0.63 meters in Little Creek, it would require a vertical accuracy of approximately 0.16 meters. This vertical accuracy is what is typically advertised, but only seems to be obtained under optimal conditions (Csanyi, et al., 2005, French, 2003, McKean, 2005, Reutebuch et al., 2003). Therefore, it may take continued improvement in the current technology to accurately detect change in small, low relief channels, located in steep terrain under thick canopy cover. 
While these findings represent 2002 technology, and have not supported the use of LiDAR for detecting channel change, the results overall are promising. As LiDAR technology improves, the applications explored in natural resources management may become more widespread. However, many LiDAR surveys conducted now are covering larger areas, such as counties or entire states. These surveys may be conducted at point densities less than the available maximum. The level of detail presented by this study is not a surprise, given the lower point densities and sparse ground coverage. The data presented here was collected at an altitude of 1,828 $\mathrm{m}$ using a pulse rate of 20,000 pulses per second.

Without this study it would not be known what type of data would be produced by LiDAR under the challenging conditions that occur in the Little Creek watershed. It is important to know what can be expected by using LiDAR in conditions that drastically limit the number of ground-returns. LiDAR data is becoming increasingly available to the general public and it is important to have a full understanding of what LiDAR is capable of under all types of conditions.

\subsection{Recommendations for Further Study}

As previously mentioned, LiDAR is a constantly improving technology. As technological advances continue to be made it will be imperative to also continue to conduct studies similar to this one to see if improvements in the technology translate to improvements in the ground data that is received. 
Further study is needed to see if changes to the flight plan that was used in this study would improve the ground point density. Future studies should consider conducting a LiDAR survey of the study area using more flight lines at a lower altitude. While adding cost to the LiDAR survey, it may provide more ground points and improve the ability of a LiDAR survey to measure channel characteristics.

In addition, to surveying with more flight lines at a lower altitude it would also be beneficial to make certain that the flight occurs during optimal leaf off conditions. While this does not account for the entire canopy over the study area it may help to decrease the number of returns received from the overstory canopy and increase the amount of returns received from the ground.

Another possible way to increase ground returns may be to survey the area using an increased pulse rate. LiDAR is now capable of surveying with pulse rates upwards of 100,000 pulses per second. This is 5 times what was used in this study. It needs to be determined if a higher pulse rate would only increase returns from the overstory canopy or if this increase in pulse rate would also lead to an increase in ground returns.

As shown in this study, there is a strong vertical relationship among the LiDAR generated thalweg data and the ground survey thalweg data. More investigation needs to be conducted to determine if LiDAR can be used detect change in a longitudinal profile of a channel such as Little Creek. 
Finally, it would be useful to determine the level of change LiDAR is able to detect. While this study shows that a LiDAR is not capable of detecting change of crosssectional profiles on a small scale in Little Creek, LiDAR may be able to detect larger scale changes such as significant landslides or other large-scale mass wasting events that were not considered as part of this study. Ultimately, more study is needed using the most current LiDAR technologies to document the improving capabilities of LiDAR and to evaluate accuracies for detecting change in channel morphologic characteristics. 


\section{List of References}

Bowen, Zachary H., and Robert G. Waltermire, 2002. Evaluation of Light Detection and Ranging (LIDAR) for Measuring River Corridor Topography. Journal of the American Water Resources Association (JAWRA) 38(1):33-41.

Bray, D., 2006. A study of channel changes in a reach of the North Nashwaaksis stream, New Brunswick, Canada. Earth Surface Processes and Landforms Vol 12 Issue 2:151-165

California Forest Practice Rules, 2009. California Department of Forestry and Fire Protection, Title 14, California Code of Regulations, Chapters 4, 4.5, and 10, Sacramento, CA.

Charlton, M.E., 2003. Application of Airborne LiDAR in River Environments: The River Coquet, Northumberland, UK. Earth Surface Processes and Landforms 28:299-306

Csanyi, Nora, Toth, Charles K, Grejner-Brzezinska, Dorota, and Ray, John, 2005. Improvement of LIDAR Data Accuracy Using LIDAR Specific Ground Targets. In: ASPRS 2005 Annual Conference, pp. 1-11.

Davis, P.A., et. al., 2002. Evaluation of LiDAR and Photogrametry for Monitoring Volume Changes in Riparian Resources Within the Grand Canyon, Arizona. Pecora 15/Land Satellite Information IV/ISPRS Commission I/FIEOS 2002 Conference Proceedings

French, J.R., 2003. Airborne LiDAR in Support of Geomorphological and Hydraulic Modeling. Earth Surface Processes and Landforms 28:321-335

Harrelson, Cheryl C., Rawlins, C.L., Potyondy, John P., 1994. Stream Channel Reference Sites: An illustrated Guide to Field Technique. Gen. Tech. Rep. RM-245. Fort Collins, CO: U.S. Department of Agriculture, Forest Service, Rocky Mountain Forest and Range Experiment Station.

Haugerud, R. A. and Harding, D. J. 2001. Some Algorithms for Virtual Deforestation (VDF) of LIDAR Topographic Survey Data. International Archives of Photogrammetry and Remote Sensing, XXXIV-3/W4:211-217.

Hickman, J.C., 1993. The Jepson Manual: Higher Plants of California, University of California Press, Berkeley, CA.

Hodgson, M.E., Jensen, J.R., Schmidt, L., Schill, S., and Davis, B., 2003. An evaluation of LIDAR- and IFSARderived digital elevation models in leaf-on conditions with USGS Level 1 and Level 2 DEMs. Remote Sensing of Environment 84. pp. 295308 
Hodgson, M.E., Jensen, J., Raber, G., Tullis, J., Davis, B., Thompson, G., and Schuckman, K., 2005. An Evaluation of Lidar-derived Elevation and Terrain Slope in Leaf-off Conditions. Photogrammetric Engineering \& Remote Sensing Vol. 71, No. 7, July 2005, pp. 817-823.

Hyyppä J., Pyysalo U., Hyyppä H., Haggren H., and Ruppert G., 2005. Accuracy of laser scanning for DTM generation in forested areas. Proceedings of SPIE 4035 Laser Radar Technology and Applications V, 26-28 April, Orland USA. (International Society for Optical Engineering), Vol. 4035, pp. 119-130.

Keim, Richard F., Skaugset, Arne E.. 1999. Digital terrain modeling of small stream channels with a total-station theodolite. Advances in Water Resources, Vol. 23, Issue 1, p. 41-48

Kraus, K., and Pfeiffer, N., 1998. Determination of terrain models in wooded areas with airborne laser scanner data. ISPRS Journal of Photogrammetry and Remote Sensing 54:193-203.

Madej, M.A., 2000. Personal communication, United States Geological Survey.

Madej, M.A. and V. Ozaki. 1996 . Channel response to sediment wave propagation and movement, Redwood Creek, California, USA. Earth Surface Processes and Landforms. Vol. 21, p. 911-927

McKean, J., Roering, J., 2005. Operational Accuracy of Lidar in Mountainous Terrain. U.S.D.A. Forest Service, Rocky Mountain Research Station, Boise, ID 83712 USA

Mietz, Steven, Phil Davis, Keith Kohl, and Mark Manone, 2002. An Evaluation of LIDAR Vertical Accuracy in Grand Canyon, Arizona. Available at: http://gis.esri.com/library/userconf/proc02/abstracts/a0725.html. Assessed in September 2005.

Miller, Scott N., 2004. Semi-Automated Extraction and Validation of Channel Morphology from LiDAR and IFSAR Terrain Data. ASPRS Annual Conference Proceedings May 23-28, 2004. Denver, Colorado

Pereira, L.M. Gomes and Janssen, L.L.F., 1999. Suitability of laser data for DTM generation: a case study in the context of road planning and design. ISPRS Journal of Photogrammetry \& Remote Sensing 54 1999. 244-253

Reutenbuch, Stephen E., Robert J. McGaughey, Hans-Erik Anderson, and Ward W.Carson, 2003. Accuracy of a High-Resolution Lidar Terrain Model Under a Conifer Forest Canopy. Canadian Journal of Remote Sensing (29)5:527-535. 
Sawyer, J.O., and T. Keeler-Wolf, 1995. A Manual of California Vegetation, California Native Plant Society, Sacramento, CA.

Strahler, A.N., 1964. Quantitative geomorphology of drainage basins and channel networks. In Chow, V., (ed) Handbook of Applied Hydrology, New York, McGraw-Hill: 39-76.

Stumpf, K.A. 1993. "The Estimation of Forest Vegetation Cover Descriptions Using a Vertical Densitometer." Presented at the Joint Inventory and Biometrics Working Groups session at the SAF National Convention, Indianapolis, IN.

White, R. A. 2010. Accuracy of forest roads and stream channel characteristics derived from LiDAR in forested mountain conditions. Master's Thesis. California Polytechnic State University San Luis Obispo, CA 


\section{Appendix A}

Hillshades with cross-sectional profiles of all study reaches. The orange points are control points located in the study reaches, the yellow points are cross-sectional profile end points and the black points represent the LiDAR ground returns in the area.

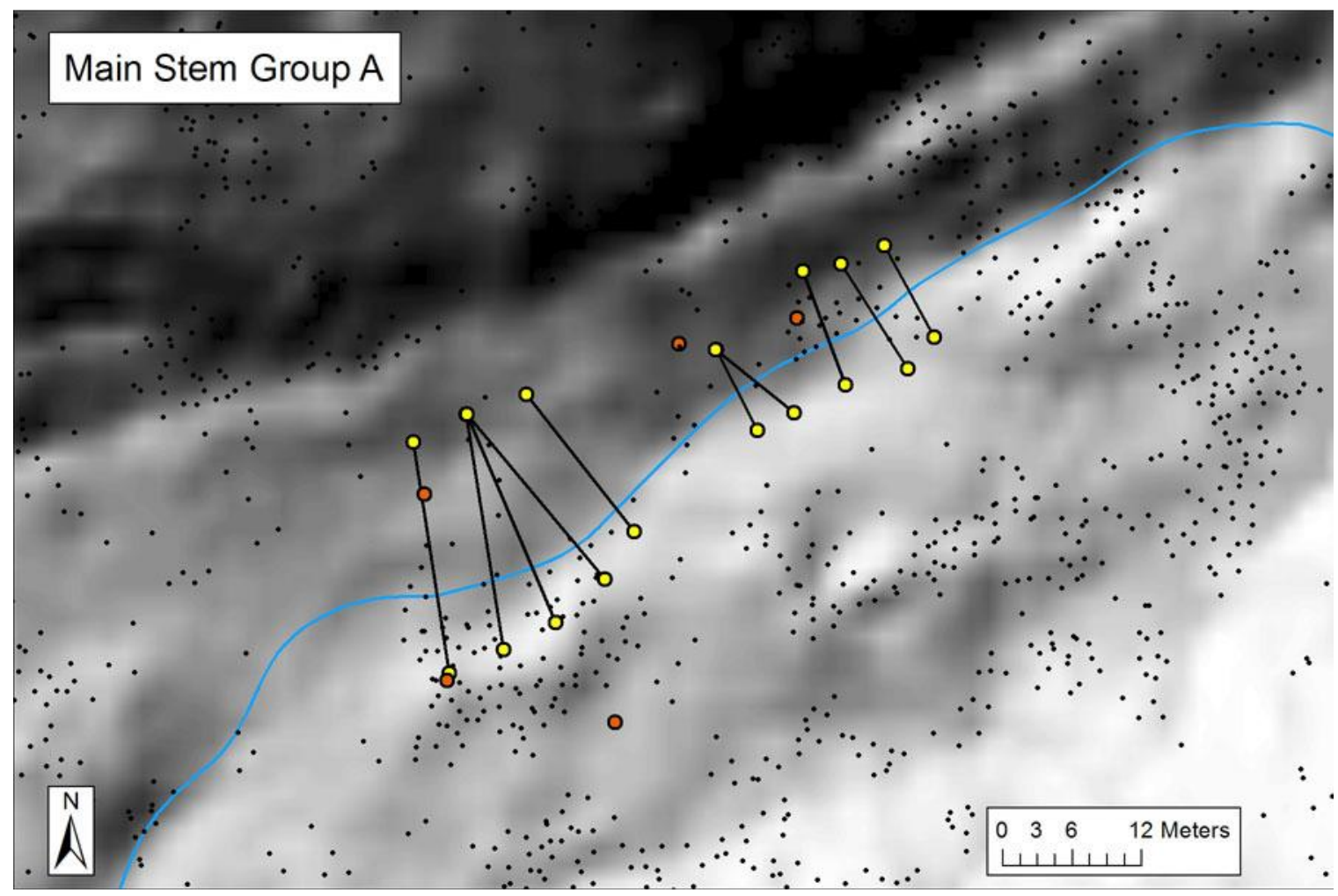



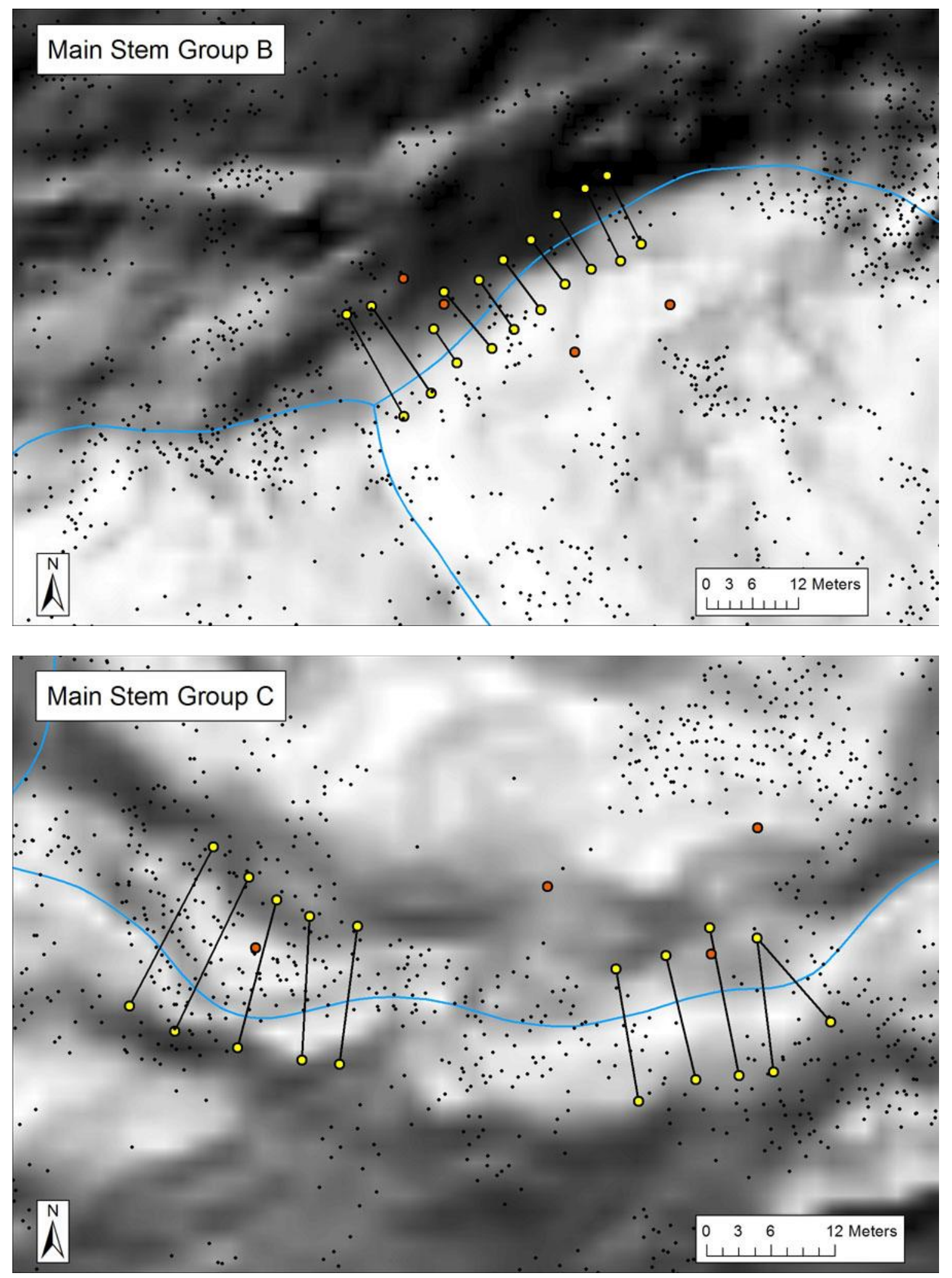

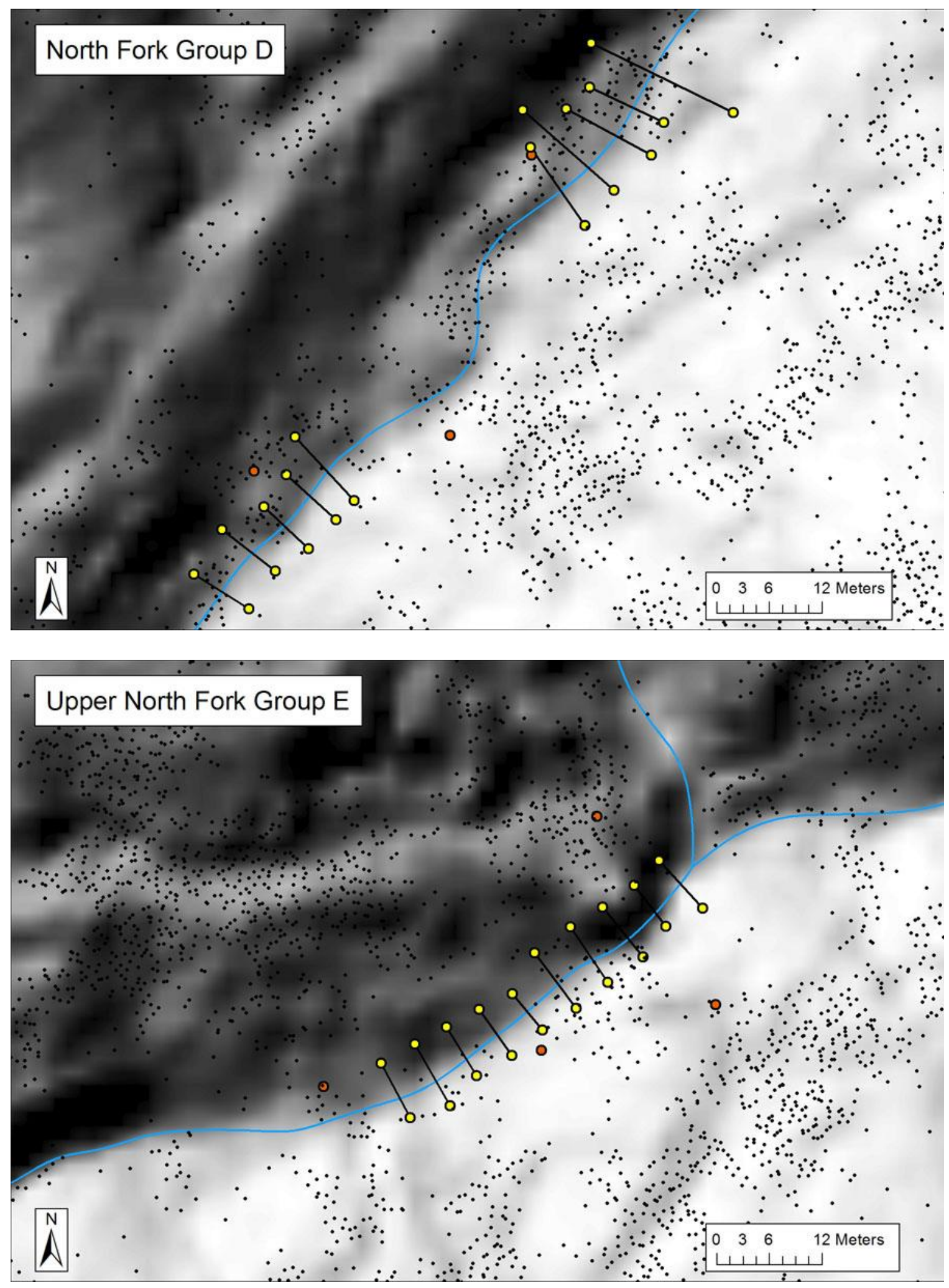


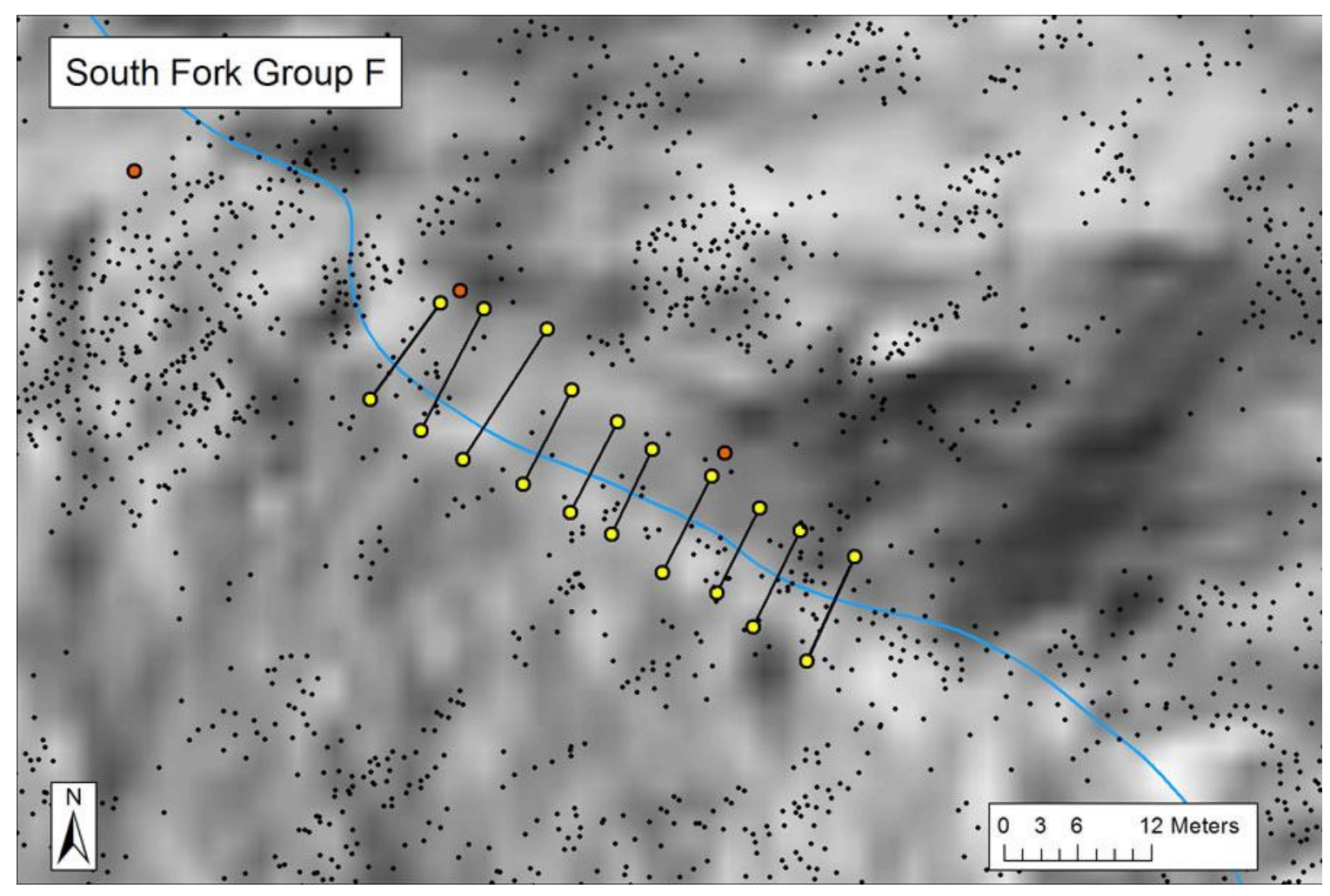




\section{Appendix B}

Linear regression comparing the bankfull width, depth, and area as calculated using the ground survey data and the GRID and LiDAR datasets.
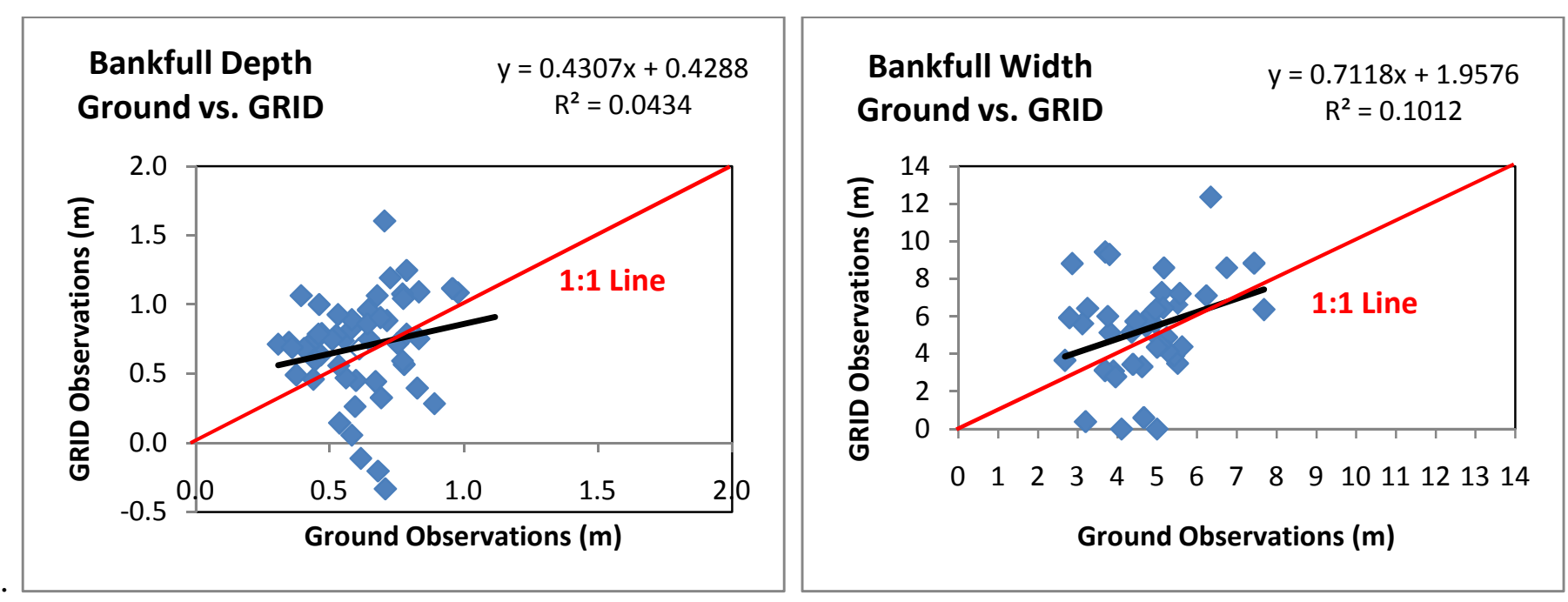

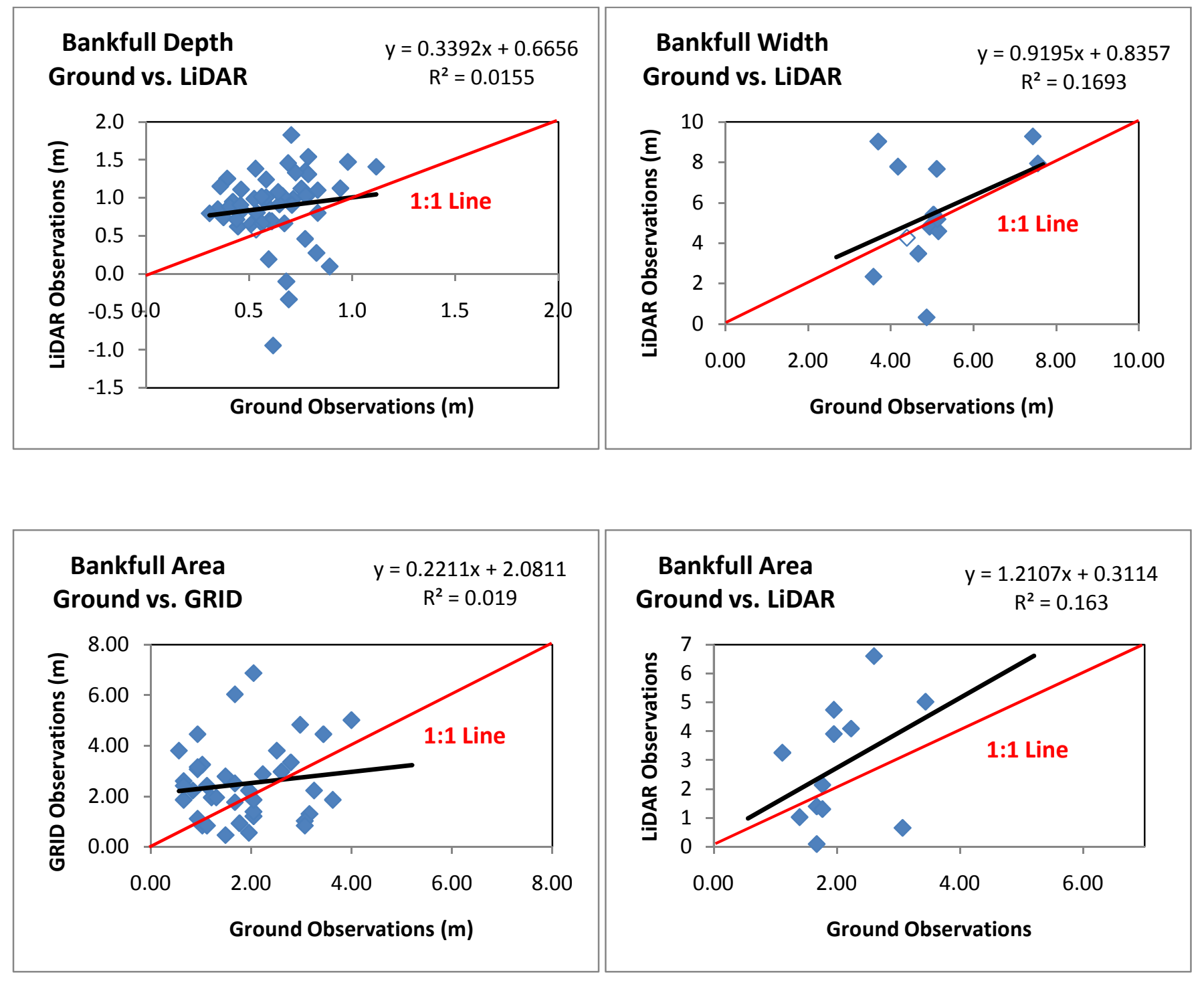
Appendix C

Plots of all cross-sectional profiles at all study reaches
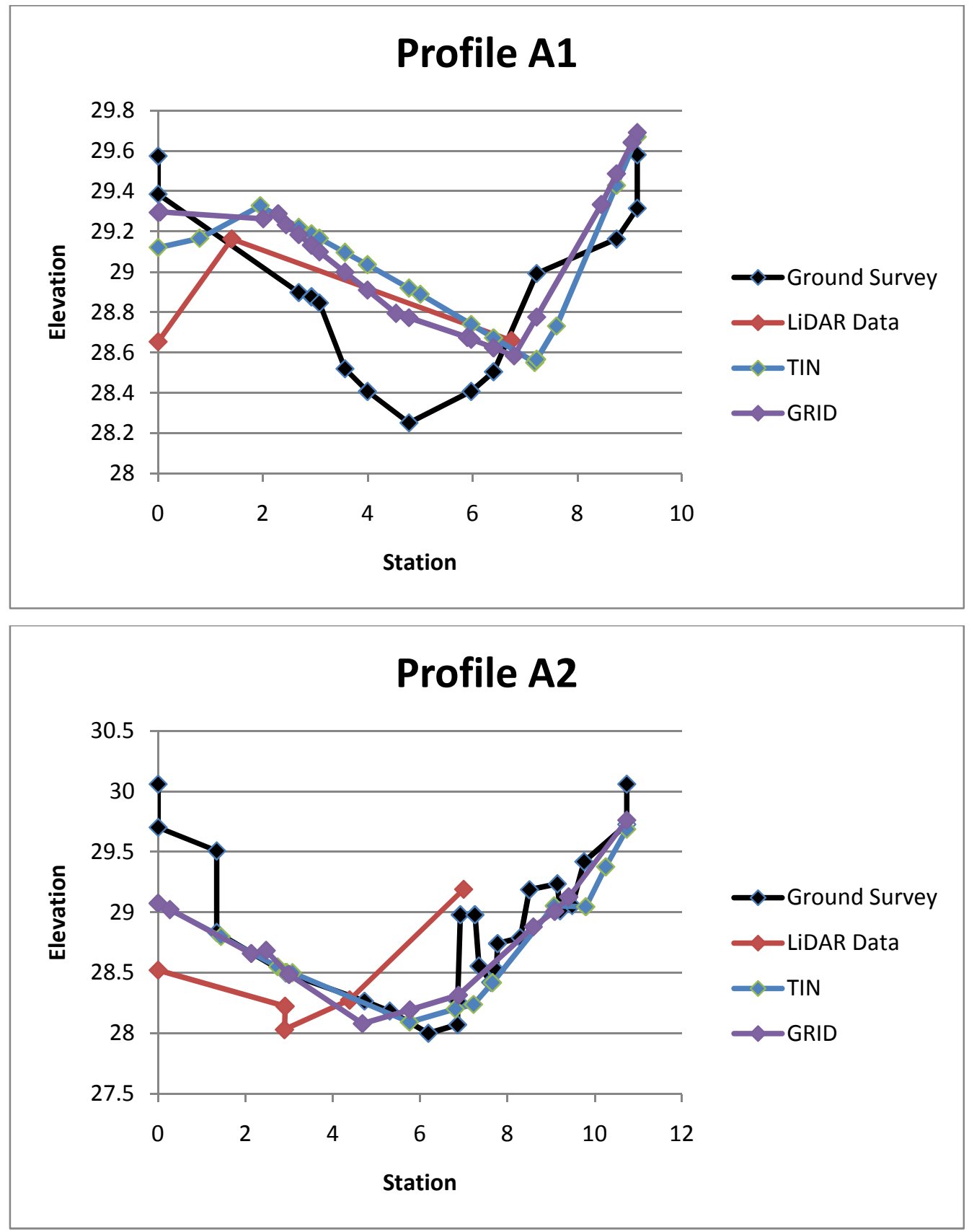

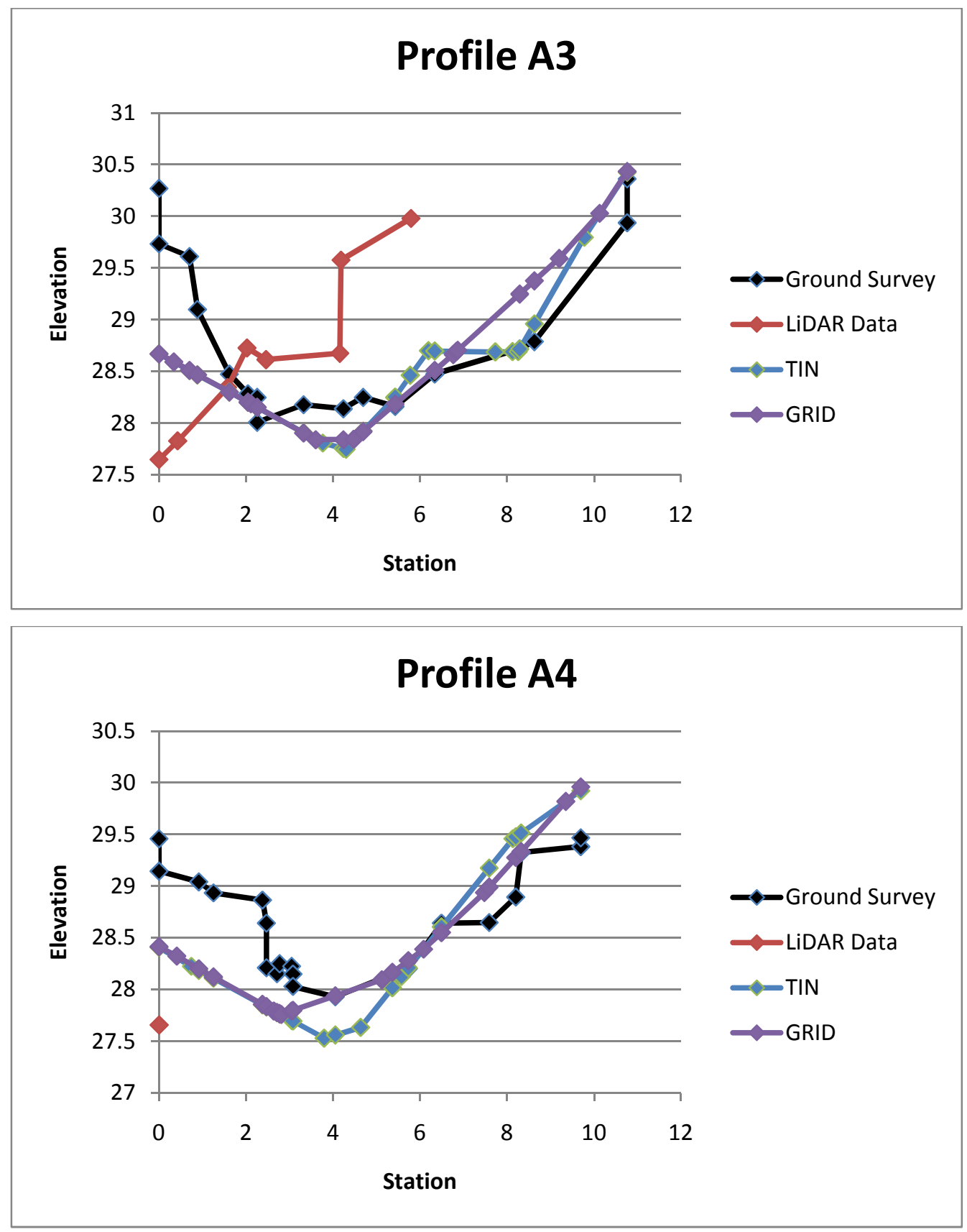

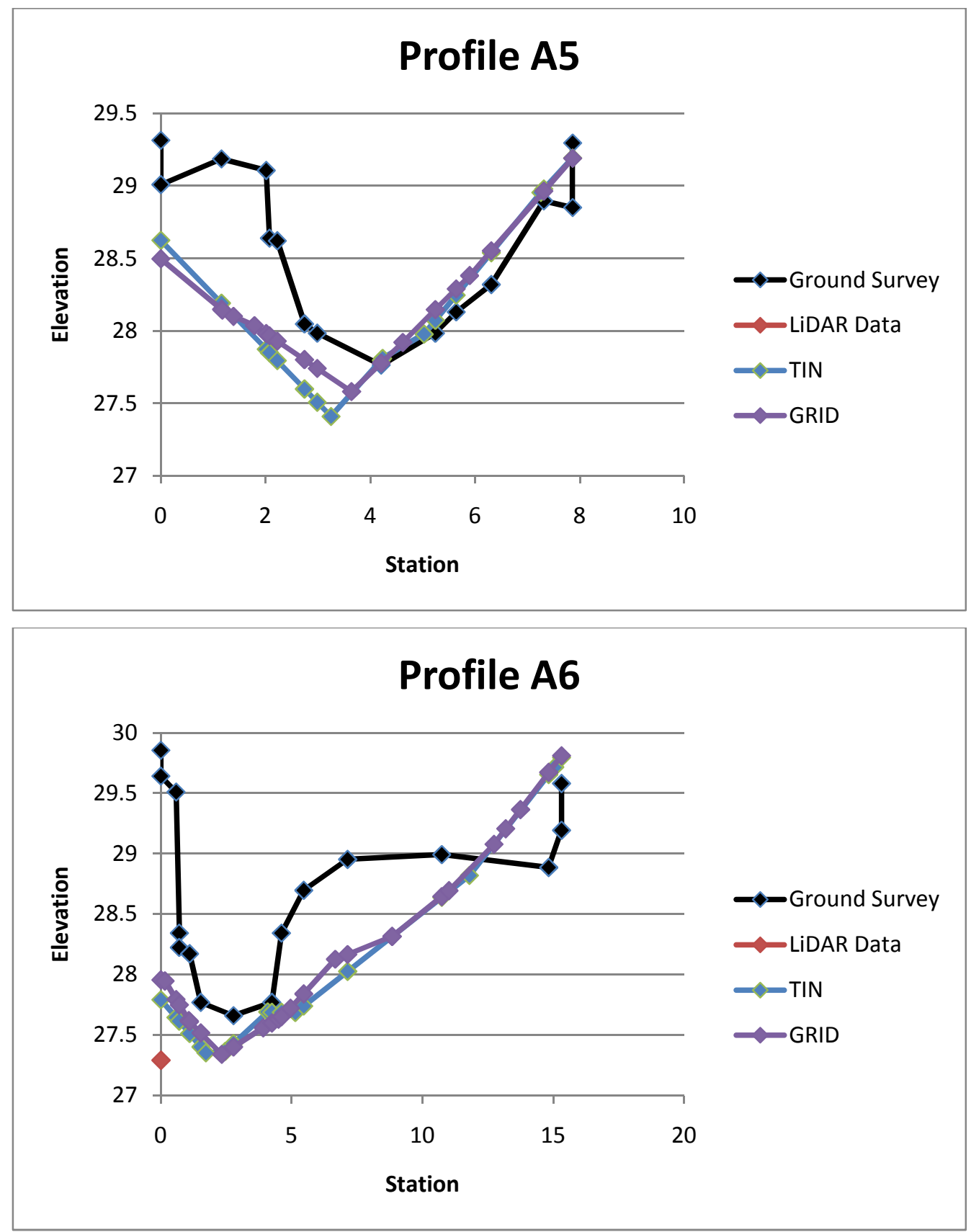

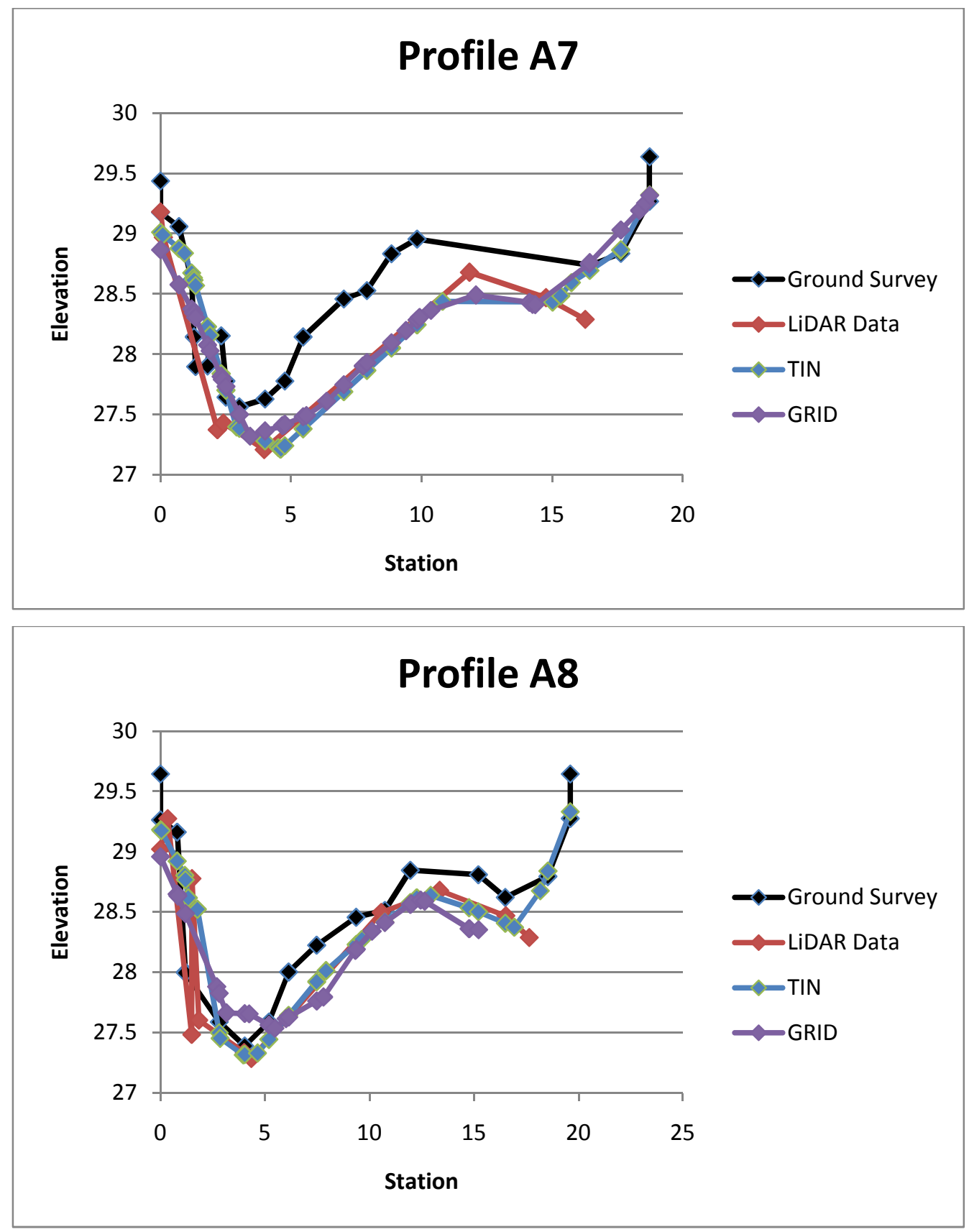

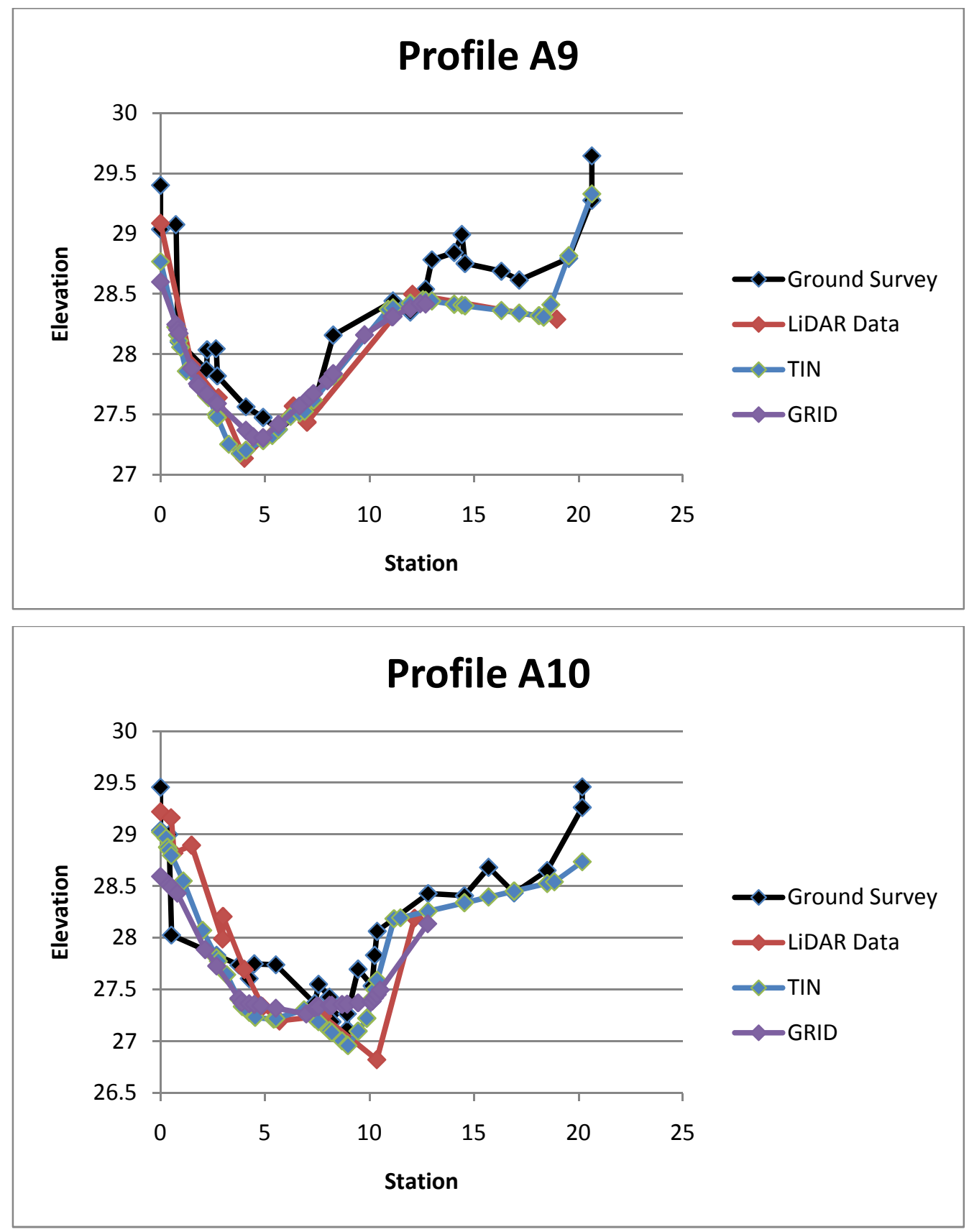

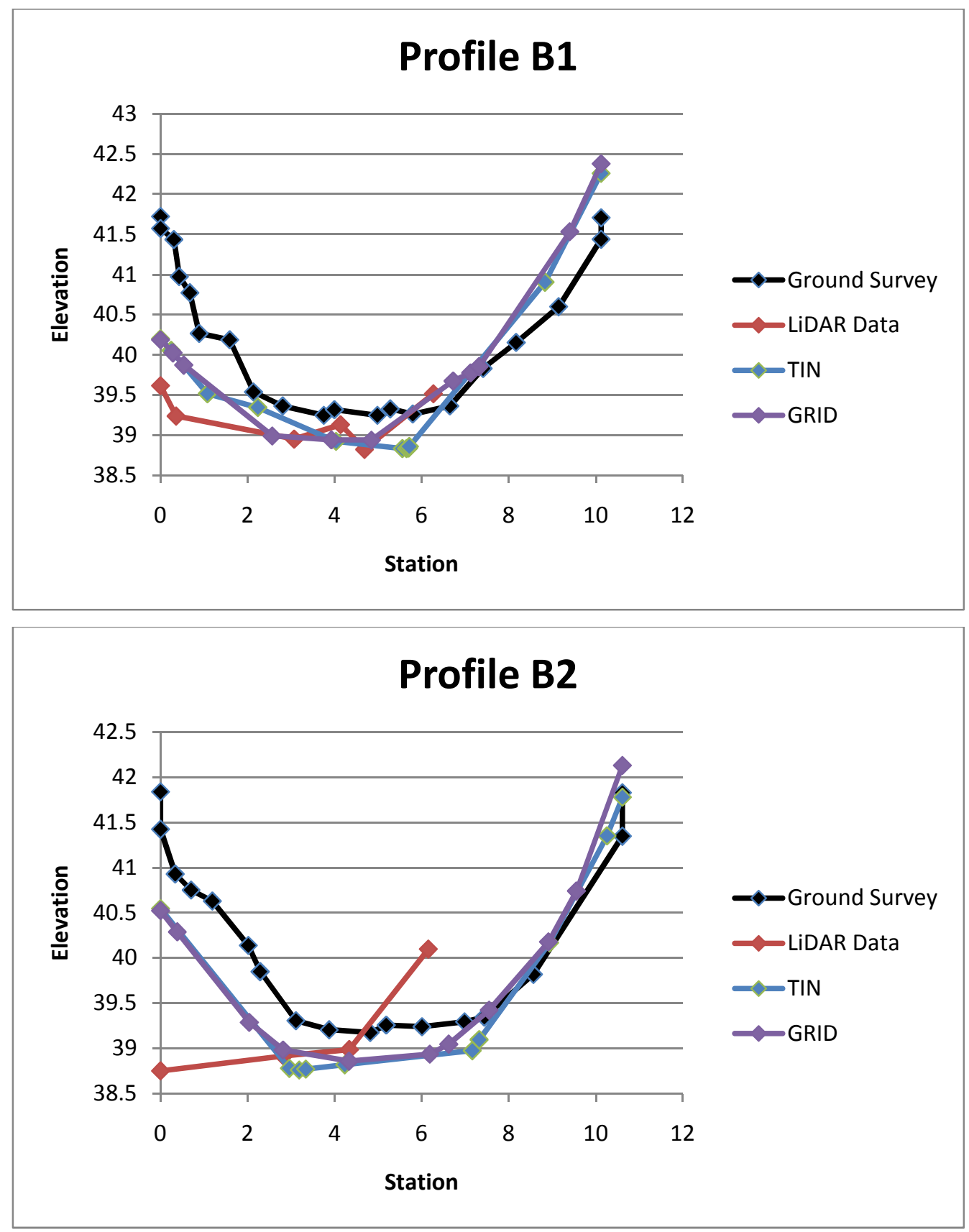

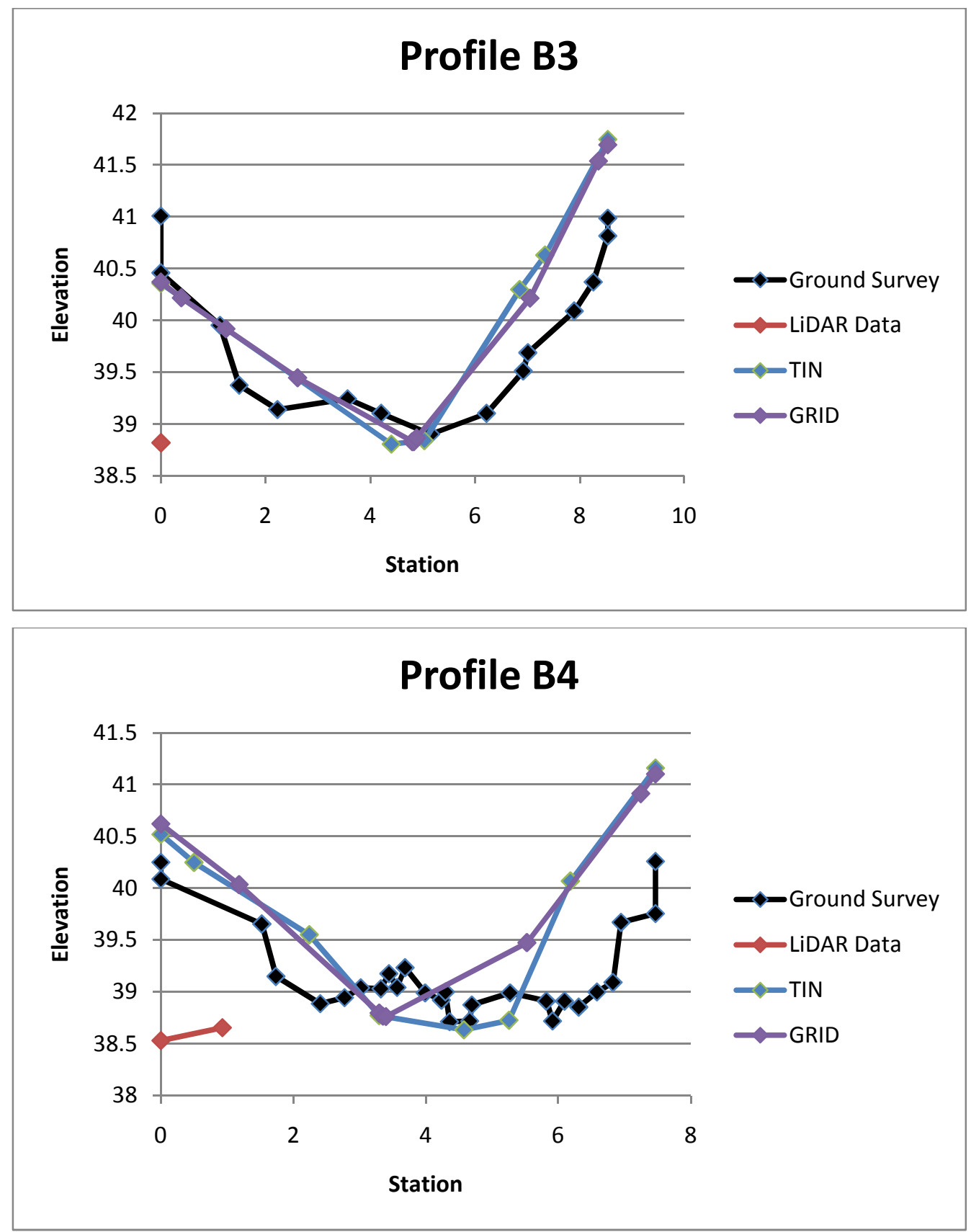

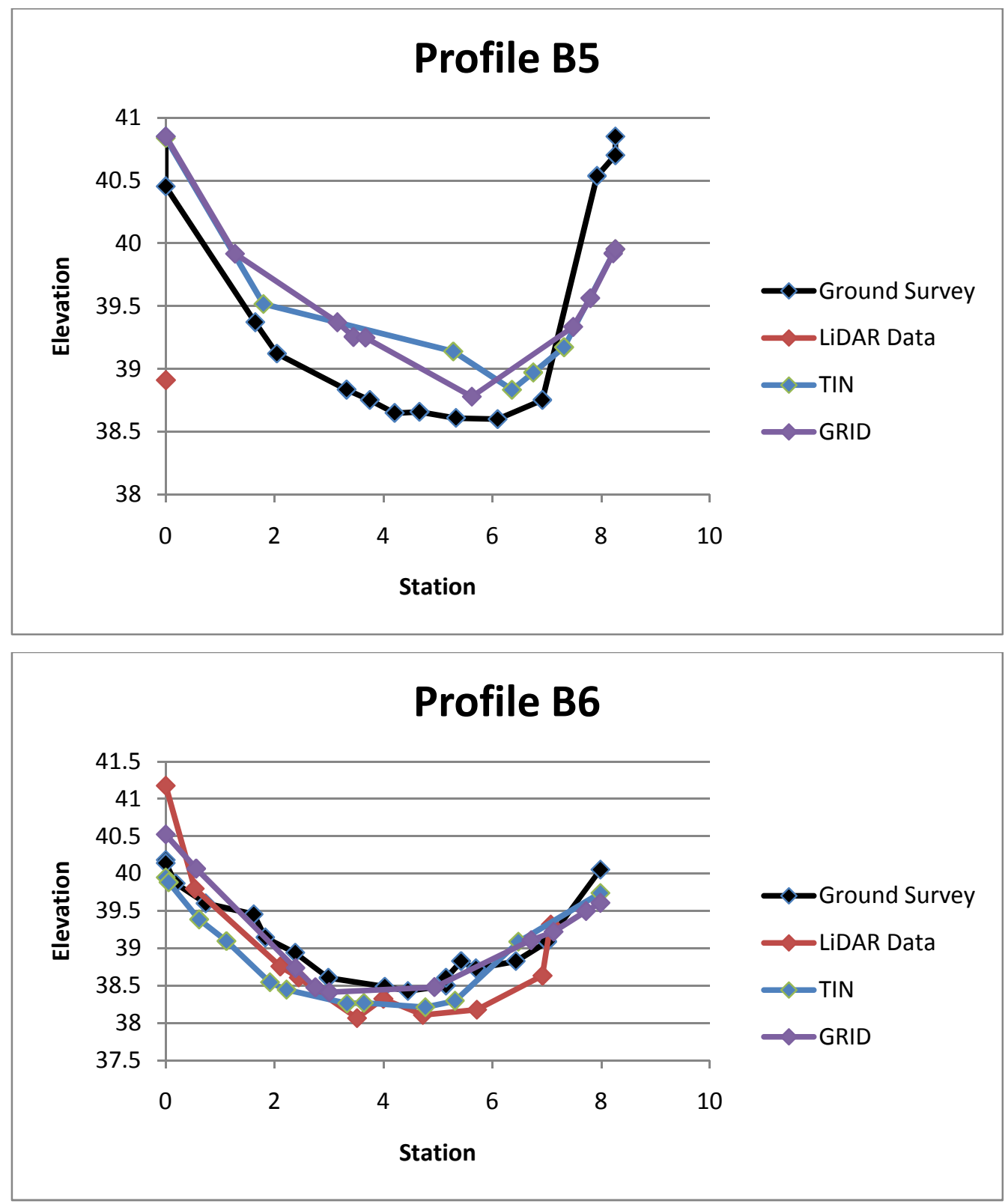

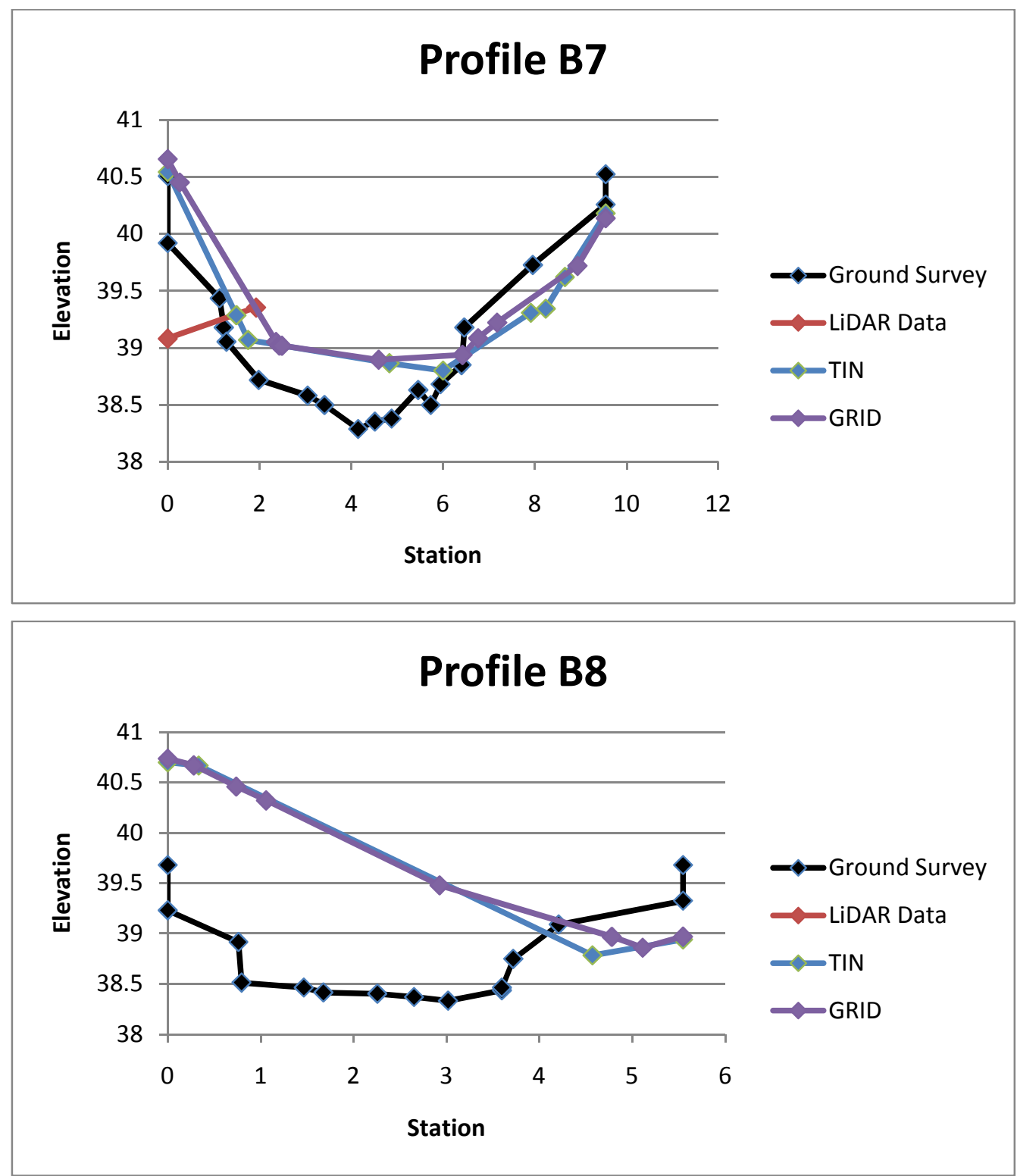

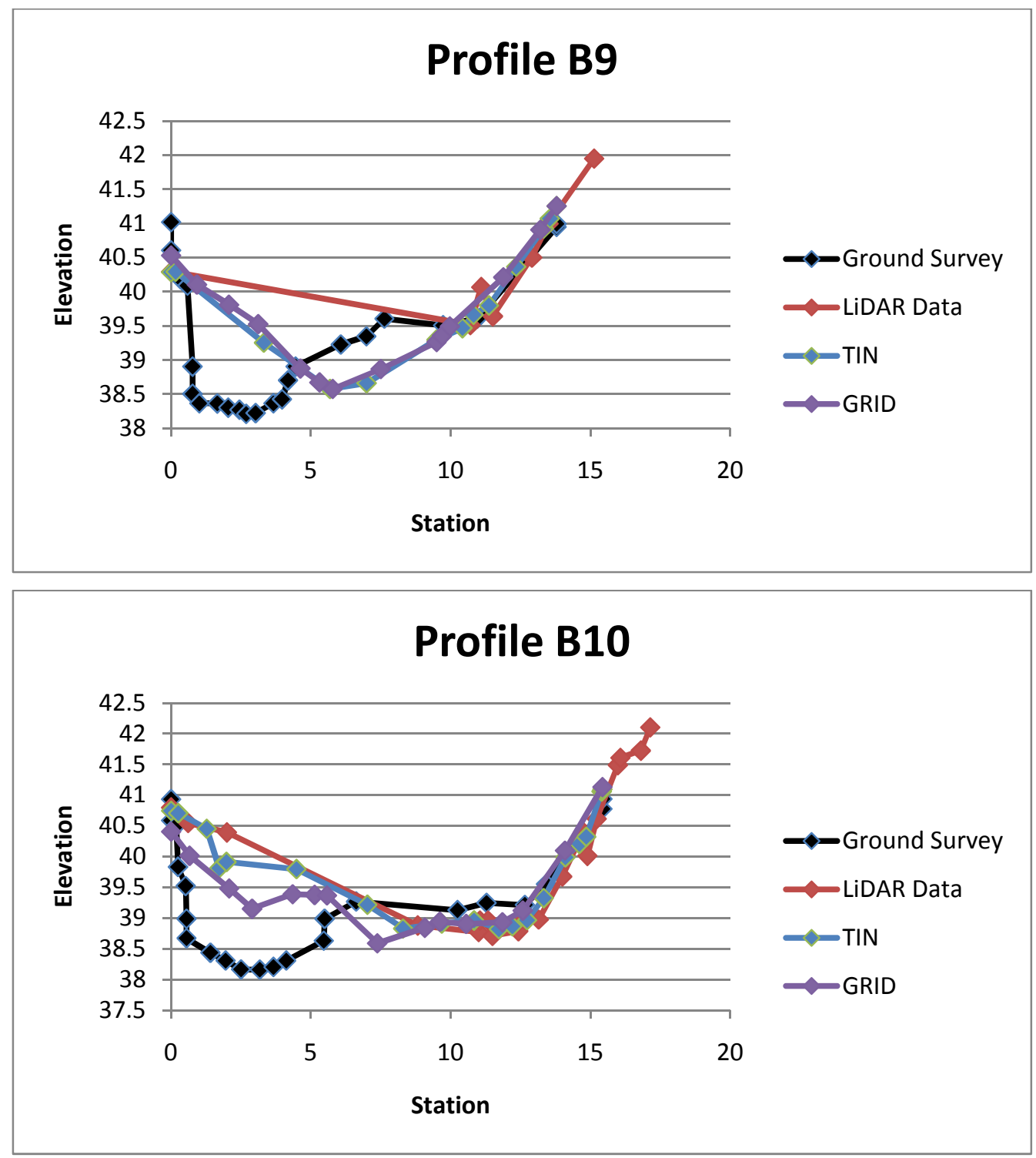

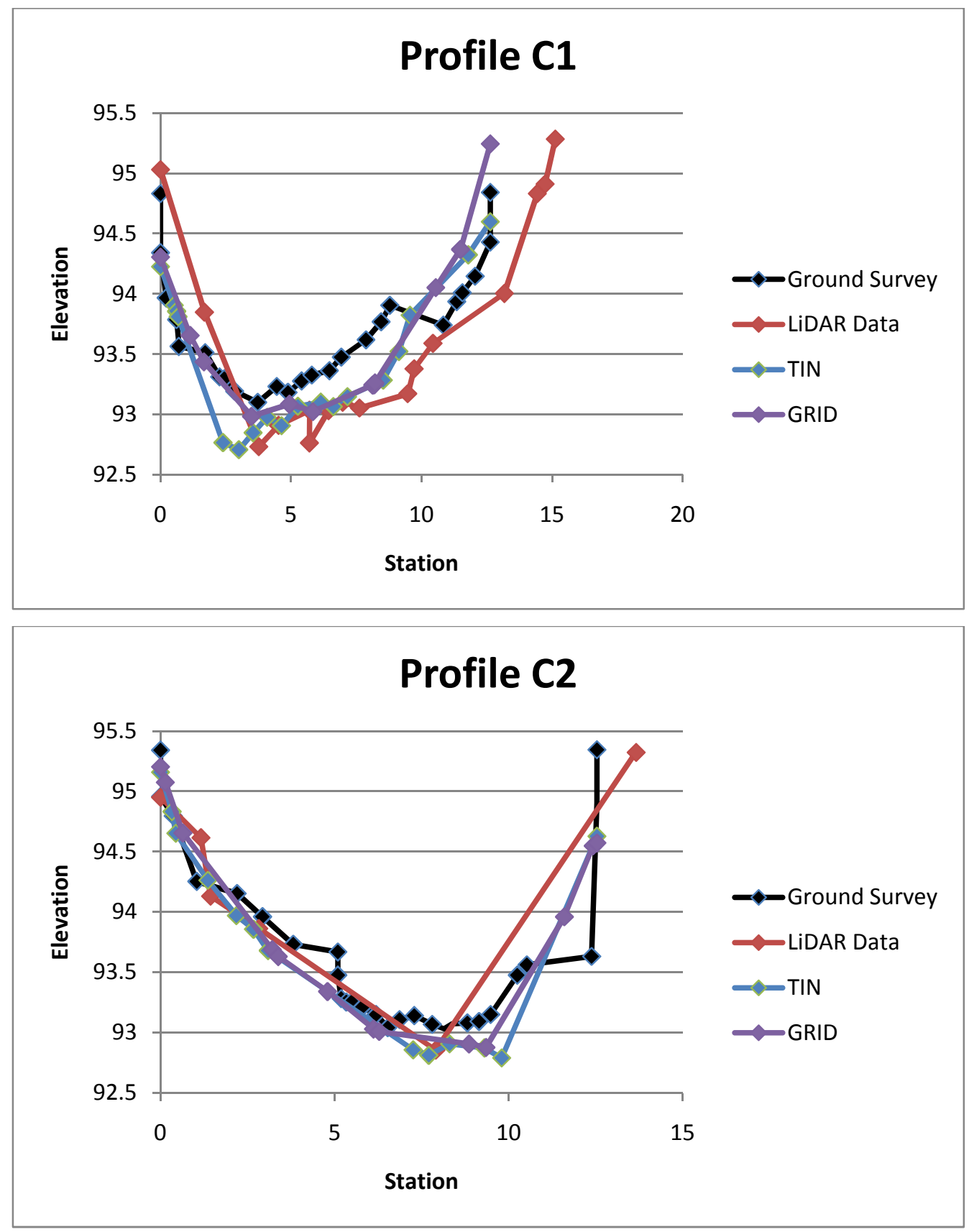

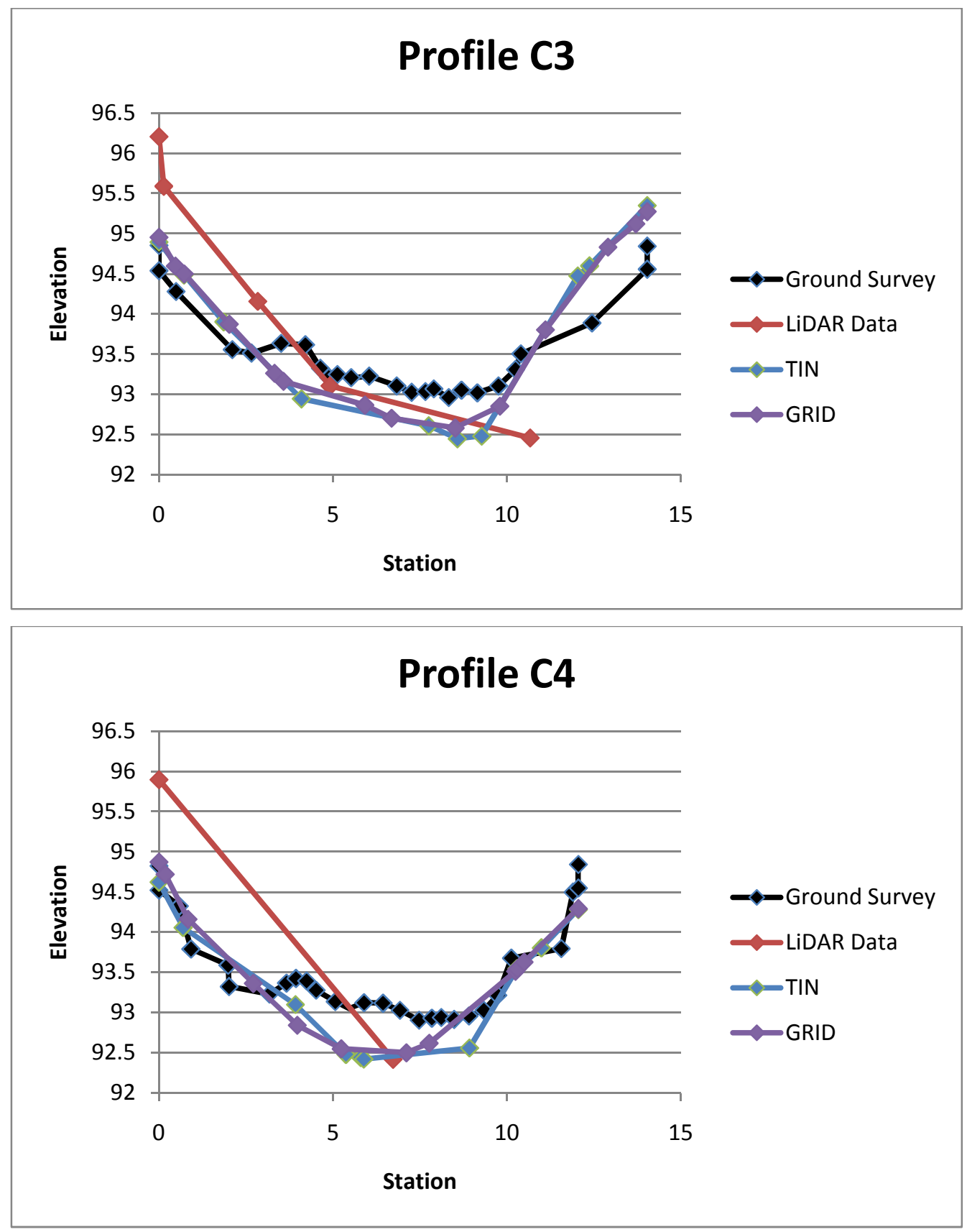

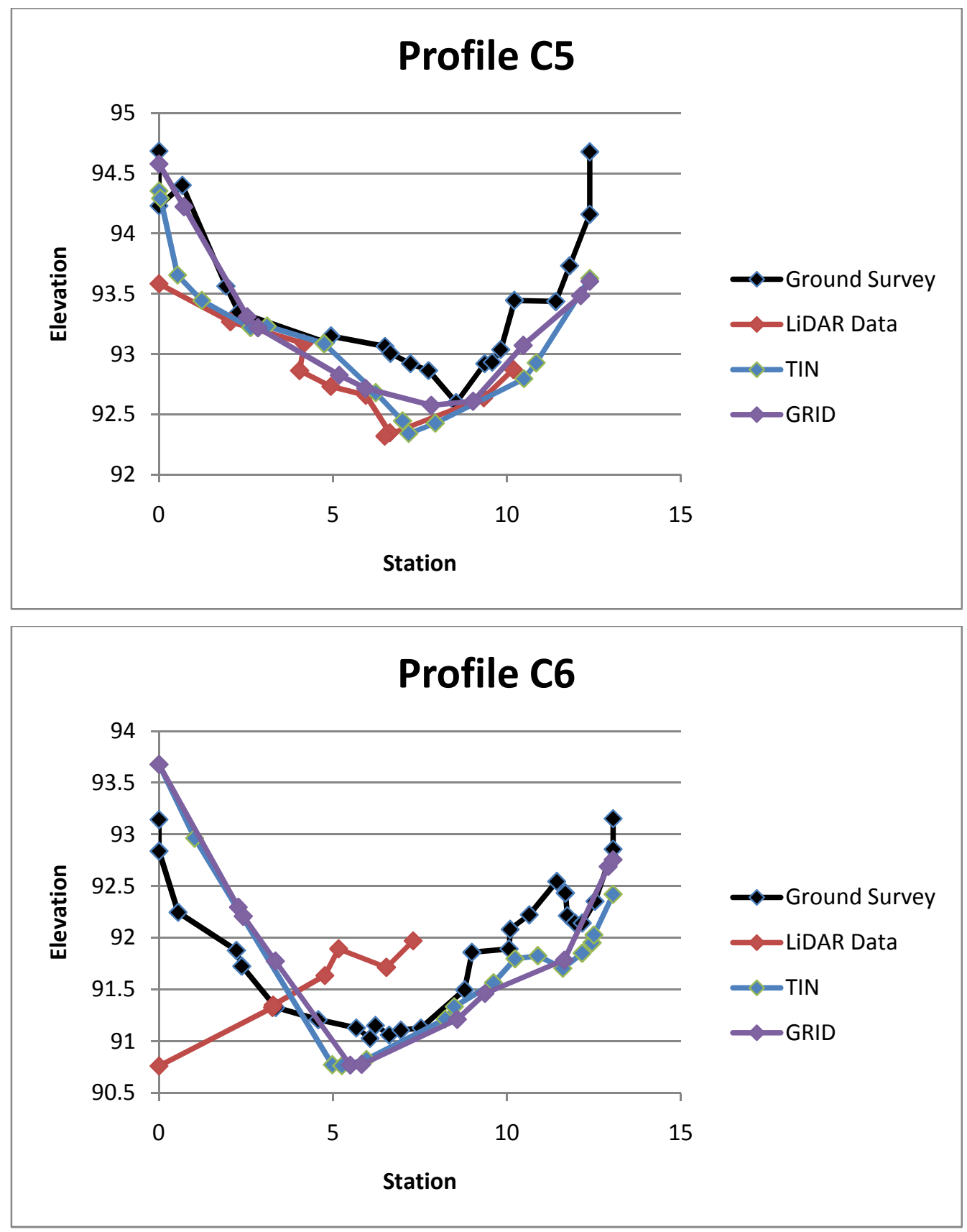

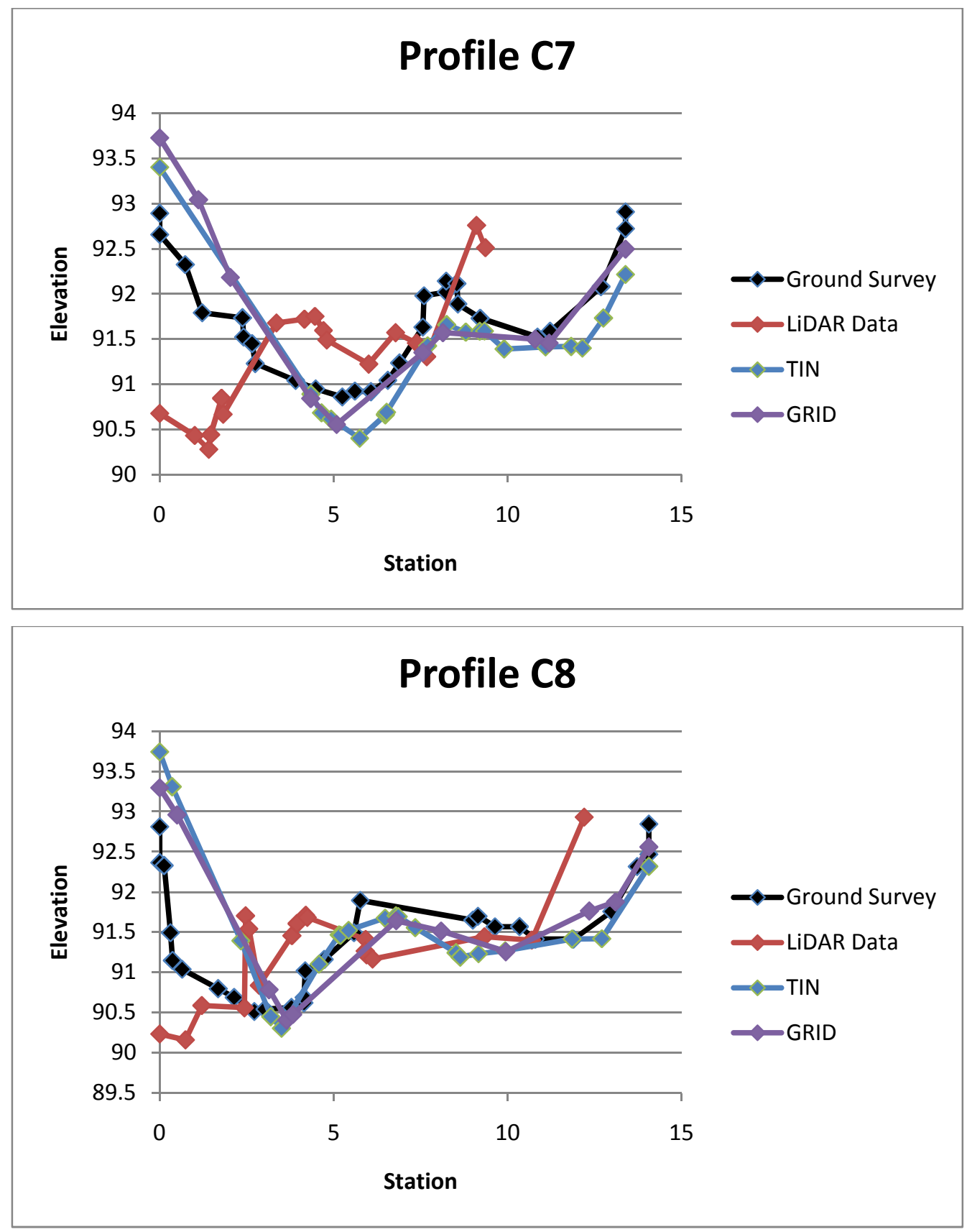

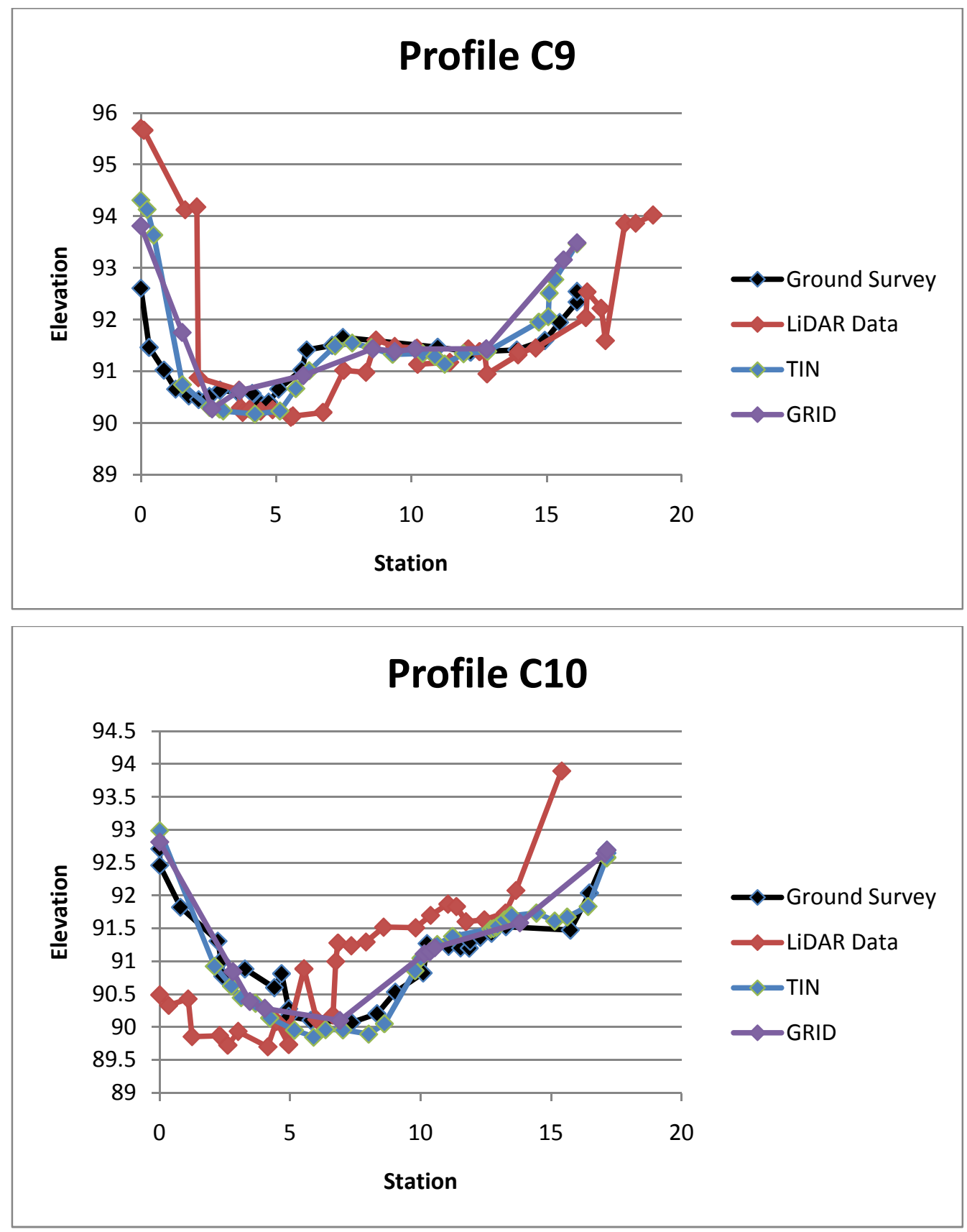

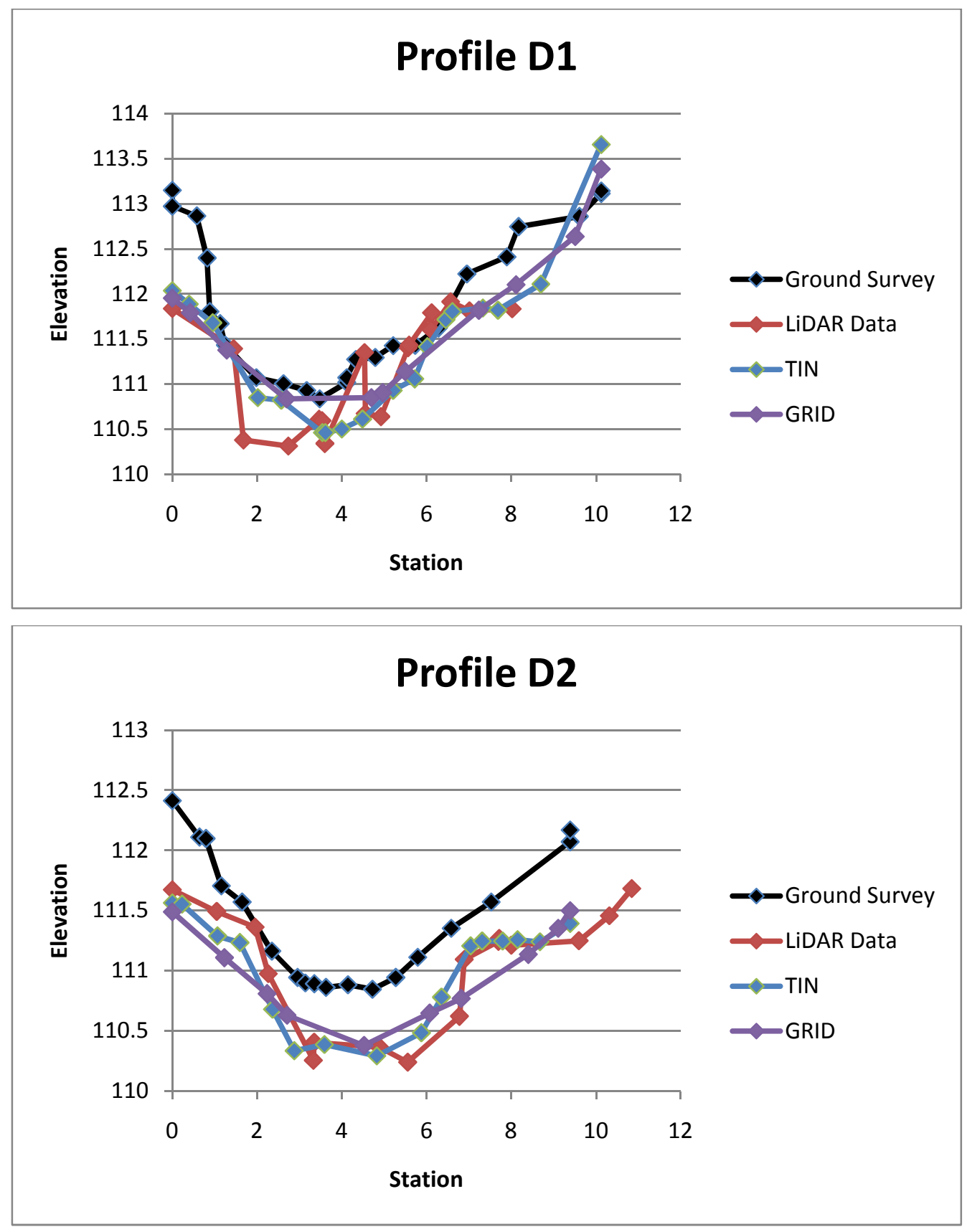

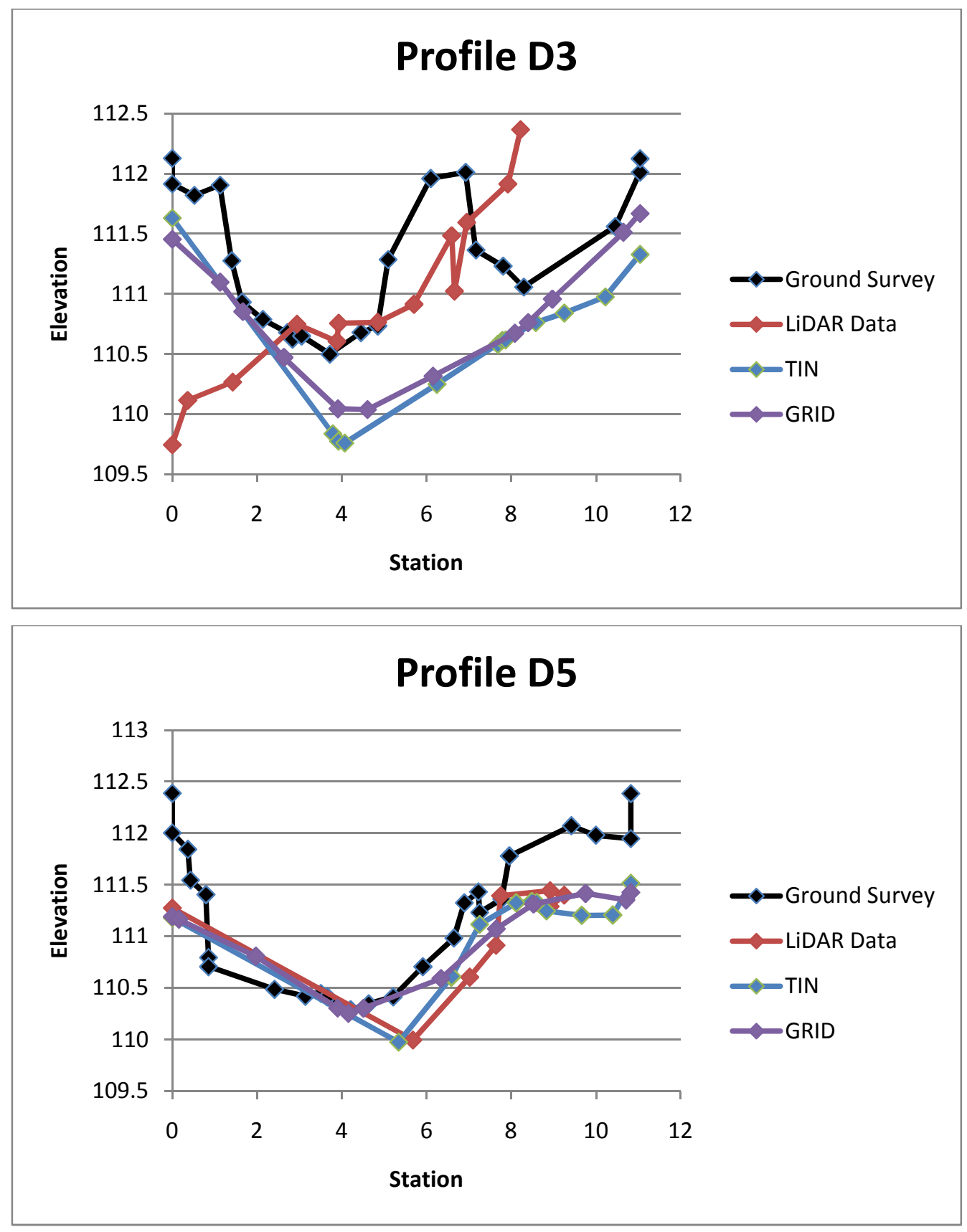

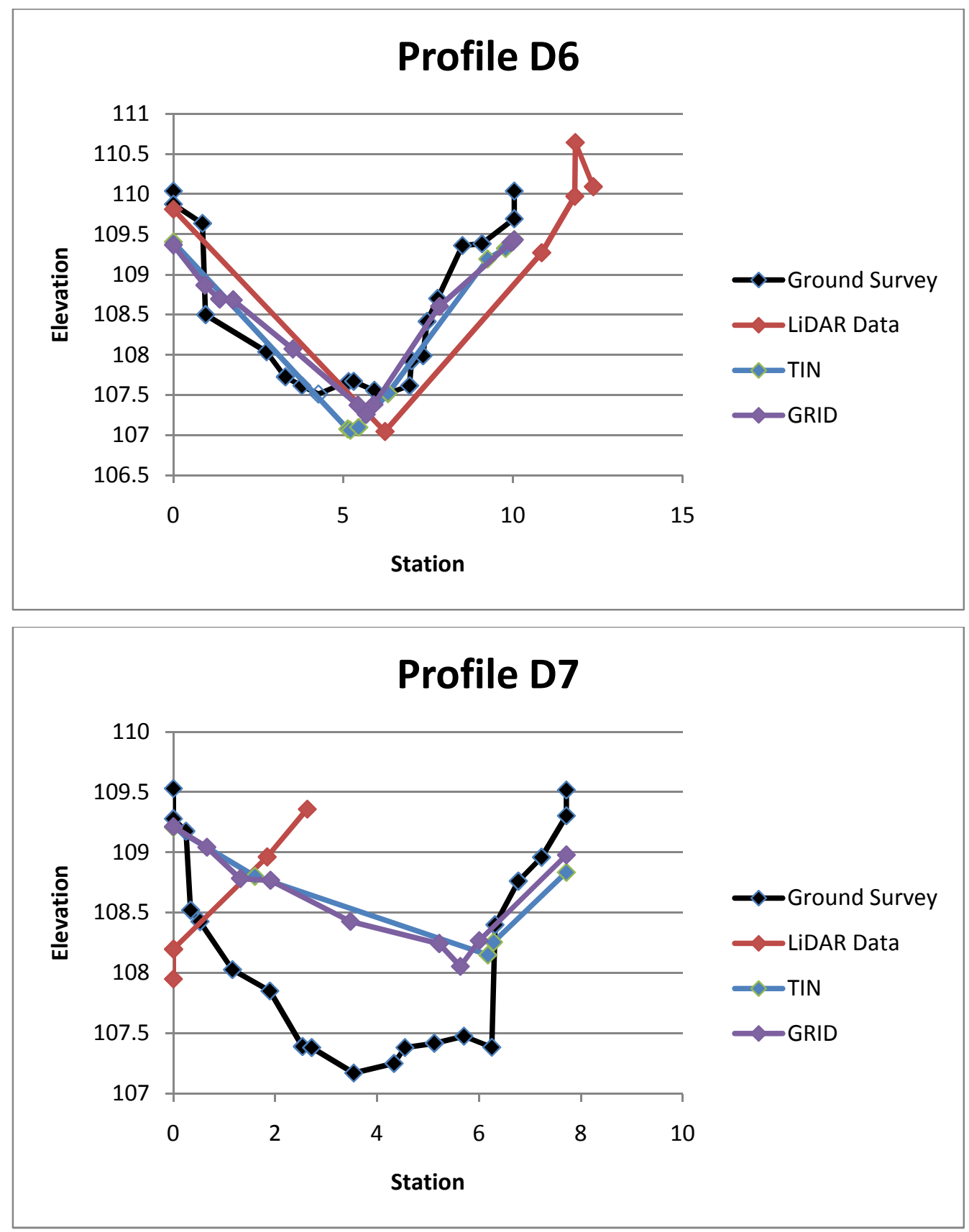

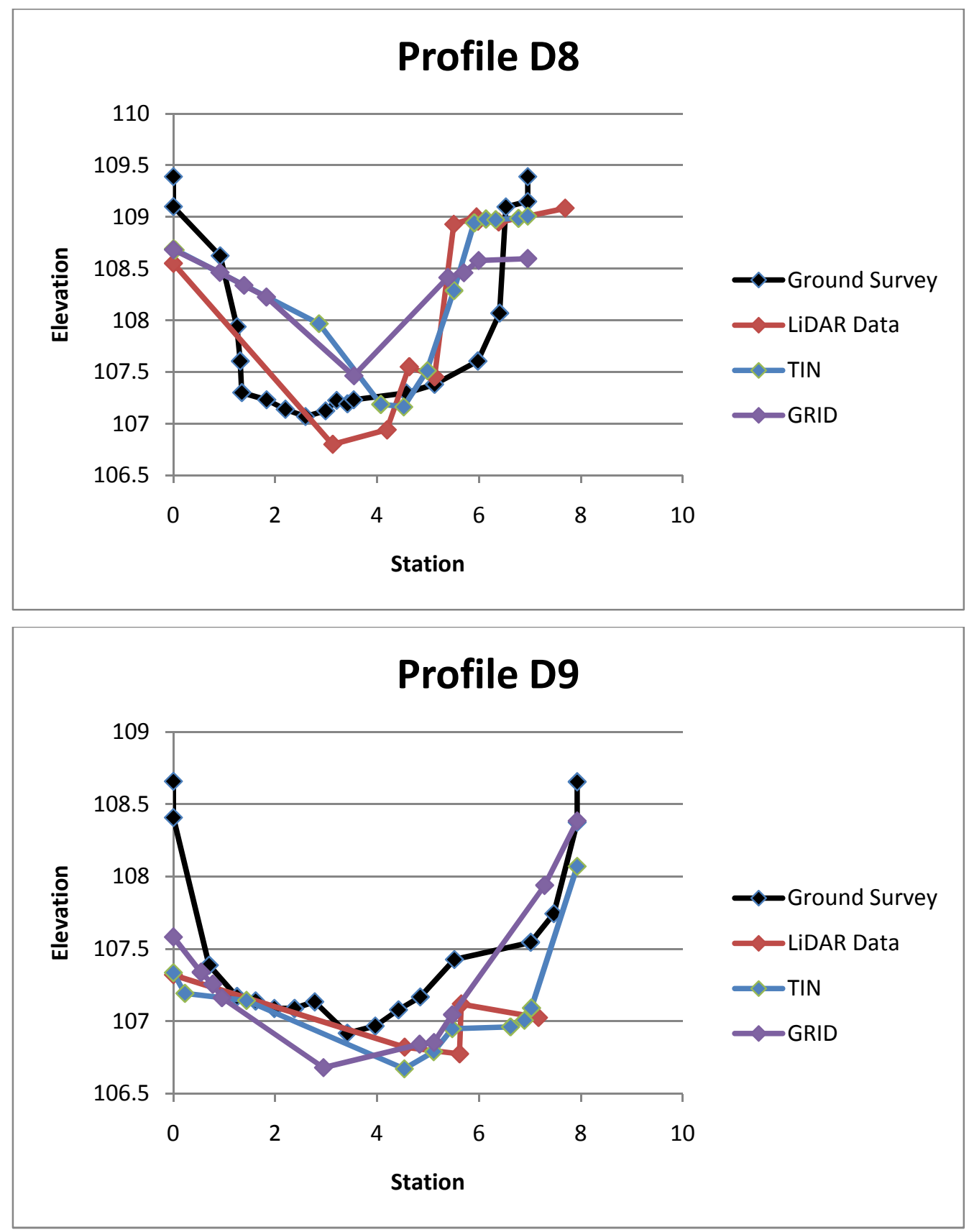

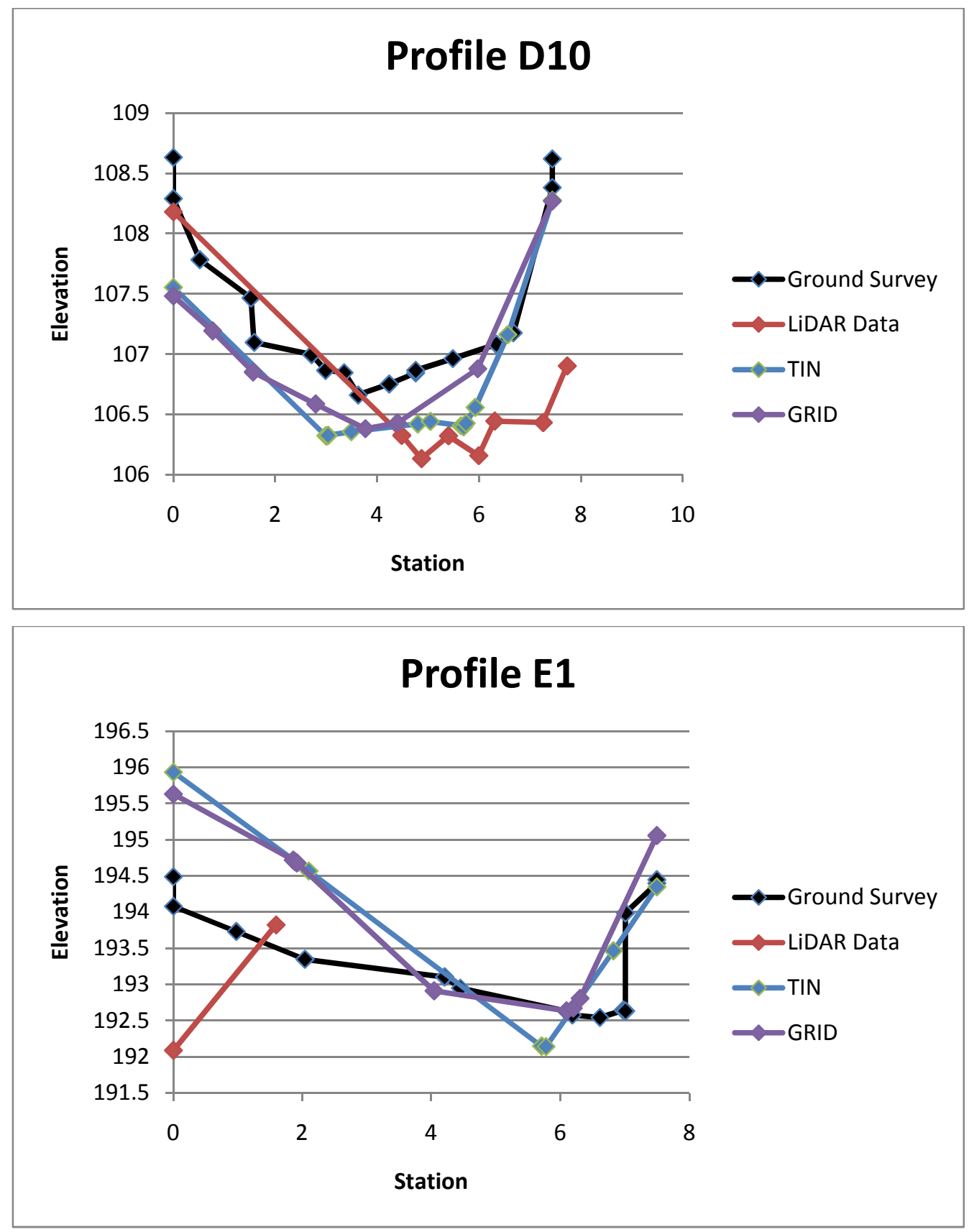

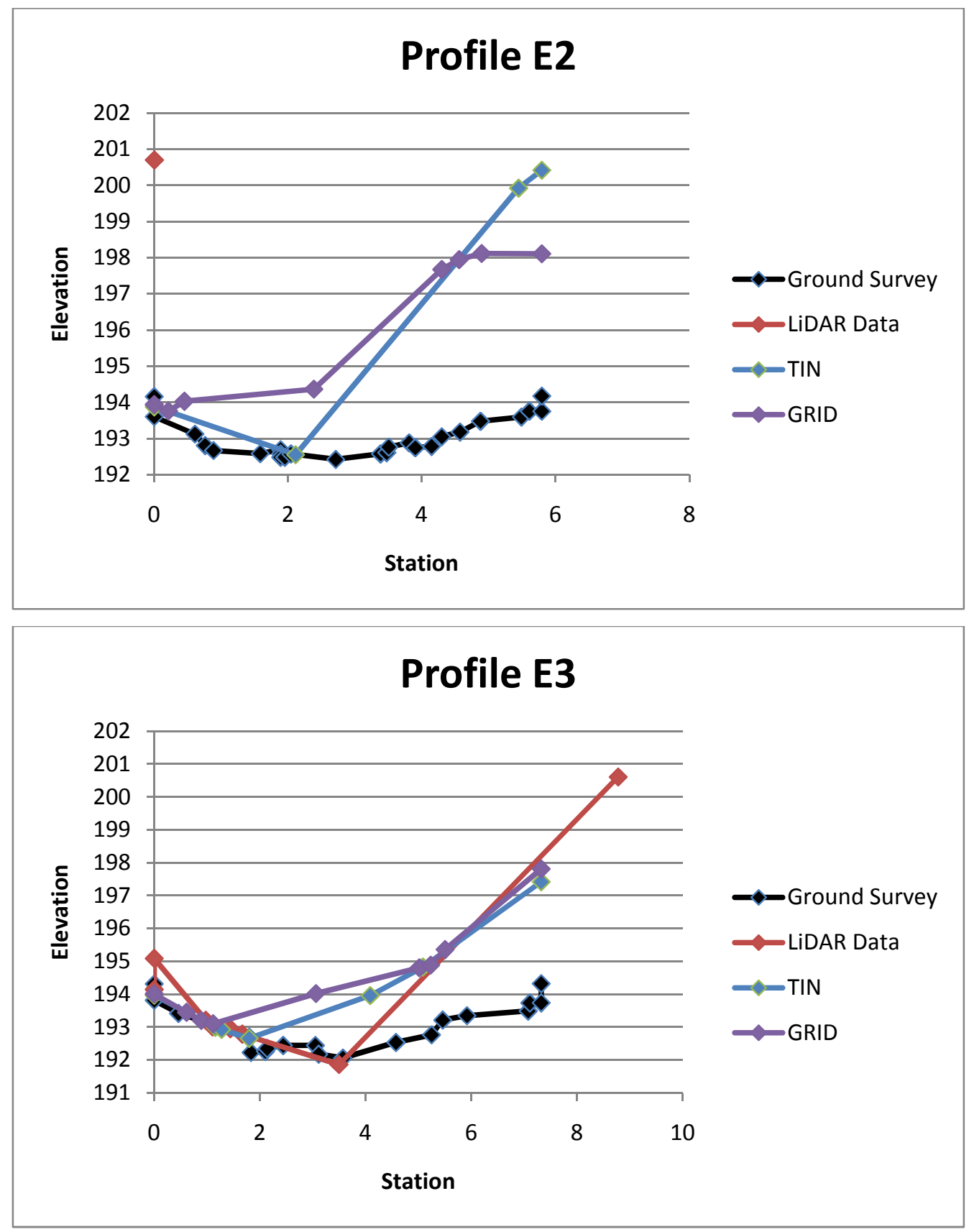

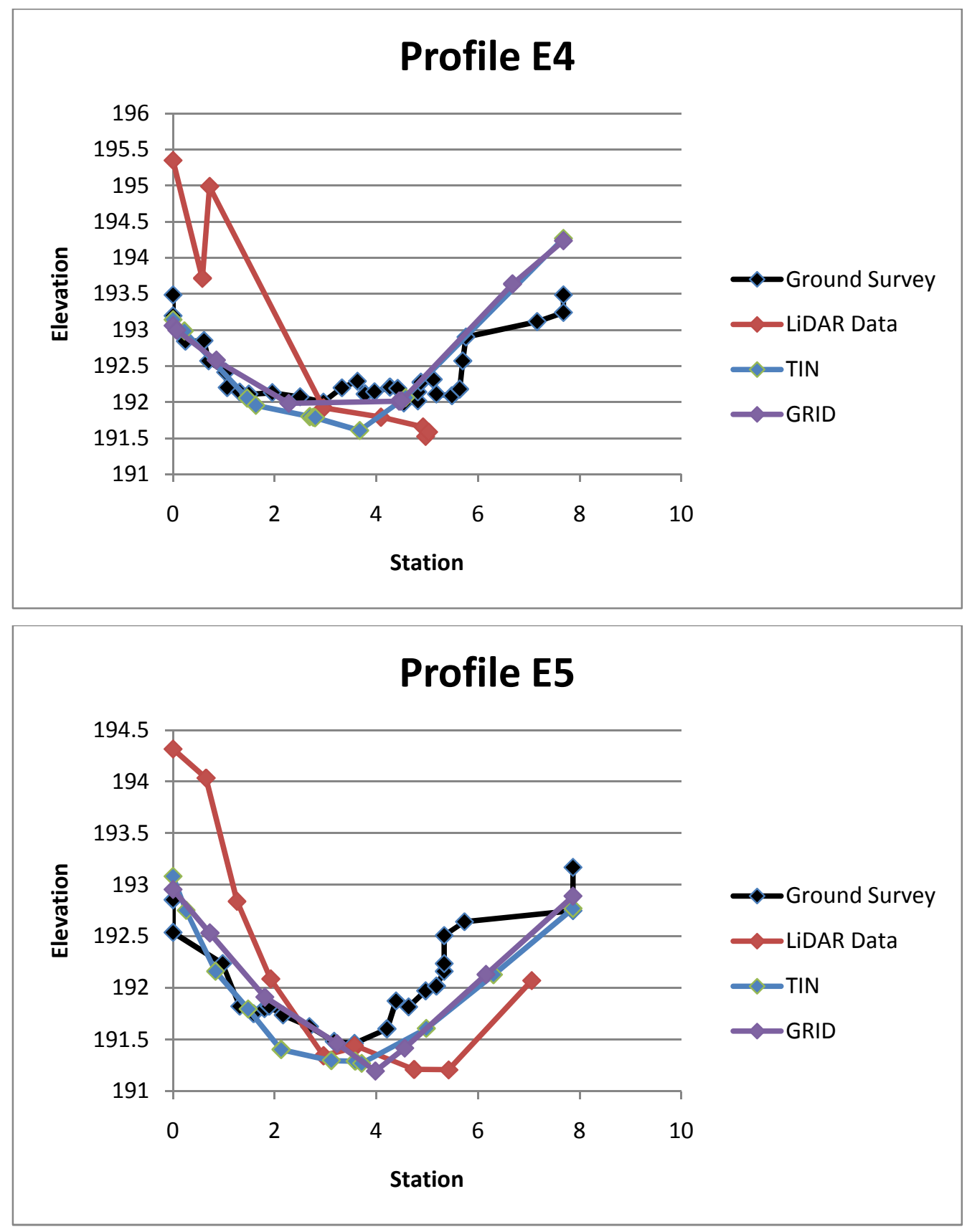

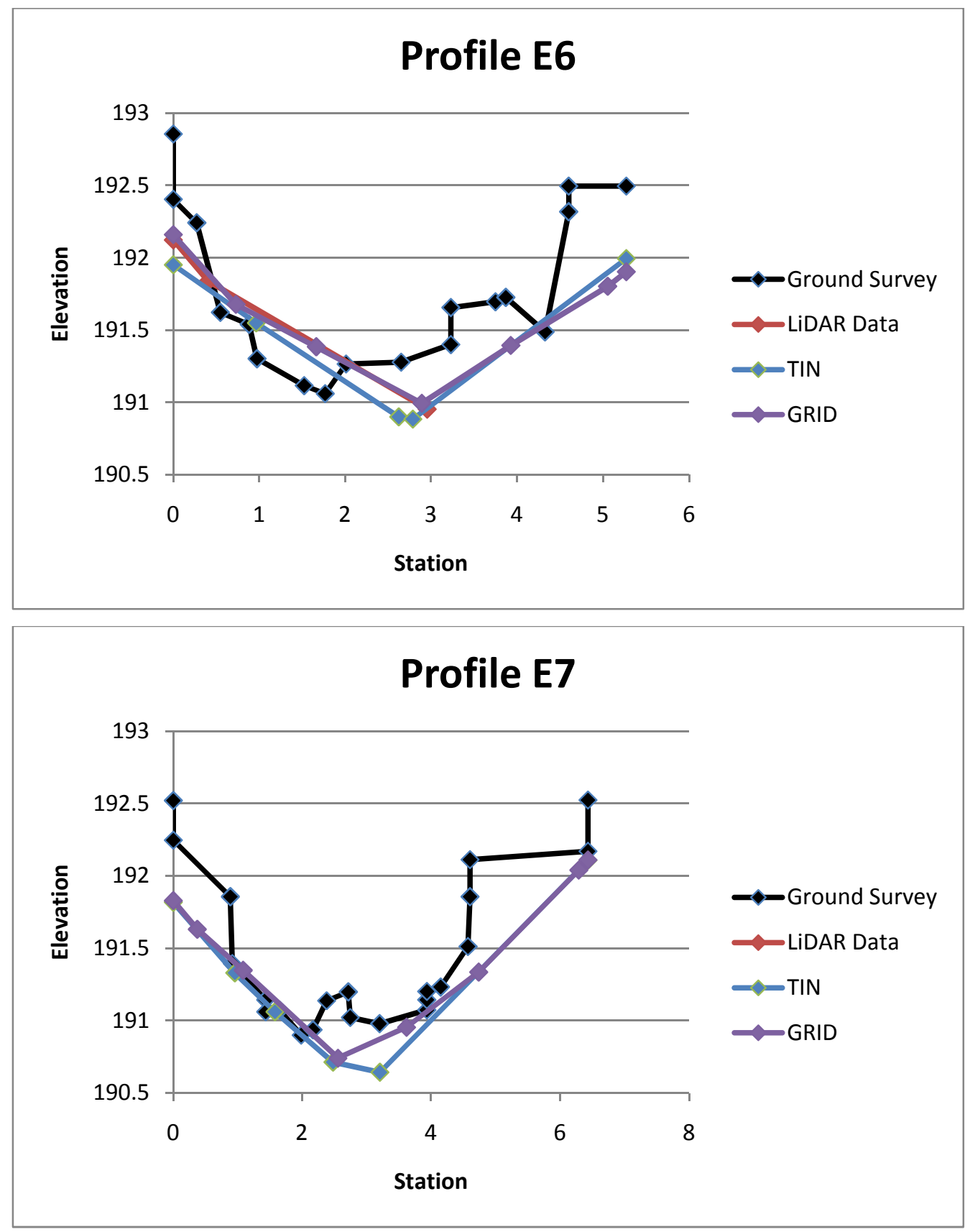

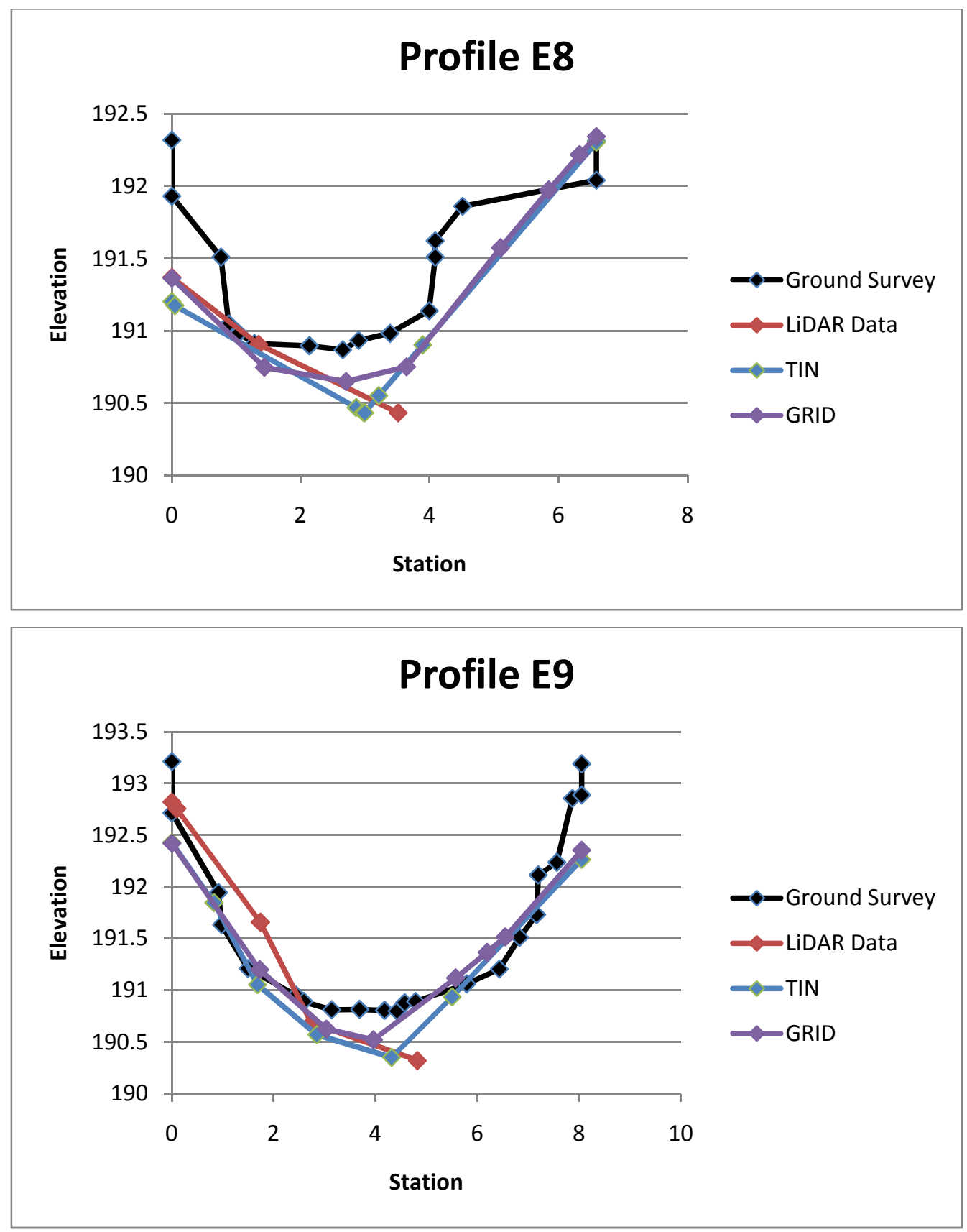

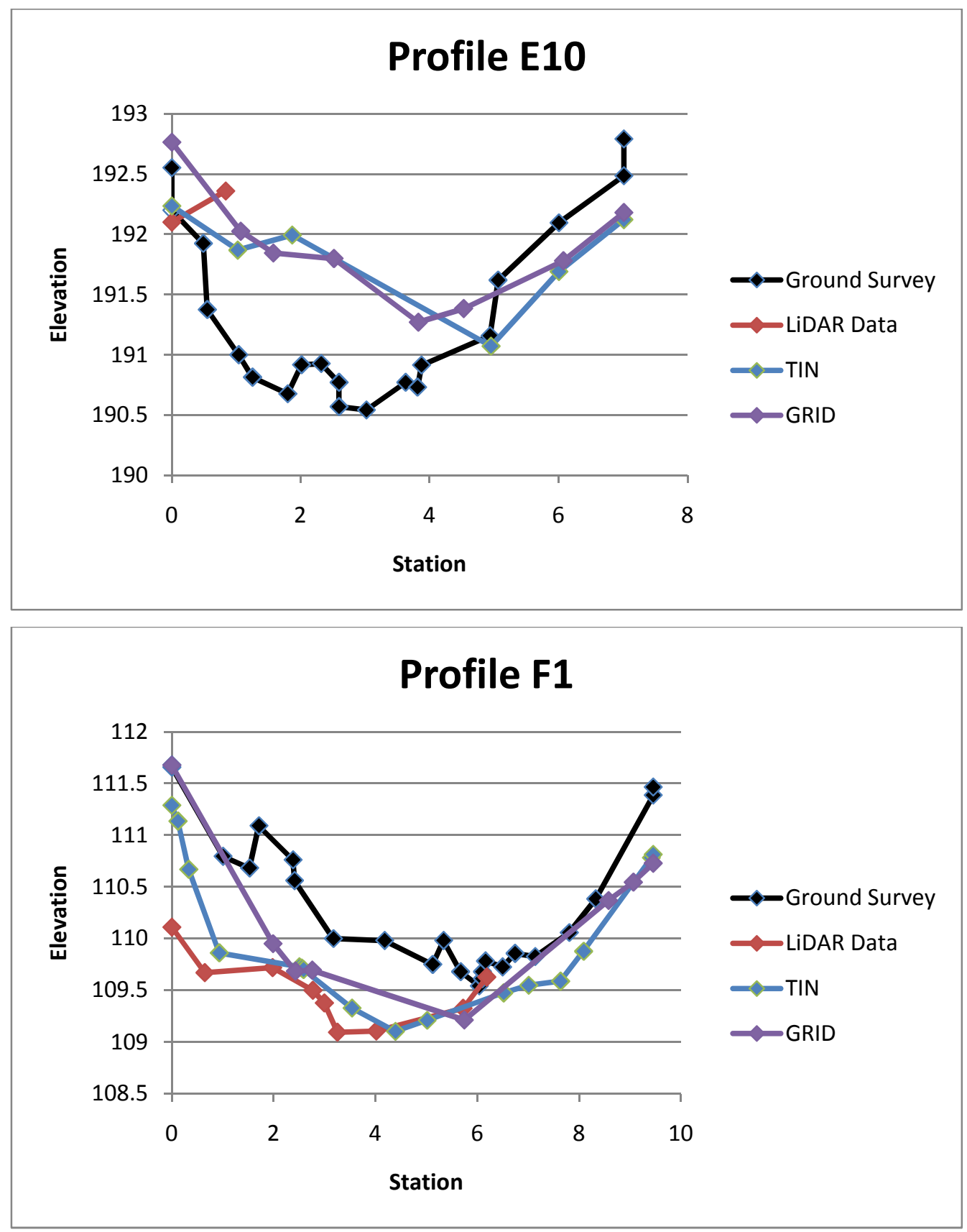

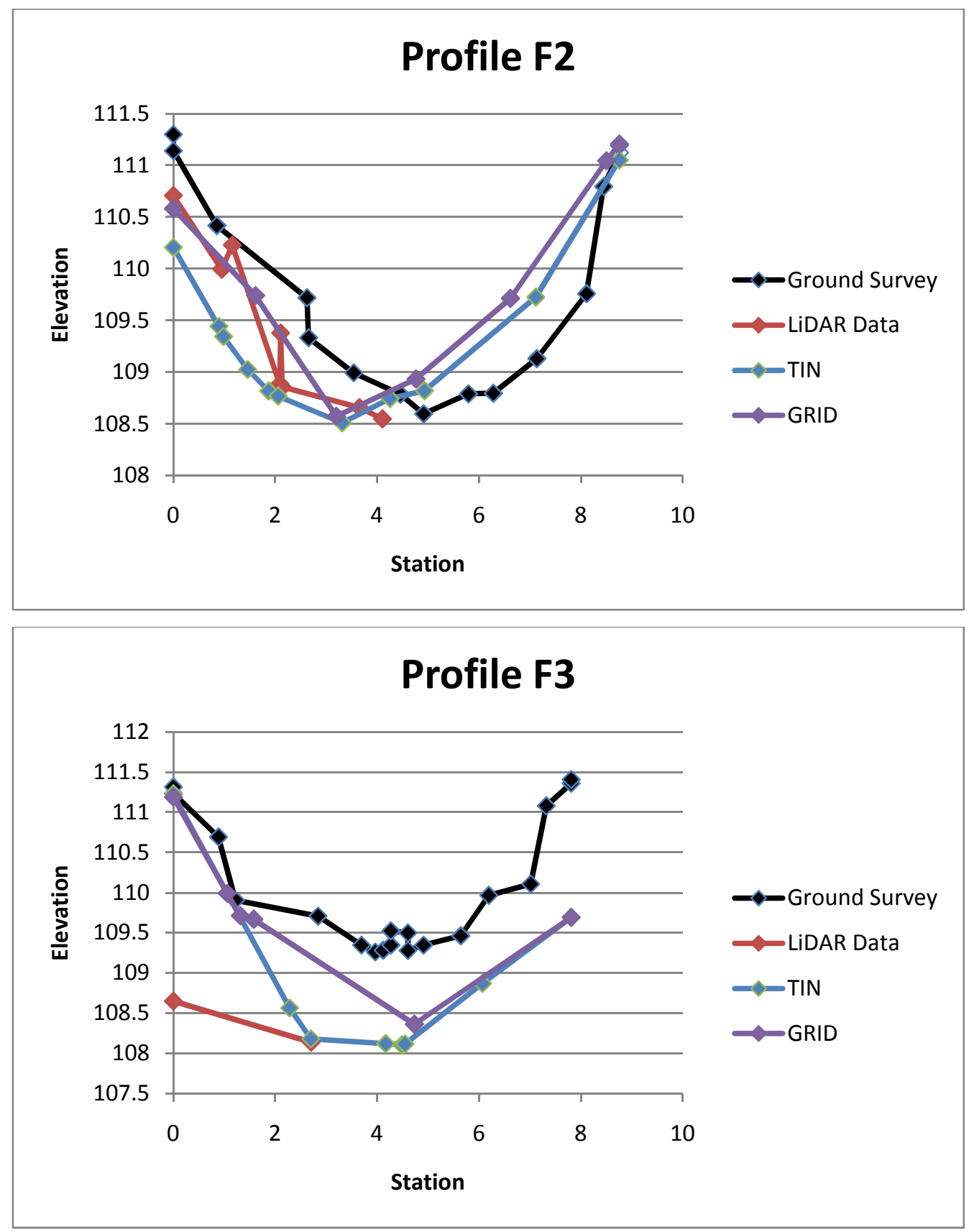

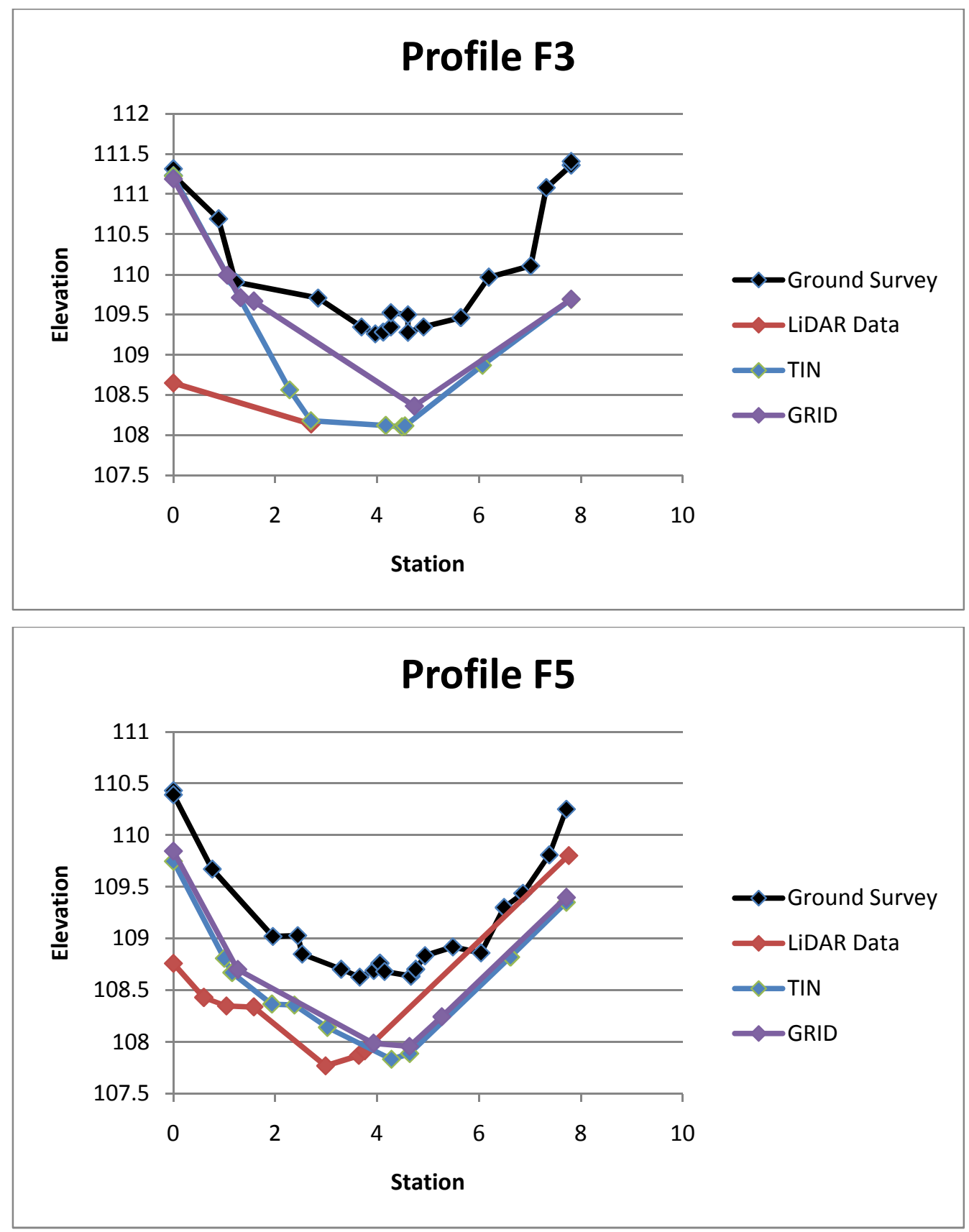

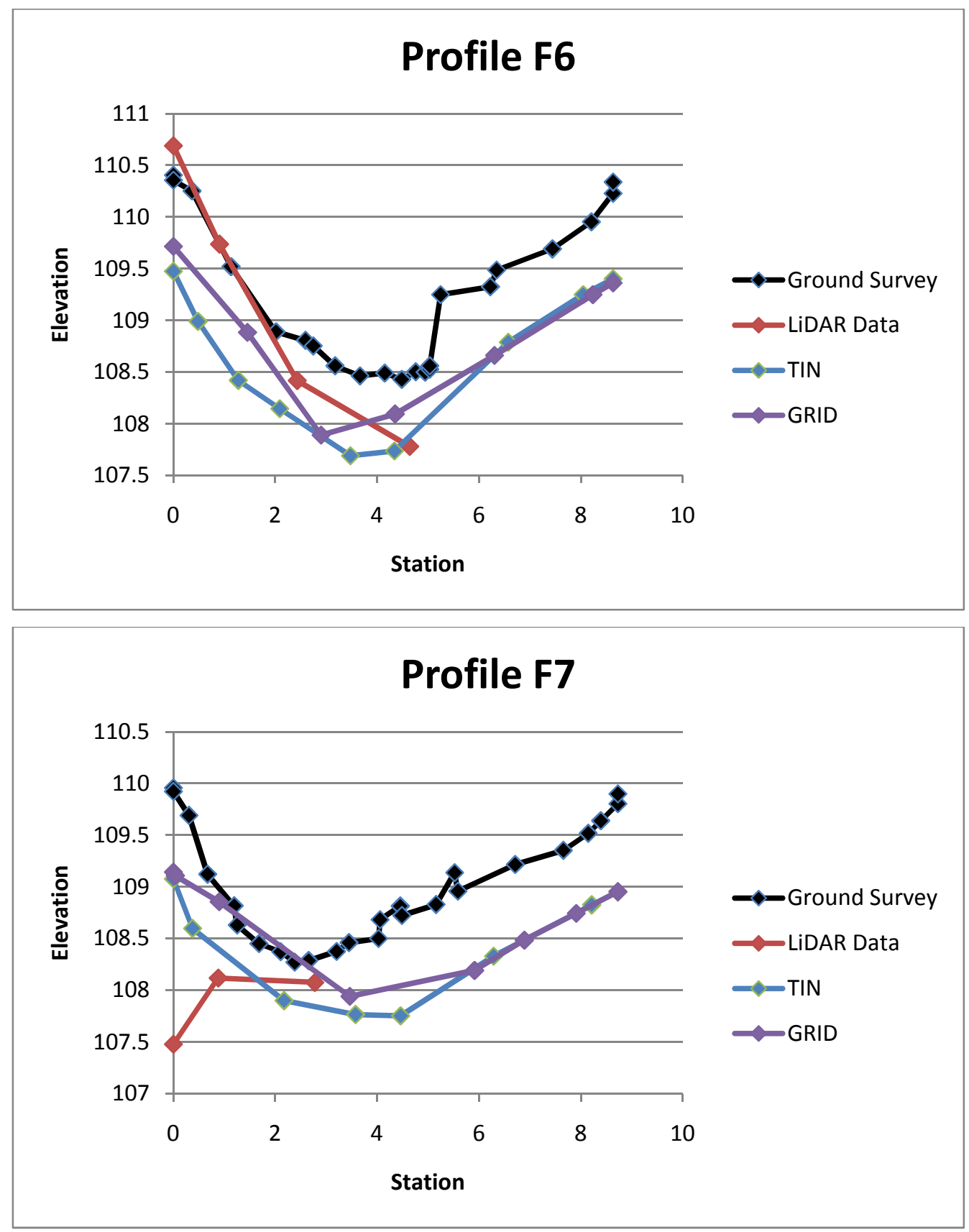

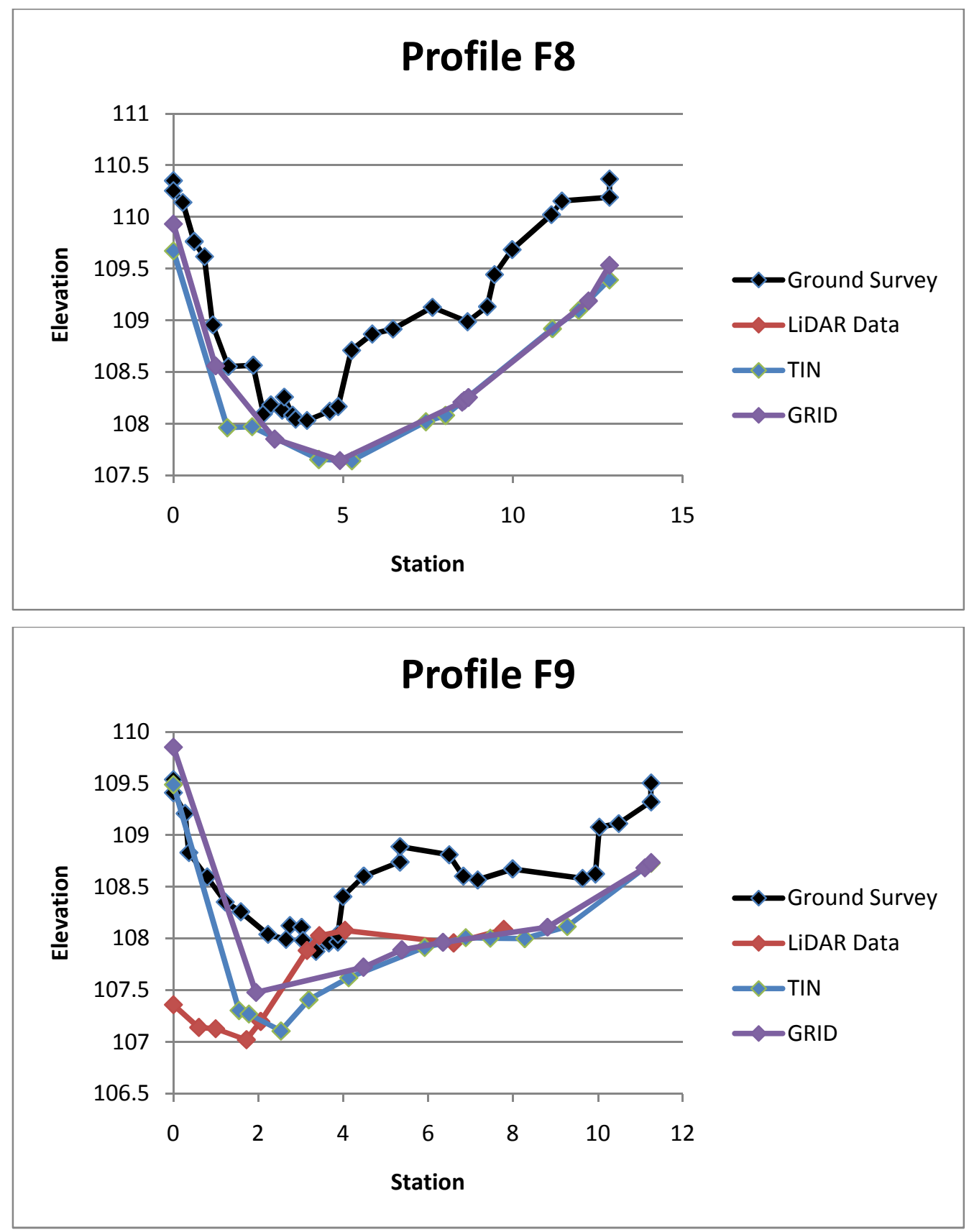


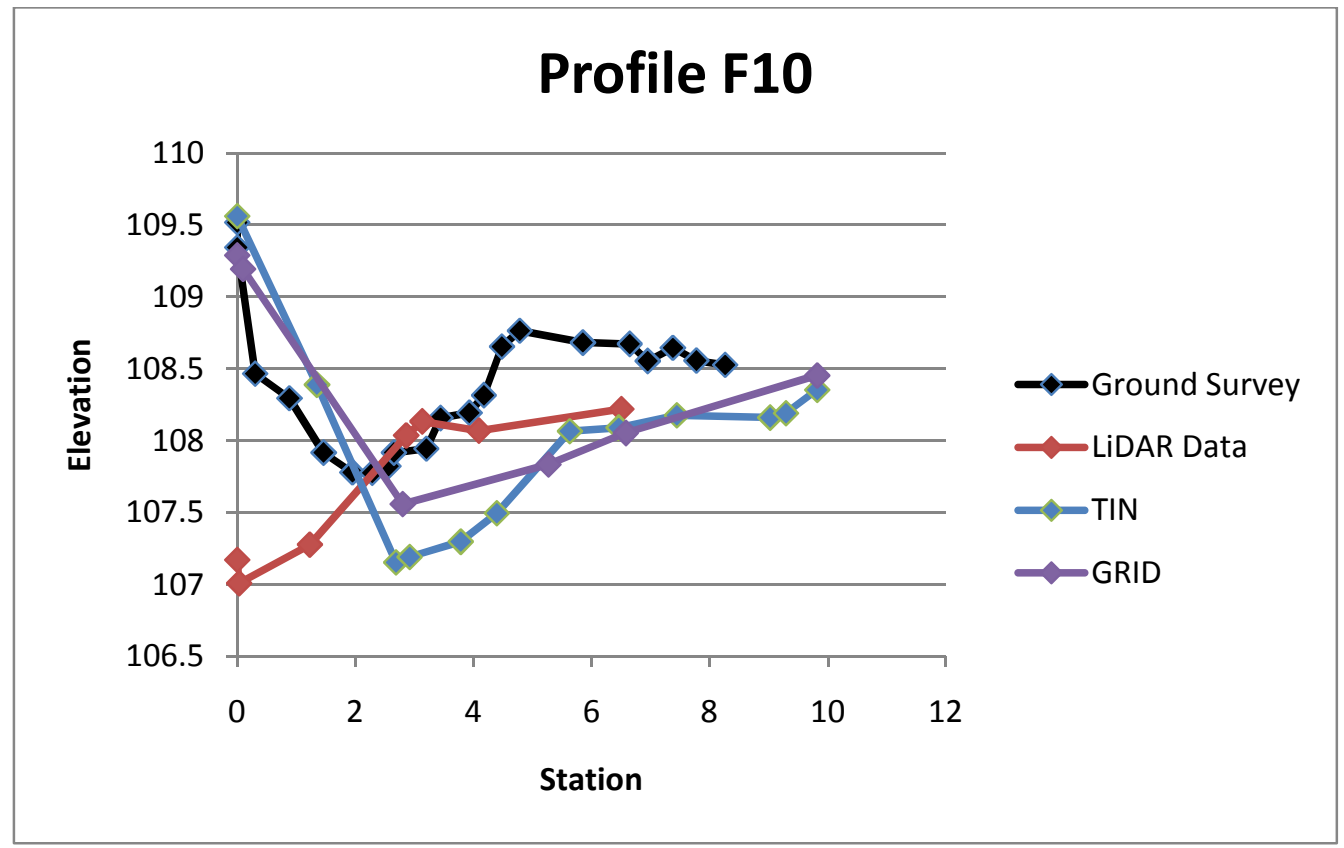

